\title{
Application of the Method of Characteristics to Predict Attenuation in Unsteady Partially Filled Pipe Flow
}

U.S. DEPARTMENT OF COMMERCE

National Bureau of Standards

Center for Building Technology

Washington, DC 20234

and

Drainage Research Group

Department of Building Technology Brunel University

Uxbridge, U.K.

December 1981

Issued March 1982

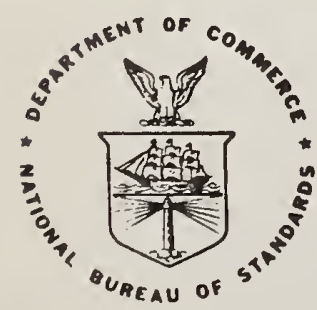



...

\section{APPLICATION OF THE METHOD OF CHARACTERISTICS TO PREDICT ATTENUATION IN UNSTEADY PARTIALLY FILLED PIPE FLOW}

Dr. J. A. Swaffield

U.S. DEPARTMENT OF COMMERCE

National Bureau of Standards

Center for Building Technology

Washington, DC 20234

and

Drainage Research Group

Department of Building Technology

Brunel University

Uxbridge, U.K.

December 1981

Issued March 1982

U.S. DEPARTMENT OF COMMERCE, Malcolm Baldrige, Secretary NATIONAL BUREAU OF STANDARDS, Ernest Ambler, Director 


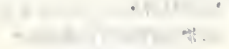

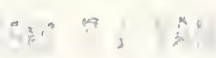




\section{PREFACE}

This report is one of a group documentating National Bureau of Standards (NBS) research and analysis efforts in developing water conservation test methods, analysis, economics, and strategies for implementation and acceptance. This work is sponsored by the Department of Housing and Urban Development/Office of Policy Development and Research, Division of Energy Building Technology and Standards, under HUD Interagency Agreement H-48-78.

Report prepared by Dr. J. A. Swaffleld, Senfor Lecturer, Drainage Research Group, Department of Building Technology, Brunel University, Uxbridge, U.K., during a study leave perlod as a guest research worker at NBS/Stevens Institute of Technology. 
The mechanism of flow attenuation in partially filled unsteady pipe flow is presented and shown to have relevance to the design of gravity drainage systems.

The equations defining unsteady flow in partially fllled pipe are derfved and shown to be capable of solution by means of the method of characteristics. This technique as a method of predicting flow depth, velocity and wave speed along a long drainage pipe at a range of pipe gradients, diameters and roughmess coefficlents was tested by means of numerical examples for a series of simulations run on a digital computer. Additionally, limited experimental verification of the analysis technique is presented for the supercritical flow response to a short duration inflow surge.

Generally the technique developed was found to be applicable to the design of drainage systems and further work is proposed to both extend the experimental verification and for the greater complexity of the multi-branched pipe system.

Key words: building drainage; computer model; surge attenuation; unsteady flow. 
Notation $\ldots \ldots \ldots \ldots \ldots \ldots \ldots \ldots \ldots \ldots \ldots \ldots \ldots \ldots \ldots \ldots \ldots \ldots \ldots \ldots \ldots \ldots \ldots \ldots$ vix

1. INTRODUCTION $\ldots \ldots \ldots \ldots \ldots \ldots \ldots \ldots \ldots \ldots \ldots \ldots \ldots \ldots \ldots \ldots \ldots \ldots \ldots \ldots \ldots \ldots$

2. FLOW ATTENUATION IN LONG PARTIALLY FILLED PIPE FLOW ............ 3

3. DEVELOPMENT OF THE NUMER ICAL SOLUTION .................... 6

3.1 Summary of the Method of Characteristics Solution of the Equations Defining Unsteady Flow in Partially Filled Pipe Flow .........................................

3.2 Partially Filled Pipe Flow Regimes ................... 7

3.3 Application of the Method of Characteristics Solution to

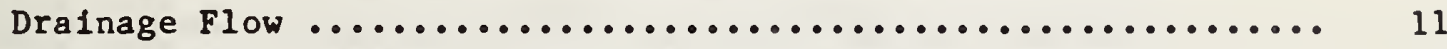

3.3.1 Inttial Steady Conditions Along the Plpe Length ........ 12

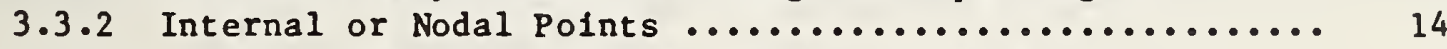

3.3.3 Entry Boundary Conditions, Supercritical Flow ......... 14

3.3.4 Entry Boundary Conditions, Subcritical Flow ........... 14

3.3.5 Exit Boundary Conditions, Supercritical Flow .......... 15

3.3.6 Exit Boundary Conditions, Subcritical Flow ........... 15

4. CALCULATION TECHNIQUES AND PRESENTATION OF RESULTS ............. 16

4.1 Determination of Normal and Critical Depths ............. 16

4.2 Numerical Integration for Surface Profiles ............... 16

4.3 Choice of time step $\ldots \ldots \ldots \ldots \ldots \ldots \ldots \ldots \ldots \ldots \ldots \ldots \ldots \ldots \ldots \ldots \ldots$

4.4 Presentation of Results $\ldots \ldots \ldots \ldots \ldots \ldots \ldots \ldots \ldots \ldots \ldots \ldots \ldots \ldots \ldots$

5. DISCUSSION OF UNSTEADY FLOW S IMULATION RESULTS ............... 19

5.1 Influence of Specified Time Interval Grid Size on Predicted Flow Paramaters ..................................

5.2 Influence of Surge Duration on Partially Filled Plpe Flow Response ...................................... 20

5.3 Influence of Pipe Slope, Diameter and Roughness on Predicted Variations in Flow Depth and Velocity 


\section{CONTENTS (Cont.)}

Page

5.4 Influence of Initial steady Flow Value on Predicted Flow Attenuation .................................... 22

5.5 Estimate of Computer Run Time $\ldots \ldots \ldots \ldots \ldots \ldots \ldots \ldots \ldots \ldots \ldots \ldots$

6. EXPER IMENTAL VER IF ICATION ............................... 24

7. CONCLUSIONS AND FURTHER WORK $\ldots \ldots \ldots \ldots \ldots \ldots \ldots \ldots \ldots \ldots \ldots \ldots \ldots \ldots \ldots . \ldots \ldots$

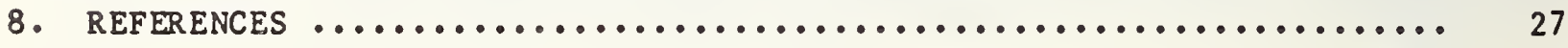

Figures $\ldots \ldots \ldots \ldots \ldots \ldots \ldots \ldots \ldots \ldots \ldots \ldots \ldots \ldots \ldots \ldots \ldots \ldots \ldots \ldots \ldots \ldots \ldots \ldots \ldots \ldots \ldots$

Appendix I Program TRAnSCC .............................. 52

Appendix II Typical Output TRANSCC, Supercritical Flow Case .......... 71 
1 Propagation of positive and negative surges in partially filled plpe flow ...................................... 28

2 Surge attenuation as observed in drainage pipe flow ..........

3 Application of momentum equation to unsteady flow in a general

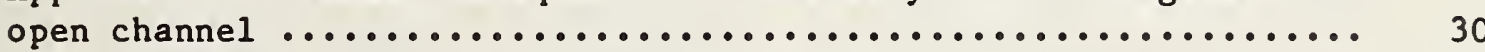

4 Modification to specified time interval grid for sub and

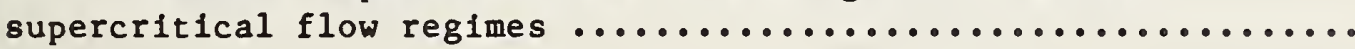

5 Application of specified time interval grid to subcritical partially filled pipe flow with known entry and exit boundary

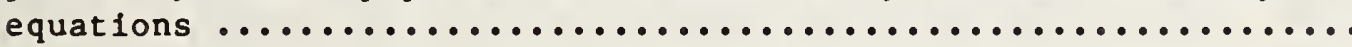

6 Relationship between flow specific energy and flow depth, 1llustrating the boundary between sub and supercritical flow

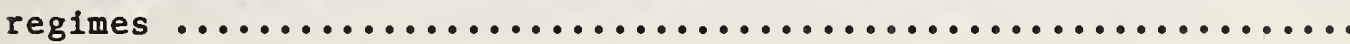

7 Summary of pipe cross section and depth dependent parameter

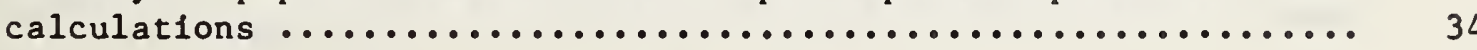

8 Basis of gradually varied flow depth prediction .............

9 Schematic representation of numerical integration to determine

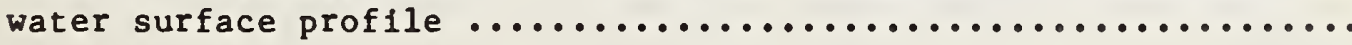

10 Influence of the choice of pipe section length on subcritical flow parameter predictions ............................

11 Influence of the choice of pipe section length on supercritical

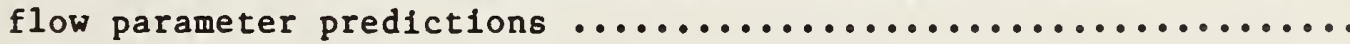

12 Depth of flow predictions for a surge introduced into subcritical

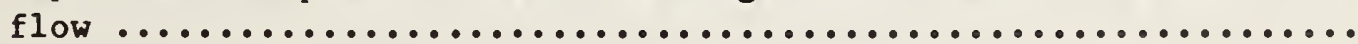

13 Depth of flow prediction for a surge introduced into

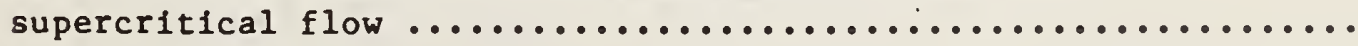

14 Comparison of surge response to a 2 s peak duration inflow at pipe gradients of $1 / 100$ and $1 / 300 \ldots \ldots \ldots \ldots \ldots \ldots \ldots \ldots \ldots$

15 Comparison of surge response to a 2 s and 6 s peak flow duration Inflow at a pipe gradient of $1 / 300 \ldots \ldots \ldots \ldots \ldots \ldots \ldots \ldots \ldots . . . \ldots$ 


\section{LIST OF FIGURES (Cont.)}

Page

16 Comparison of surge response to a $6 \mathrm{~s}$ peak inflow duration at plpe gradients of $1 / 100$ and $1 / 300 \ldots \ldots \ldots \ldots \ldots \ldots \ldots \ldots \ldots \ldots \ldots$

17 Flow attenuation along a $30 \mathrm{~m}$ plpe, $0.1 \mathrm{~m}$ diameter at gradients

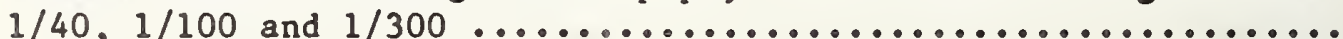

18 Flow depth predictions along a $30 \mathrm{~m}$ pipe at $1 / 40,1 / 100$ and $1 / 300$ gradients in response to a $1.27 /$ s peak inflow surge ...... 45

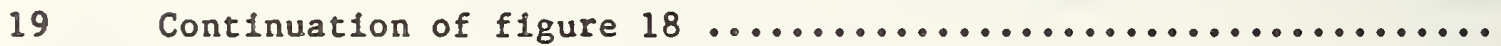

20 Peak flow rate predicted along a 30 m pipe for pipe gradients $1 / 40,1 / 100,1 / 300$ and pipe diameters of $0.15,0.1$, and 0.075

21 Peak flow rate and depth predictions along a $15 \mathrm{~m}$ pipe, diameter $0.1 \mathrm{~m}$ illustrating the dependence on roughness coefficient ......

22 Effect of the Initial steady flow on response to a $4.21 / \mathrm{s}$ peak

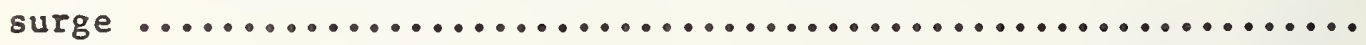

23 Summary of experimental test $\mathrm{r} 1 \mathrm{~g}$ and associated inflow and depth

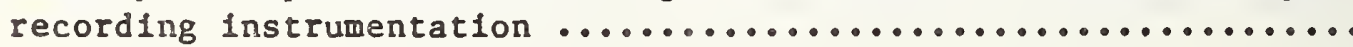

24 Comparison of observed and predicted water depth vs. time profiles 


\section{NOTAT ION}

A Plpe flow cross section area, $\mathrm{m}^{2}$

$\mathrm{C}^{+}, \mathrm{C}^{-} \quad$ Notation referring to the positive and negative characteristics

c Wave speed, $\mathrm{m} / \mathrm{s}$

E

Specific energy $=h+v^{2} / 2 g, m$

$F_{\mathbf{r}}$

Froude $N^{\circ}=V / \sqrt{g h}$

8

Acceleration due to gravity, $\mathrm{m} / \mathrm{sec}^{2}$

h Flow depth, m :

m

Aydraulic mean depth, m

$N, n \quad N^{\circ}$ of pipe length sections employed

P

Wetted channel perimeter, m

Q

Flow rate, $\ell / s$

So

P1pe slope

S

Slope of energy grade line, defined by Manning's Equation

$\mathrm{T}$

Surface width of flow within partially filled channel, m

t

Time, sec

v

Local mean velocity, $\mathrm{m} / \mathrm{s}$

$x 1-4$

Functions of $h, v, c$ and $S$ calculated at each base point at each time step

$\mathbf{x}$

Distance, positive in initial flow direction, $m$

$\alpha$

P1pe slope, $S_{0}=\sin \alpha$

$\Delta t$

Time step, sec

$\Delta \mathbf{x}$

P1pe section length, m

$\theta$

$\Delta t / \Delta x, 8 e c / m ;$ also subtended angle in figure 7

p

Fluid density, gm $\sec ^{2} / \mathrm{m}^{4}$ 
NOTATIONS (Cont.)

$\tau_{0} \quad$ Wall to fluld shear stress, $\mathrm{gm} / \mathrm{m}^{2}$

Suffixes

$A, B, C$ Calculated points in an $x-t$ grid at time $t$

c Critical flow conditions

n Normal flow conditions

P Calculated points in an $x-t$ grid at time $t+\Delta t$

$R$, $S \quad$ Interpolated points in an $x-t$ grid at time $t$

$U, D$ Upstream and downsteam conditions relative to the solid boundary 


\section{INTRODUCTION}

Observations of flow in long partially filled drainage pipes has shown that the shape of an input surge wave is materially altered during its passage along the system. In the absence of any downstream inflow the surge is observed to attenuate, that is the depth of water in the pipe decreases and the time taken for the surge to pass any station is seen to increase, indicating a reduced flow rate at any downstream time and distance coordinates.

This effect is of course well known and has been observed in large scale open channel flow and in flood routing studies. In the uniform channel case it is dependent on frictional effects, while the similar observations in flood routing are also dependent on the variable storage characteristics of the natural valleys followed by the flood.

In the design of drainage systems this flow attenuation can be of significant importance, particularly in the context of reduced water consumption. In simplifying some of the criteria commonly applied to drainage design it is possible to highlight two conflicting criteria that are affected by flow attenuation:

(1) The prevention of pressure variations within a building's drainage pipework in order to avoid the diminution of appliance trap seals is a major design criterion. If the flow in a portion of the pipe system becomes full bore then positive alr pressures are generated that can force odors past trap seals. Thus the maintenance of partially filled pipe flow is a major consideration and has led historically to conservative pipe sizing.

(2) The removal of waste solids discharged into the drainage system is to a large extent dependent on the maintenance of flow depth behind the solid during its transportation. It will be seen that this criterion can be considered as being in possible opposition to the need to retain a clear air passage through the pipe network.

An accurate prediction technique for flow attenuation that was capable of dealing with both random inflows along the length of a drain pipe and a variable loading in terms of frequency of use of the appliances served by the system would be capable of effecting design decisions under both the criteria outlined above.

By definition therefore the technique would have to be a numerical solution based on relatively small time increments and capable of modelling the hydraulic properties of the system as well as being applicable in a general way to quite complex pipe networks.

The flow in the drainage system at any time may be generally described by the unsteady flow differential equations. Based on the application of the principles of momentum and flow continuity to an element of flow a pair of hyperbolic partial differential equations may be shown to describe the flow in terms of two independent variables, distance $x$ and time $t$, and two dependent 
variables, flow depth and velocity. These equations, that have been fully developed in an earlier report [1], may be solved numerically by performing two basic steps, first a combination of the equations to yield a pair of finite difference algebraic equations applicable along predetermined characteristics drawn in the $x-t$ plane, and the solution of these equations with representative system boundary conditions.

This solution technique, known generally as the wethod of characteristics, meets the solution criterla set out above and indeed has been used extensively in the analysis of pressure surge in full bore complex pipe networks.

This report therefore presents the results of a series of computer simulations for partialiy filled flow attenuation in drainage sized pipes subject to typical prescribed inflow surges. In addition the mechanism of wave attenuation is described together with a summary of the development of the necessary unsteady flow equations. Detalls of the computer progran TRANSCC are included together with the data preparation instructions. Limited experimental verification of the analysis is also presented based on transient flow depth measurements for hydraulic characteristics of surge flows which have been conducted as part of the test program for solid transport mechanisms in the Plumbing Research Laboratory of NBS CBT. 


\section{FLOW ATTENUATION IN LONG PARTIALLY FILLED PIPE FLOW}

Gravity driven flow in partially filled pipes or open channels may be characterized by the observation that the flow depth may change in response to both the applied loading and the frictional forces acting on the fluid flow. In order to explain the mechanism of this depth change, or attenuation, observed in long channels or free surface pipe flow it is necessary to consider wave propagation in these flow regimes.

It may be shown [2] that in non rectangular channels the wave propagation velocity is related to flow depth via the channel geometry,

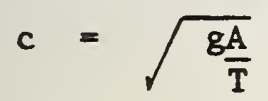

where $T$ is the flow surface width and $A$ is the flow cross section area, both functions of flow depth and channel geometry.

This implies that deeper waves travel faster than shallower waves and would thus overtake leading shallower water or conversely outdistance following shallower flow. Obviously this model is percelved in the flow by changes in the observed depth profile shape.

Figure 1 illustrates the propagation of both positive and negative waves in frictionless channels. If the wave front is considered to be made up of a large number of very small waves placed one on top of the other then it may be seen that, in the theoretically frictionless channel, the wave profile steepens for the positive wave and attenuates for the negative wave. The deeper waves in each case travel faster than the shallower waves, thus in the positive surge the crest overtakes the leading edge and the profile steepens. Alternatively for the negative surge the crest outdistances the trailing edge resulting in a spreading out of the wave.

The presence of frictional effects materially alters this situation. As the forces generated depend on the square of velocity the introduction of frictional effects results in modifications to both the positive and negative surge shape changes described above. Figure 1 illustrates the reduction in negative surge attenuation as the deeper wave, travelling at the higher velocity, is retarded relative to the shallower trailing waves and to its frictionless performance.

Similarly the steepening of the positive wave front is reduced and, depending on the channel friction, possibly attenuated as shown.

The effect of this mechanism on observed partially filled pipe flow is a progressively reducing depth downstream for a surge introduced into a long pipe, figure 2, associated with a reduction in the peak flow rate recorded at any downstream section.

This flow attenuation and reduced flow depth has direct implications on drainage system design, particularly in the context of water conservation. 
Consider an isolated finfte discharge introduced into a long drainage pipe. As this proceeds along the plpe, its depth decreases and the length of the water wave increases, 1.e., the flowrate at any section is attenuated.

If the pipe is designed on the basis of a given number of such discharges wth no allowance for either flow attenuation or the probability of simultaneous discharge then it w1ll be seen that the pipe is either oversized or the maximum loading, allowing for a probability usage pattern for the appliances contributing to the loading, will be underestimated.

In the U.K. particularly this discussion has been represented by the numerical limit to the number of domestic dwellings that may be connected to a standard $100 \mathrm{~mm}$ drain. Current design recommendation could be substantially increased if flow attenuation and inflow probability were combined and included in the design calculations.

It has been shown [3] that the transport of solids through drainage systems is substantially dependent on flow depth 80 that the exclusion of depth attenuation calculations also indicates an enhanced probability of solid deposition in long pipes. These effects are naturally aggravated if water conservation proposals are accepted for existing installed systems, and reinforce the view that water conservation should also include a study of pipe sizing, leading elther to possible reductions in standard pipe diameters or to increased appliance loading for existing pipework.

At present there is little experimental data on flow attenuation in long pipelines. Burberry [4] presented limited laboratory test results together with frequency of appliance operation tables that support the arguments above. However in this case laboratory tests are limited in their usefulness due to the complexity of the flow combinations possible in an installed system. For example the attenuation of an appliance discharge, such as a water closet $\left(w . c_{.}\right)$, can be measured in the laboratory in pipes at a range of gradients and lengths, however in practice this attenuated flow could be joined at some downstream location by another discharge emanating from another appliance. Thus if the benefits of flow attenuation are to be included in drainage design and conversely the maintenance problems inherent in disregarding this effect in a water conserving system are to be avoided, then it is necessary to develop a predictive technique that would include random flow additions in both time and location along the drainage system.

Due to the complexity of drainage systems in such building complexes as hospitals, this analysis would have to involve a computerized solution that would be based on the full unsteady flow equations. Such a solution would have to be capable of accepting multiple inputs to a branched system and would be expected to yield predictions of flow depths and velocities, including backflow at pipe junctions.

The current report presents a feasibility study based on the use of the method of characteristics to solve the unsteady flow equations and predict flow 
attenuation for a pipe without branches. It is based on a preceeding study of the use of this technique to determine the depth build up at a deposited

stationary solid in response to a discharge moving along a drainage plpe [1]. 


\subsection{SUMMARY OF METHOD OF CHARACTER ISTICS SOLUT ION OF THE EQUATIONS DEF INING UNSTEADY FLOW IN PART IALLY FILLED P IPE FLOW}

Referring to figure 3, it has been shown [1] that the equations of motion and continulty may be expressed as

$$
\begin{aligned}
& g \frac{\partial h}{\partial x}+g\left(S-S_{0}\right)+V \frac{\partial V}{\partial x}+\frac{\partial V}{\partial t}=0 \\
& \text { VT } \frac{\partial h}{\partial x}+T \frac{\partial h}{\partial t}+A \frac{\partial V}{\partial x}=0
\end{aligned}
$$

These equations may be combined to form a total derivative expression

$$
\frac{d V}{d t}+\frac{g}{c} \frac{d h}{d t}+g\left(S-S_{0}\right)=0
$$

subject to

$$
\frac{d x}{d t}=v \pm c
$$

The wave speed being defined by

$$
c=\sqrt{\frac{\mathrm{BA}}{\mathrm{T}}}
$$

where $\mathrm{V}=$ local average flow velocity

$c=$ local wave speed

$\mathrm{h}=$ local flow depth

$\mathrm{S}_{\mathrm{o}}=$ pipe slope

$S=$ slope of the local energy grade line $=\frac{n^{2} v^{2}}{m^{4 / 3}}, n$ the Manning

coefficient and m the hydraulic mean depth

$T=$ water surface width

$A=$ water depth cross sectional area

Referring to figure 4, if the varlables $V$ and $h$ are known at $R$ and $S$ then four equations may be written in terms of the unknowns at point $P$, by means of a first order approximation,

$$
\begin{aligned}
& v_{P}-v_{R}+\frac{g}{c_{R}}\left(h_{P}-h_{R}\right)+g\left(S_{R}-s_{0}\right) \Delta t=0 \\
& x_{P}-x_{R}=\left(v_{R}+c_{R}\right) \Delta t
\end{aligned}
$$




$$
\begin{aligned}
& v_{P}-v_{S}-\frac{g}{c_{S}}\left(h_{P}-h_{S}\right)+g\left(s_{s}-s_{0}\right) \Delta t=0 \\
& x_{P}-x_{S}=\left(v_{S}-c_{S}\right) \Delta t
\end{aligned}
$$

It is stressed that these equations are paired and that equations 6 and 8 only apply as long as equation 7 and 9 are satisfied. This introduces the characteristics 1 ines $\mathrm{C}^{+}$and $\mathrm{C}^{-}$, shown in figure 5 .

It is also necessary that the time step $\Delta t$ is sufficiently small for $R$ and $S$ (points in the $x-t$ plane) to fall within $\pm \Delta x$ of point $P$ as shown in figure 4.

From figure 5 it will be seen, provided boundary equations governing the conditions at the extremities of the system are known, that an orderly solution may proceed ylelding flow depth and velocity at each pipe section at each time increment.

The basis for the system boundary conditions are set out below.

\subsection{PARTIALLY FILLED P IPE FLOW REG IMES}

Two flow regimes may be identified for open channels or partially filled plpes:

(1) Subcritical flow, Froude $N^{\circ}=\frac{V}{\sqrt{g h}}<1$

Here the local wave speed exceeds the flow average velocity, thus waves may be propagated both upstream and downstream in the flow, 1.e., $c>V$.

(2) Supercritical flow, Froude $\mathrm{N}^{\circ}>1$

Here the local wave speed is less than the average flow velocity at that section and hence waves cannot be propagated upstream, 1.e., v $>c$.

The flow regime applicable to any partially filled pipe flow may be determined by a comparison of the flow normal and critical depths as described, following the equations $10-15$.

Under steady unfform flow conditions the force balance equation for an element of flow is normally expressed by the Chezy equation

$$
\begin{aligned}
& V=C \sqrt{\mathrm{m} \mathrm{S}_{\mathrm{O}}} \\
& \mathrm{m}=\text { hydraulic mean depth } \mathrm{A} / \mathrm{P}, \mathrm{m} \\
& \mathrm{S}_{\mathrm{O}}=\sin \theta \text {-duct slope } \\
& \mathrm{V}=\text { mean velocity } \mathrm{m} / \mathrm{s} \\
& \mathrm{C}=\text { Chezy constant. } \\
& \mathrm{P}=\mathrm{p} \text { ipe wetted perimeter. }
\end{aligned}
$$

The value of loss coefficient $C$ was found by Manning to be dependent on hydraulic mean depth and duct surface roughness $n$. The Manning formula is the 
simplest of the open channel equations:

$$
\begin{aligned}
& V=\frac{1}{n} m^{2 / 3} s_{0}^{1 / 2} \\
& Q=\frac{1}{n} A m^{2 / 3} s_{0}^{1 / 2}
\end{aligned}
$$

where $Q$ is the flow rate $\mathrm{m}^{3} / \mathrm{s}$

$A$ is the flow cross sectional area, $m^{2}$

The value of the Manning coefficient, $n$, varies with pipe or channel material. Chow [2] suggests values in the range 0.009 to 0.020 for materials commonly found in building drainage systems.

Equation 10 effectively determines the flow depth under steady, uniform conditions, only one value of $h$ yielding the values of $A$ and $m$ necessary to satisfy the equation. As this depth is by definition constant downstream, $d h / d x=0$, it must also be the terminal depth corresponding to the flow terminal velocity at that channel slope.

This depth, $h_{n}$, is commonly referred to as the normal depth.

The specific energy of the flow may be defined as

$$
E=h+\frac{v^{2}}{2 g}
$$

where $\mathrm{h}=$ local flow depth, m

$\mathrm{V}=$ local average flow velocity, $\mathrm{m} / \mathrm{s}$

It may be shown that for a rectangular channel, width w, that there are two possible depths for any particular value of $E$ above a minimum.

$$
E=h+\frac{v^{2}}{2 g}=h+\frac{Q^{2}}{2 g A^{2}}
$$

with $A=$ hw for rectangular case, then

$$
\begin{aligned}
& E=h+\frac{Q^{2}}{2 g(h w)^{2}} \\
& h^{3}-E h^{2}+Q^{2} / 2 g w^{2}=0
\end{aligned}
$$

For $E$ constant, this equation has three roots, two real, one imaginary.

Figure 6 illustrates the alternate depths possible in such a situation and their significance in terms of the flow definition. 
From equation 12 and figure 6 it may also be seen that the flow specific energy has a minimum value below which the given flow conditions cannot exist. In a general, non rectangular channel this value may be determined:

$$
\begin{aligned}
& E=h+\frac{Q^{2}}{2 g A^{2}} \\
& \frac{d E}{d h}=0=1-\frac{Q^{2}}{g A^{3}} \frac{d A}{d h}
\end{aligned}
$$

From figure 3

$$
\mathrm{dA}=\mathrm{T} d \mathrm{~h}
$$

where $T$ is the surface width at any depth, $h$.

From equations (13) and (14) the minimum value of $E$ will occur at a depth value, $h_{c}$, that satisfies the expression

$$
1-Q^{2} T / g A^{3}=0
$$

where $T$ and $A$ are both $f(h)$

This value of $h$ is referred to as the flow critical depth $h_{c}$.

If the normal flow depth $h_{n}$ exceeds $h_{c}$ then the terminal flow would be termed subcritical, or tranquil flow. If $h_{n}$ is less than $h_{c}$ then the flow is termed rapid or supercritical.

It should be stressed that $h_{c}$ is independent of pipe slope and pipe surface roughness; while the normal depth is dependent on both. Thus the same volume flow rate in any particular pipe may be rapid or tranquil depending on pipe slope, and similarly the same flow rate in a series of constant diameter pipes will be tranquil or rapid depending on roughness.

Pipes or channels in which rapid flow is normal are termed steep, plpes or channels in which tranquil flow is normal are termed of mild slope.

Figure 4 illustrates the importance of these two flow regimes on the solution of equations 6 to 9 .

If $c>V$ then the conditions at $P$ are determined by the intersection of the $\mathrm{C}^{+}$and $\mathrm{C}^{-}$drawn from $\mathrm{P}$ into the $\mathrm{AC}$ and $\mathrm{BC}$ sections.

If $c<V$ then conditions in the downstream section $B C$ cannot effect point $P$. The slope of the $C^{-}$characteristic, PS, becomes positive and both $R$ and $S$ lie in the AC section as shown.

Both subcritical and supercritical flow are encountered in the drainage applications considered and the equations derived below cover both conditions. 
Referring to figure 4 for subcritical flow:

$$
\begin{aligned}
& \frac{v_{C}-v_{R}}{v_{C}-v_{A}}=\frac{x_{C}-z_{R}}{x_{C}-x_{A}}=\left(v_{R}+c_{R}\right) \frac{\Delta t}{\Delta x} \\
& \frac{{ }_{C}-c_{R}}{c_{C}-c_{A}}=\frac{x_{C}-x_{R}}{{ }_{x_{C}}-x_{A}}=\left(v_{R}+c_{R}\right) \frac{\Delta t}{\Delta x}
\end{aligned}
$$

and $\frac{h_{C}-h_{R}}{h_{C}-h_{A}}=\left(v_{R}+c_{R}\right) \frac{\Delta t}{\Delta x}$

as $x_{P}=x_{C}$ and $x_{P}-x_{R}=\left(v_{R}+c_{R}\right) \Delta t$

Solution yields

$$
\begin{aligned}
& v_{R}=\frac{v_{c}+\theta\left(-v_{C} c_{A}+c_{C} v_{A}\right)}{1+\theta\left(v_{C}-v_{A}+c_{C}-c_{A}\right)} \\
& c_{R}=\frac{c_{c}\left(1-v_{R} \theta\right)+c_{A} v_{R} \theta}{1+c_{C} \theta-c_{A} \theta} \\
& h_{R}={ }_{C} h_{C}-\left(h_{C}-h_{A}\right)\left(\theta\left(v_{R}+c_{R}\right)\right)
\end{aligned}
$$

where $\theta=\Delta t / \Delta x$

Similarly

$$
\begin{aligned}
& v_{S}=\frac{v_{c}-\theta\left(v_{C} c_{B}-c_{C} V_{B}\right)}{1-\theta\left(v_{c}-v_{B}-c_{C}+c_{B}\right)} \\
& c_{S}=\frac{c_{c}+v_{S} \theta\left(c_{C}-c_{B}\right)}{1+\theta\left(c_{C}-c_{B}\right)} \\
& h_{S}=h_{C}+\theta\left(v_{S}-c_{S}\right)\left(h_{C}-h_{B}\right)
\end{aligned}
$$

For the supercritical flow regime the equations determining $R$ in figure 4 remain unchanged. The interpolation equations for $S^{\prime}$ in figure 4 may be determined by an identical technique to that shown above,

$$
\begin{aligned}
& v_{C}-v_{S^{\prime}}=\left(v_{C}-v_{A}\right) \theta\left(v_{S^{\prime}}-c_{S^{\prime}}\right) \\
& c_{C}-c_{S^{\prime}}=\left(c_{C}-c_{A}\right) \theta\left(V_{S^{\prime}}-c_{S^{\prime}}\right)
\end{aligned}
$$

and $h_{C}-h_{S^{\prime}}=\left(h_{C}-h_{A}\right) \theta\left(V_{S},-c_{S^{\prime}}\right)$

Solution yields

$$
v_{S^{\prime}}=\frac{v_{C}\left(1-c_{A} \theta\right)-v_{A} c_{C} \theta}{1+\theta\left(v_{C}-v_{A}+c_{A}-c_{C}\right)}
$$




$$
c_{S^{\prime}}=\frac{c_{C}+v_{S^{\prime}} \theta\left(c_{A}-c_{C}\right)}{1+c_{A}{ }^{\theta}-c_{C}{ }^{\theta}}
$$

From equations 7 and 9 it will be seen that

$$
\frac{d t}{d x}=\frac{1}{v \pm c}
$$

hence if $(V+C)$ becomes large then $\Delta t$ becomes small for a constant $\Delta x$. This implies that the progress of the numerical solution could become prohibitively slow for supercritical flow conditions. Fox [5] suggests a check within any program that will terminate the solution if $\Delta t$ falls below a specified value, however this comment by Fox applies to the existing applications of the method of characteristics, which have been limited to large civil engineering open channel or river flooding flow problems. It is likely that the reduction in $\Delta t$ will not be a significant problem with the relative values of $V$ and $C$ encountered in drainage sized pipe applications due to their dependence on pipe geometry and flow rate. This point will be returned to later in the discussion of the supercritical flow simulations.

The determination of conditions at $P$ at time $t+\Delta t$ requires the following steps (i-iv), for either sub or supercritical flow conditions

(1) All conditions known at time $t$ for nodal points $A, B, C$ etc, figure 4

(1i) Values of $\mathrm{V}, \mathrm{h}$ and $\mathrm{c}$ at interpolation points $\mathrm{R}, \mathrm{S}$, or $\mathrm{S}^{\prime}$ calculated from equations $16-23$.

(iii) Using these values of $\mathrm{V}, \mathrm{h}$, and $\mathrm{c}$ the conditions at $\mathrm{P}, 1 . \mathrm{e}$. velocity $V$ and depth $h$, at time $t+\Delta t$ are calculated by means of equations 6 and 8 .

(iv) The value of wave speed $c$ at $P$ at time $t+\Delta t$ is calculated from equation 5. The value of flow surface width and cross sectional area are calculated from flow depth, $h$, and the channel shape relationships, figure 7 .

(v) The sequence is repeated at each new time step.

\subsection{APPLICATION OF THE METHOD OF CHARACTER IST ICS SOLUTION TO DRAINAGE FLOW}

For convenience the application of the solution developed above to drainage pipe flow may be considered under two headings, namely boundary conditions and characteristic equation solution at intermediate pipe sections. Both of these headings must be further subdivided depending on whether the flow is termed sub or supercritical.

The equations 6 to 9 may be restated as 


$$
\begin{array}{ll}
v_{P}=x 2-x 1 h_{p} & \text { f for } C^{+} \\
x_{p}-x_{R}=\left(v_{R}+c_{R}\right) \Delta t & \\
v_{P}=x 4+x 3 h_{P} & \text { f for } C^{-} \\
x_{P}-x_{S}=\left(v_{S}-c_{S}\right) \Delta t &
\end{array}
$$

$$
\begin{aligned}
& \text { where } X I=g / c_{R} \\
& \mathrm{X}_{3}=\mathrm{g} / \mathrm{cs}_{\mathrm{S}} \\
& x 2=v_{R}+g \frac{h_{R}}{c_{R}}-g\left(s_{R}-s_{o}\right) \Delta t \\
& X_{4}=v_{S}-g \frac{h_{S}}{c_{S}}-g\left(s_{S}-s_{0}\right) \Delta t
\end{aligned}
$$

It will be noted that these equations apply in elther subcritical or supercritical flow, the interpolated values of the conditions at $S$ or $S^{\prime}$ being sufficient to define the flow reglme, figure 4.

\subsubsection{Initial Steady Conditions Along the Pipe Length}

As will be seen from figure 5 the initial conditions along the whole pipe length at time $t=0$ must be known in order for the solution to proceed. It is therefore necessary to calculate the steady state flow velocity and depth throughout the pipe length initially, together with the initial wave speed. This process may be carried out by the following steps.

(i) Determine the steady flow normal and critical depths as set out previously. This determines whether the flow is subcritical or supercritical.

(11) For supercritical flow the normal flow depth may be assumed to apply throughout the pipe length. As the velocity exceeds the wave speed there is no effect propagated upstream from the pipe discharge point. This implies that the flow leaves the pipe at normal depth and for a known flow rate and pipe dimension allows the local velocity and wave speed to be calculated along the whole pipe length.

(iii) For subcritical flow the initial water surface profile is more complicated as the effect of the pipe discharge is propagated upstream. In subcritical flow it has been found that the depth of flow is at its critical value at the discharge point with the water depth then rising upstream until the normal steady flow depth is achieved. Calculation of this depth profile is presented in [6] and summarized below in terms of the gradually varied flow profile prediction technique. 
Gradually varled flow 18 steady non-unfform flow of a spectal type. The flow parameters are assumed to change slowly, if at all, in the flow direction.

The basic assumption in the treatment of this type of flow is that the local head loss at any section is given by the Manning expression (11), for the 1dentical local flow depth and rate under assumed steady, unfform flow conditions.

Depth profile predictions by numerical integration are based on this assumption, expressed in terms of figure 8 by

$$
\frac{d}{d L}\left\{\frac{v^{2}}{2 g}+\left(z_{O}-s_{o} L\right)+h\right\}=-\left\{\frac{n Q}{\mathrm{Am}^{2 / 3}}\right\}^{2}
$$

where $\left(Z_{0}-S_{0} L\right)$ is the elevation at distance $L$ along the channel, measured in the downstream direction; $S_{0}$ is $\sin \theta$, channel bed slope,

hence $-\frac{V}{g} \frac{d V}{d L}+s_{0}-\frac{d h}{d L}=\left(\frac{n Q}{\mathrm{Am}^{2 / 3}}\right)^{2}$

and as, $Q=V A$

$$
\frac{d V}{d L} A+V \frac{d A}{d L}=0
$$

and as $\frac{\mathrm{dA}}{\mathrm{dh}}=\mathrm{T}$ from equation 5 it follows that

$$
\frac{d V}{d L}=-\frac{V}{A} \frac{d A}{d L}=-\frac{V T}{A} \frac{d h}{d L}=-\frac{Q T}{A^{2}} \frac{d h}{d L}
$$

and substituting in equation 28 yields

$$
\begin{aligned}
& \frac{Q^{2} T}{g A^{3}} \frac{d h}{d L}+s_{0}-\frac{d h}{d L}=\left\{\frac{n Q}{A m^{2 / 3}}\right\}^{2} \\
& d L=\left\{\frac{1-Q^{2} T / g A^{3}}{S_{0}-\left(n Q / A m^{2 / 3}\right)^{2}}\right\} d h \\
& L=\int_{h} \frac{1-Q^{2} T / g A^{3}}{S_{0}-\left(n Q / A m^{2 / 3}\right)^{2}} d h
\end{aligned}
$$

where $L$ is the distance between two known depths $h_{0}, h_{1}$.

Plgure 9 1llustrates this numerical integration, which may be convenfently achieved by Simpson's rule.

The numerator and denominator of equation 30 will be recognized as the equations determining the critical and normal flow depths in an open channel. 
When the term $\left(1-Q^{2} \mathrm{~T} / g \mathrm{~A}^{3}\right)$ is zero the flow is at critical depth, $1 . e .$, there is no change in $L$ for a change in $h$.

When the term $S_{0}-\left(\mathrm{nQ} / \mathrm{Am}^{2 / 3}\right)^{2}$ is zero uniform flow depth is achieved, $1 . e$. , there is no change in $h$ for a change in $L$.

The initial depth at each section $\Delta x$ apart along the pipe may then be calculated from the proflle produced by the integration of equation 30 . Flow velocity is then calculated based on a constant flow rate through the pipe and oimilarly wave speed is determined based on flow depth and channel geometry.

Once the initial flow depth, velocity and wave speed have been determined the unsteady flow calculation procedure may begin.

\subsubsection{Internal or Nodal Points}

Simultaneous solution of equations 25 and 26 at all points $\Delta x$ apart between $\mathrm{x}=\Delta \mathrm{x}$ and $\mathrm{x}=(\mathrm{L}-\Delta \mathrm{x})$ will yleld the required values of flow depth and velocity at the end of each time step. Wave speed may then also be determined from equation 5. This process applies to elther sub or supercritical flow conditions as the particular regime is represented in the interpolations required to fix points $R, S$ or $S^{\prime}$, figure 4.

\subsubsection{Entry Boundary Condition, Supercritical Flow}

In this case the inflow profile alone determines the flow depth at pipe entry as downstream conditions, that would have been represented by the $C^{-}$characteristic in subcritical flow, cannot effect the flow conditions at the upstream boundary, as by definition the flow velocity exceeds the wave speed.

Hence the boundary condition is obtained from the flow profile $Q=f(t)$ solved with the normal depth expression

$$
Q=\frac{1}{n} \mathrm{Am}^{2 / 3} \mathrm{~s}_{0}^{1 / 2}
$$

where $A$ and $m$ are both $f(h)$. This equation may be rewritten in the form

$$
1-\frac{(n Q)^{2}}{A^{2} m^{4 / 3} S_{0}}=0
$$

and this boundary expression may be solved at each time step with a known $Q$ by the bisection technique; this technique is described later.

\subsubsection{Entry Boundary Condition, Subcritical Flow}

For subcritical flow the downstream conditions do contribute to the entry flow depth and velocity. In this case the inflow profile $Q=f(t)$ is solved with the $\mathrm{C}^{-}$characteristic 


$$
\begin{aligned}
& Q=f(t)=v_{1} A_{1} \\
& v_{1}=X 4+X 3 h_{1} \\
& Q(t)=A_{1}\left(X 4+X 3 h_{1}\right)
\end{aligned}
$$

where suffix 1 refers to the entry boundary location and $A=f(h)$ dependent on the pipe cross sectional geometry.

In the form

$$
Q(t)-f\left(h_{1}\right)\left(X 4+X 3 h_{1}\right)=0
$$

this boundary equation may be solved by the bisection technique.

\subsubsection{Exit Boundary Condition, Supercritical Flow}

As the flow velocity exceeds the local wave speed the exit boundary condition may be determined in the same manner as the upstream nodal points, namely by the simultaneous solution of the $\mathrm{C}^{+}$and $\mathrm{C}^{-}$characteristics. With reference to figure 4 both the $R$ and $S^{\prime}$ points lie upstream of the pipe exit.

The exit condition may be included in the nodal point calculations for the supercritical flow case, no separate exit subroutine being necessary in the program as equations 25 and 26 are sufficient.

\subsubsection{Exit Boundary Condition, Subcritical Flow}

At pipe exit in the subcritical flow regime the flow depth approaches the critical depth value, given by zero value of equation 15 :

$$
\frac{Q^{2}}{\mathrm{gA}_{\text {crit }}^{3}} \mathrm{~T}_{\text {crit }}=1,
$$

where $A$ and $T$ are $f(h)$

This condition may be solved with the $\mathrm{C}^{+}$characteristic

$$
\mathrm{v}_{\mathrm{N}+1}=\mathrm{x} 2-\mathrm{x}_{1} \mathrm{~h}_{\mathrm{N}+1}
$$

where $N=N^{\circ}$ of pipe length sections, $\Delta x$.

The boundary condition becomes

$$
\left[\left(X 2-X 1 h_{N+1}\right) A_{N+1}\right]^{2} \frac{T_{N+1}}{g A_{N+1}^{3}}-1=0
$$

Solution may again be achieved by use of the bisection method together with the use of the area to depth relationship for the channel. 


\section{CALCULATION TECHNIQUES AND PRESENTATION OF RESULTS}

\subsection{DETERMINATION OF NORMAL AND CRITICAL DEPTHS}

The bisection method was used to solve the equation defining both critical flow depth

$$
X=1-Q^{2} T / g A^{3}
$$

and normal flow depth

$$
Y=S_{0}-\left(n Q / A m^{2 / 3}\right)^{2} \text {. }
$$

that feature as boundary conditions.

It may be assumed that both $X$ and $Y$ have zero values for some value of depth $h$ in the range $0<h<D$ for the pipe case.

This initial interval is bisected and $h=D / 2$ used to evaluate $X$, $Y$. If the resulting values are positive then the root is less than the midpoint and the upper limit is reset equal to the $h$ value just used and the remaining interval 0 to $\mathrm{D} / 2$ bisected. The process repeats until a root is obtained. If the $X$ or $Y$ value had been negative then the root would be greater than the trial $h$ value, in this case the lower limit is reset to the trial $h$ value and the interval bisected.

Due to the need to include the area depth relationship this solution must be undertaken by an iterative process. The time taken depends on the complexity of the area-depth function.

\subsection{NUMER ICAL INTEGRATION FOR SURFACE PROFILES}

The integration of the position vs depth profile

$$
L=\int_{h_{1}}^{h_{2}} \frac{1-Q T^{2} / g A^{3}}{S_{0}-\left(n Q A m^{2 / 3}\right)^{2}} d h
$$

$\mathrm{h}_{1}$

is achieved by means of Simpson's Rule. Let the integral $\mathrm{X}=\int \mathrm{F}(\mathrm{h}) \mathrm{dh}$, ho

than if the interval $h_{1}-h_{0}$ is divided into 2 equal increments, the value of $X$ Is given by

$$
X=\frac{1}{3} d h\left[F\left(h_{0}\right)+4 F\left(h_{0}+d h\right)+F\left(h_{0}+2 d h\right)\right]
$$

As the integration progresses the length traversed may be accumulated as $L_{n+1}=L_{n}+X$ at the completion of each integration. 


\subsection{CHOICE OF TIME STEP}

Referring to figure 41 will be seen that the time step chosen must be such that the points $R$ and $S$ fall within $\pm \Delta x$ of point $P$. In order for this to occur for all sections along the plpe it follows that

$$
\Delta t=\frac{\Delta x}{(V+c)_{\max }}
$$

This expression ylelds the smallest possible time step as the maximum values of flow velocity and wave speed at any plpe section has been used.

In order to ensure that the computation proceeds as quickly as possible the computer program presented calculates a new time step magnitude at each time increment so that the time step increases when $V$ and $c$ decrease but decreases to malntain a stable solution when $V$ and $c$ are increasing in response to an inflow surge.

\subsection{PRESENTATION OF RESULTS}

The objective of the simulated pipe flow data developed from use of the Fortran computer program TRANSCC, run on the NBS CBT Perkin Elmer 732 computer, was to identify the potential of the method of characteristics solution for flow attenuation prediction and also to highlight any limitations inherent to the technique.

The following test cases were investigated and are reported here:

(1) Investigation of effect of the number of nodes, 1.e., pipe computational section length $\Delta x$, for subcritical flow, plpe slope $1 / 300$, diameter $0.1 \mathrm{~m}$, length 5m, and for supercritical flow, plpe slope $1 / 40$, diameter $0.1 \mathrm{~m}$, length $5 \mathrm{~m}$.

(2) Investigation of effect of peak flow duration, elther 2 or 6 seconds at $1.0 \mathrm{l} / \mathrm{s}$ at pipe slopes of $1 / 100$ or $1 / 300$, plpe diameter $0.1 \mathrm{~m}$, pipe length $5 \mathrm{~m}$.

(3) Effect of pipe gradient on flow attenuation in a $30 \mathrm{~m}$ long, $0.1 \mathrm{~m}$ diameter pipe, pipe slopes of $1 / 40,1 / 100,1 / 300$.

(4) Effect of pipe diameter on flow attenuation, pipe diameters $0.15 \mathrm{~m}, 0.1 \mathrm{~m}$, $0.075 \mathrm{~m}$ at $1 / 40,1 / 100,1 / 300$ slopes, $30 \mathrm{~m}$ long pipe.

(5) All simulations above employed a constant Manning coefficient of 0.015 . The effect of varying Manning coefficient from 0.009 to 0.020 in a $0.1 \mathrm{~m}$ diameter, $15 \mathrm{~m}$ long $\mathrm{plpe}$ at $1 / 100$ slope was also investigated.

(6) The effect of the initial flow rate assumed in the pipe was studied, varied from $0.2 \mathrm{l} / \mathrm{s}$ to $0.05 \mathrm{l} / \mathrm{s}$ in a 0.1 m diameter pipe, $15 \mathrm{~m}$ long, at $1 / 300$ and $1 / 40$ pipe gradient subjected to peak inflow rates of 1.2 and $4.2 \mathrm{l} / \mathrm{s}$. 
The results of these simulations are presented in graphical form and are discussed. 


\section{DISCUSSION OF UNSTEADY FLOW SIMULATION RESULTS}

\subsection{INFLUENCE OF SPECIF IED TIME INTERVAL GR ID SIZE ON PREDICTED FLOW PARAMETERS}

In order to apply the solution technique described the pipe length must be split into a number of equal increment at length $\Delta x$. The calculation time is dependent on this subdivision length and on the local wave speed and flow velocity via the expression

$$
\Delta t=\frac{\Delta x}{v+c}
$$

Hence for a given pipe length and duration of flow simulation the computing time and consequently cost, is determined by the cholce of the number of pipe sections adequate to provide an acceptable prediction of the flow parameter variation with time.

Figure 10 1llustrates the effect of dividing a $5 \mathrm{~m}$ length of pipe, into 5,10 or 30 equal computational subdivisions, $\Delta x$ varying from $1 \mathrm{~m}$ to $0.167 \mathrm{~m}$.

The variations in predicted flow rate at each node along the pipe length may be explained entirely in terms of the interpolation required to yleld the base conditions for each computing time step, outlined in figure 4.

The interpolation in figure 4, necessary to determine conditions at $R$ and $S$ at time $t$, from calculated values of depth, velocity and wave speed at $A, B$ and $C$, effectively assumes that disturbances arriving at $A$, $B$ or $C$ at time $t$ effect conditions ahead of their true positions, namely at $R$ and $S$.

Therefore the initial depth increase propagated in the pipe flow by the rise in the inflow curve, $Q=f(t)$, would be expected to register earlier at any particular section if the number of pipe sections were small. With larger pipe section lengths the apparent disturbance propagation speed is increased due to this interpolation technique.

Similarly any decrease in depth at the inlet would also be recorded earlier at a downstream section if the $\Delta x$ chosen were large. As the depth and flow velocity predictions may be thought of as summations of positive and negative change waves moving back and forth along the flow it is therefore to be expected that the peak values predicted for flow depth and velocity will increase towards a true limit as the pipe computing section length decreases.

These effects are clearly seen in the simulated results presented in figure 10. As the number of pipe sections increases from 5 to 30 , so does the peak flow rate predicted, although the change between 5 and 10 sections is several times the change between 10 and 30 sections, indicating an approach to a true prediction limit.

Figure 11 repeats this assessment for a supercritical flow in a pipe at a $1 / 40$ gradient. Here there is little attenuation in the first $4 \mathrm{~m}$ length when 
compared to the very pronounced attenuation in the $1 / 300$ gradient plpe of Figure 10. This lack of attenuation is explainable in terms of the frictional and mass forces acting. The effects of $\Delta x$ cholce however remain as described for the 1/300 plpe case, earlier depth changes belng detected with the larger pipe sectlons together with reduced peak flow rate predictions.

Figures 12 and 13 1llustrate the depth changes along both the $1 / 40$ and $1 / 300$ plpe lengths for the inflow surge considered above. One point mentioned in the derivation of the flow boundary conditions is clearly demonstrated by these results, namely the Initlal water surface profile and the assoclated exit depth criteria.

For the 1/300 gradient pipe the flow is subcritical and hence the depth decreases at exit to the appropriate critical value. Figure 12 illustrates this profile for the steady initial flow of $0.1 \mathrm{l} / \mathrm{s}$ calculated by the gradually varied flow analysis described. The flow in the $1 / 40$ pipe, figure 13 is by contrast supercritical and hence the flow depth along the whole pipe length remains at 1 ts normal value at all pipe sections, this depth being by definition both less than the critical depth appropriate to this pipe slope, dlameter and flow rate and less than the corresponding normal depth in the shallower gradient, 1/300, pipe.

The cholce of incremental length and the associated time step is to some extent a matter of experience. In general the flow simulations presented in this report were carried out with an incremental length of $0.5 \mathrm{~m}$, this length being felt to be a reasonable compromise between short computer running time and an adequate representation of the flow depth and velocity time profiles.

\subsection{INFLUENCE OF SURGE DURATION ON PARTIALLY FILLED PIPE FLOW RESPONSE}

In a study of surge wave propagation Wyly [7] noted that the peak surge depth was dependent on the duration of the surge flow. This effect is clearly demonstrated in figures 14,15 , and 16 , by means of a comparison of the attenuation in peak flow rates predicted at pipe slopes of $1 / 100$ and $1 / 300$ for two surge durations.

It w11l be seen that the effect of extending the duration of the Inflow peak rate of $1 \mathrm{l} / \mathrm{s}$ from 2 to $6 \mathrm{~s}$ is to increase substantlally the peak flow rate predicted at the downstream pipe sections. Examples have been taken at 2 and 4 m from the pipe entry.

This effect is to be expected and is in fact due to the flow establishment response characteristic of the pipe system. Obviously if the peak inflow of $1 \mathrm{l} / \mathrm{s}$ was held constant for a sufficient perlod then the flow in the pipe would become steady at this new flow rate, the water surface profile in the subcritical regime assuming the new $1 \mathrm{l} / \mathrm{s}$ characteristic normal depth with a progressive reduction to critical depth at the pipe exit. 


\subsection{INFLUENCE OF P IPE SLOPE, DIAMETER AND ROUGHNESS ON THE PREDICTED VAR IATIONS IN FLOW DEPTH AND VELOCITY}

The attenuation in flow depth and flow rate predicted by the unsteady flow analysis are caused by the balance of frictional and mass forces acting on the fluid. Within the model these friction forces are represented by the appropriate steady flow loss calculated from Mannings equation 11, but utilizing the flow velocity and depth at the particular pipe location and time step under consideration. Thus the variations in attenuation would be expected to follow the dependencies inherent in Mannings expression, namely friction forces dependent on pipe slope, roughness and diameter.

Figure 17 1llustrates the attenuation in peak flow rate at four locations at $6 \mathrm{~m}$ intervals along a $30 \mathrm{~m}$ pipe at a range of gradients, $1 / 40,1 / 100,1 / 300$. For this simulation pipe roughness and diameter were held constant. Two effects are clearly visible as gradient is reduced, namely the reduction in peak flow rate and the progressively later occurrence of this peak flow, indicating the dependence of flow velocity on pipe gradient.

Figures 18 and 19 illustrate the propagation of the surge wave at the three pipe gradients. Initially the water surface profiles at the three gradients are at normal depth with a reduction to critical depth at pipe exit in the subcritical flow cases, $1 / 100$ and $1 / 300$. As the wave travels along the pipes it will be noted that the wave progresses most rapidly in the steeper pipe, again this effect reinforces the forward movement of the peak flow rate noted in figure 17 and is predictable from the Manning expression dependency.

Figure 20 presents the peak flow rate for the 0.1 m diameter pipe from figure 17 in comparison with the predicted peak flows in $0.15 \mathrm{~m}$ and $0.075 \mathrm{~m}$ diameter plpes. At each of the three gradients considered the attenuation effect is least in the $0.15 \mathrm{~m}$ pipe and greatest in the $0.075 \mathrm{~m}$ pipe. Again this effect would be expected from the frictional forces acting for constant pipe slope and roughness.

Based on these observations it would be expected that attenuation would also be dependent on roughness, as represented by the Manning coefficient. Generally, in the simulations reported a constant value of Manning coefficient of 0.015 has been employed. This value is appropriate to cast iron pipe, Chow [2], and as such would be representative of many drainage applications. Figure 21 11lustrates the effect of reducing pipe roughness to a Manning coefficient of 0.009 representative of very smooth bore glass or plastic drainage piping, and increasing to value of 0.02 representing aged piping. A pipe gradient of $1 / 100$ was chosen to illustrate both the dependence of flow normal depth on pipe roughness and slope and the fact that subcritical or supercritical flow may be established in a constant slope pipe dependent only on pipe roughness. It will be noted from figure 21 that subcritical flow is established at Manning coefficients of 0.015 and above, supercritical flow at Manning coefficients of 0.012 and below.

Figure 21 also indicates the depth of flow dependence on pipe roughness, the smoother pipe featuring the shallower flow. Again this could be predicted for 
a given flow rate in a plpe of constant gradient from the Manning equation for steady uniform flow.

\subsection{INFLUENCE OF INITIAL AND RESIDUAL STEADY FLOW ON THE PEAR PLOW AND DEPTH PREDICTIONS}

It has been shown that in order to utilize the method of characteristics solution of the unsteady flow equations it is necessary to establish the flow depth and velocity at all points along the plpe at time zero. In the simulations presented in this report the initial conditions have been chosen to represent a steady low flow rate through the system. Inttial conditions are of course not limited to such a steady flow; however, this is by far the simplest base condition to employ.

It might appear therefore that the need to assume an initial flow in the system is a major limitation to the application of this analytical technique, however this may be shown not to be the case. The objective of the technique development reported was to provide a means of including the beneficial effects of flow attenuation on the design of long drainage pipes within, or collecting flow from, complex bullding drainage networks. A cursory study of the usage patterns of appliances within any complex building, such as a hospital, or domestic network serving a large number of living units, will indicate that such a system would be consistently carrying water at some minimum flow rate so that the response of the system to a surge input could be reasonably modelled by means of the techniques described.

Thus the initial constant flow rate in the region bounded by 0.05 to $0.2 \mathrm{l} / \mathrm{s}$ is reasonable as test conditions for the numerical solutions.

Similarly most appliance flow discharge profiles feature long, low flow, "talls", this is especially the case for such appliances as bathtubs and basins, thus the solution may be allowed to run for a given time period at a final value of steady flow and still be representative of actual flow conditions.

These constraints apply rather more to the test simulations included in this report than to the use of the techniques in a full system analysis as in the latter case the usage pattern of the system appliances would provide a continuous unsteady flow input to the system.

Figure 22 1llustrates the peak flow rate and depth response predicted along a 20 m long, $0.1 \mathrm{~m}$ diameter plpe set at gradients of $1 / 40$ and $1 / 300$, during and following an input surge of $4.2 \mathrm{l} / \mathrm{s}$. The initial and final steady flow values, assumed in the simulation, were set at $0.05,0.1$ and $0.2 \mathrm{l} / \mathrm{s}$ for each plpe slope. It may be seen that the maxlmum flow rate and depth achieved in the system at, or close to, pipe entry remains unaffected by these steady flow initial and final conditions. There is a variation in peak flow rate and depth achieved along the length of the pipe however, and this is entirely predictable In terms of the final steady state value being imposed on the system. Obviously the lower final flow rate of $0.05 \mathrm{l} / \mathrm{s}$ imposes a more rapid atrenuation on the system when compared to the higher values of 0.1 and $0.2 \mathrm{~L} / \mathrm{s}$. 
Theoretically there is no lower limit to the chosen value of final steady flow, however it should be noted that the peak flow rate to be expected in a building drain of these diameters would be in the range 8 to $10 \mathrm{l} / \mathrm{s}, 80$ that $0.05 \mathrm{l} / \mathrm{s}$ represents a very small percentage.

Although the necessity to provide an initial and final flow rate along the system is a limitation on the technique, it is unlikely that this will be in anyway detrimental to the application of the developed technique to actual system analysis.

\subsection{ESTIMATE OF COMPUTER RUN TIME}

The program TRANSCC is included in an appendix to this report. The run time of the program is dependent on the number of pipe sections chosen to represent the pipe being studied. During the duration of this study the program was run on the NBS CBT Perkin Elmer 732 computer. It was found that a $30 \mathrm{~m}$ pipe made up of 60 pipe sections could be studled for a real time of 200 seconds for a computer run time of 15 minutes if no interruptions due to other users programs were experienced. It is clear therefore that the shorter length and real time duration cases were run in 2 to 3 minutes of computer time. In view of the fact that the machine used was by no means the fastest avallable it is considered that the technique developed is practical in terms of usability costs as a design tool. 


\section{EXP ER IMENTAL VER IF ICATION}

The simulated flow attenution results presented and discussed in the proceeding section have indicated that the technique developed is capable of providing flow rate, depth and velocity predictions as a surge wave moves along a drainage pipe at a range of slopes, roughness coefficients and diameters.

Experimental verification of the accuracy of these predictions for both Bubcritical and supercritical flow regimes will be a further stage in this work, however limited verification was possible utilizing an existing NBS CBT test rig designed to study solid transportation under controlled solid geometry conditions. Figure 23 summarizes the test rig and associated finstrumentation. The discharge profile from the supply tank into the test pipe was obtained from the tank depth vs time curve as shown. Th1s profile was then used as input to the simulation program TRANSCC. The depth vs time recordings at four stations along the test pipe were produced by means of an array of water sensing pins set at opposite pipe wall locations providing alternately $0.5 \mathrm{~cm}$ intervals around the plpe circumference at four locations as shown in figure 23. A d.c. current summing amplifier was employed to provide a depth sensitive signal, as 1llustrated in figure 23 and presented in figure 24 in comparison with predicted depth profiles at 4 adjacent points along the pipe. The program as used employed 30 pipe sections to simulate the 5.5 m length, however predicted results were only output at one tenth pipe length locations, although the program output could in the future be adapted to point predictions at a series of predetermined locations as an alternative.

The comparison between observed and predicted depths is in general encouraging; however, a number of points require clarification. The pipe slope was measured at 0.02 , the Manning coefficient was assumed to be 0.012 based on avallable data; however, the results tend to indicate that the Manning coefficient was overestimated. The comparison indicates a progressive lag between observed and predicted depth, most noticable at the 4.9 m station. A reduction in Manning coefficient would also tend to reduce peak depth predictions, however it is likely that the pins tend to yield overestimates of flow depth due to meniscus effects.

Similarly errors in the inflow profile, represented in figure 23, may be seen to contribute to the depth variations close to pipe entry, particularly in the supercritical flow regime where depth is entirely dependent on the upstream flow, represented in flgure 24.

The depth comparison at the first pin station, at $0.64 \mathrm{~m}$, indicates a rather more rapid rise in depth than that predicted. It is likely that the local flow close to pipe entry is subject to splashing and local waves not capable of simulation in the current program. As expected these local effects subside before the second pin station at $0.95 \mathrm{~m}$ is reached.

The lnflow proflle employed to derive the predictions is shown in figure 23, however in order to meet the simulation requirements the flow is assumed to continue at $0.01 \mathrm{~L} / \mathrm{s}$ beyond the completion of the supply tank discharge at 7 seconds, as shown in figure 24. To some extent this requirement contributes 
to the depth $1 a g$ between observed and predicted traces, particularly at the final pin station. A final steady flow of $0.01 \mathrm{l} / \mathrm{s}$ in a $0.1 \mathrm{~m}$ diameter plpe is equivalent to a depth of $0.0027 \mathrm{~m}$ and accounts for a mafor portion of the divergence between observed and predicted depths at this station beyond the 20 second time point. As discussed previously this effect is a more serious defect in the evaluation of the artificial single surge case in the laboratory then 1t would be in practice in the study of a complex pipe network due to the usage patterns of appliances discharging to the system.

In general the results of the limited experimental verification suggest that the simulation and predictive techniques developed are capable of yielding information as to flow depth attenuation. A more detalled experimental program employing longer plpes, gradient adjustment, flow velocity and depth measurements and possible variation of pipe diameters and materials will be considered as an extension to the inftial study reported. 


\section{CONCLUSION AND FURTHER WORK}

The simulation of flow attenuation presented in this study has shown that the method of characterististic solution technique applied to the equations defining unsteady flow in partially filled pipe flow is capable of providing data on flow attenuation in long drainage pipes. A program of simulated flow tests indicated the generally expected relationships between flow attenuation and pipe diameter, gradient and roughness. Solutions to both subcritical and supercritical flow reglmes were developed and tested in flow simulations.

Iimited experimental verification was also undertaken and, within the limits imposed by pipe length and inflow profile measurement, the predicted depths were found to agree well with the measured time dependent variations.

As a result of the study reported further development of the technique is suggested to include multiple flow input to a branched pipe system. Similarly, an extended experimental program is proposed to further verify the accuracy of the flow attenuation predictions made practical by the reported techniques. 


\section{REFERENCES}

[1] Swaffield, J. A., "An initial study of the application of the numerical method of characteristics to unsteady flow analysis in partially filled gravity drainage sized pipes," NBS Report, August 1980.

[2] Chow, V. T., "Open channel hydraulics," McGraw Hill, 1970.

[3] Swaffield, J.A. and Marriott, B. S. T., "An investigation of the effect of reduced volume w.c. flush on the transport of solids in above ground drainage systems." CIB W62 meeting, Brussels, 1979.

[4] Burberry, P., "Techniques for the estimation of flows in foul drains in the light of present water conservation proposals." CIB W62 meeting, 1979.

[5] Fox, J. A., "Hydraulic analysis of unsteady flow in pipe networks." Macmillan Press, London, 1977.

[6] Swaffield J.A., "Prediction of the hydraulic jump location following a change of slope in a partially filled drainage pipe," NBS Report, August, 1980.

[7] Wyly, R. S., "Investigation of the hydraulics of horizontal drains in plumbing systems," NBS Monograph 86, 1964. 

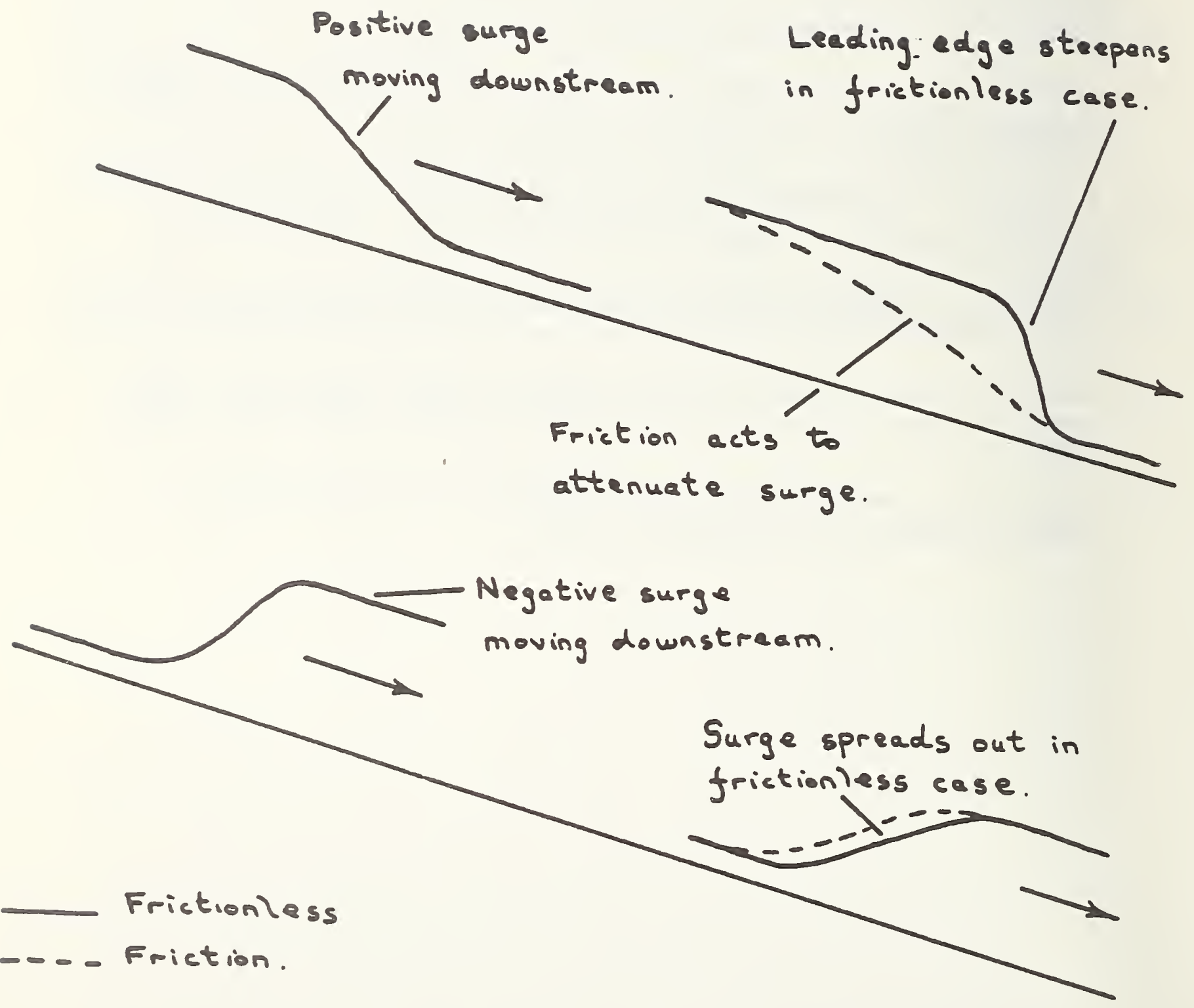

Figure 1. Propagation of positive and negative surges in partially fllled plpe flow 


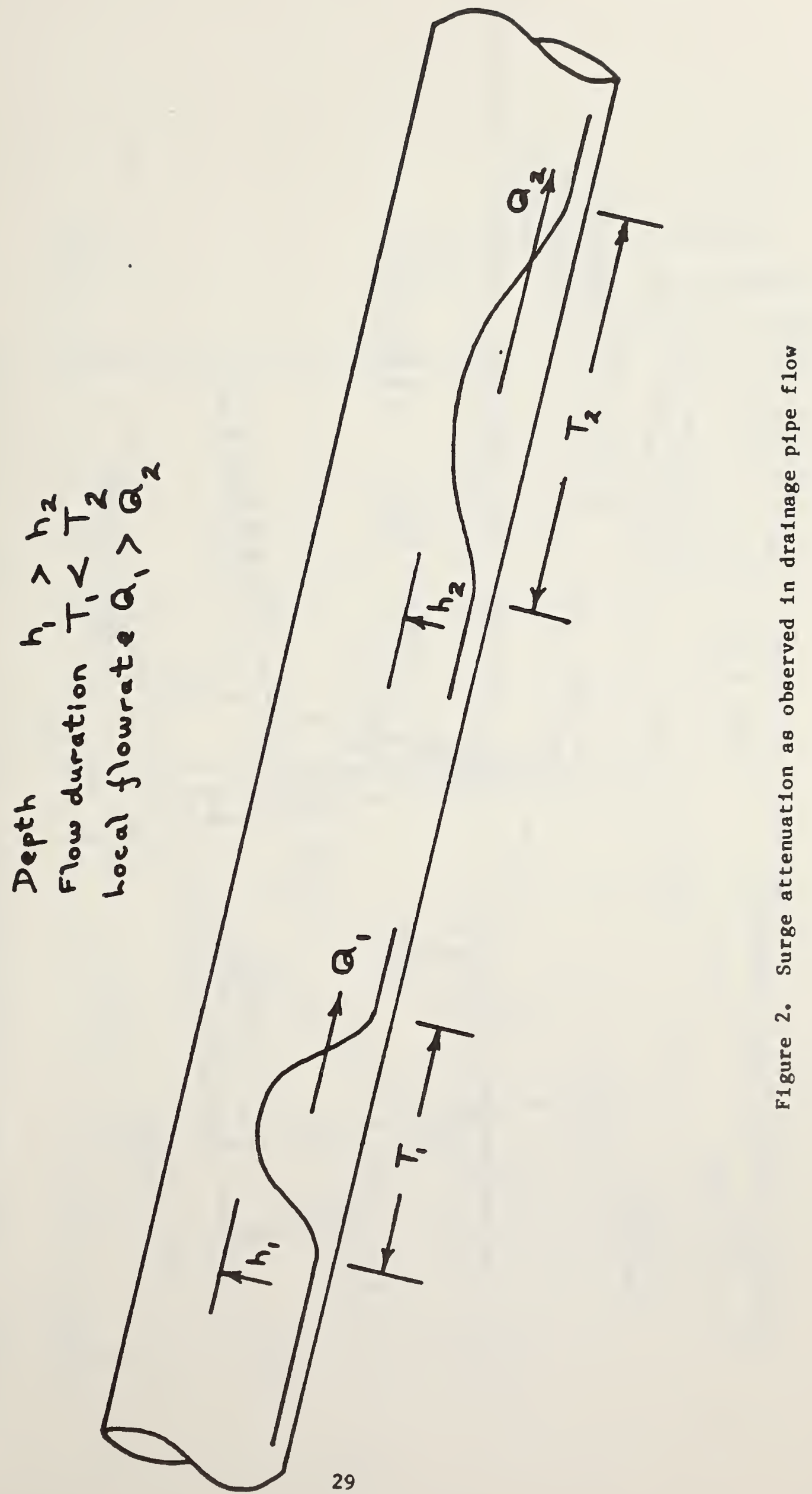




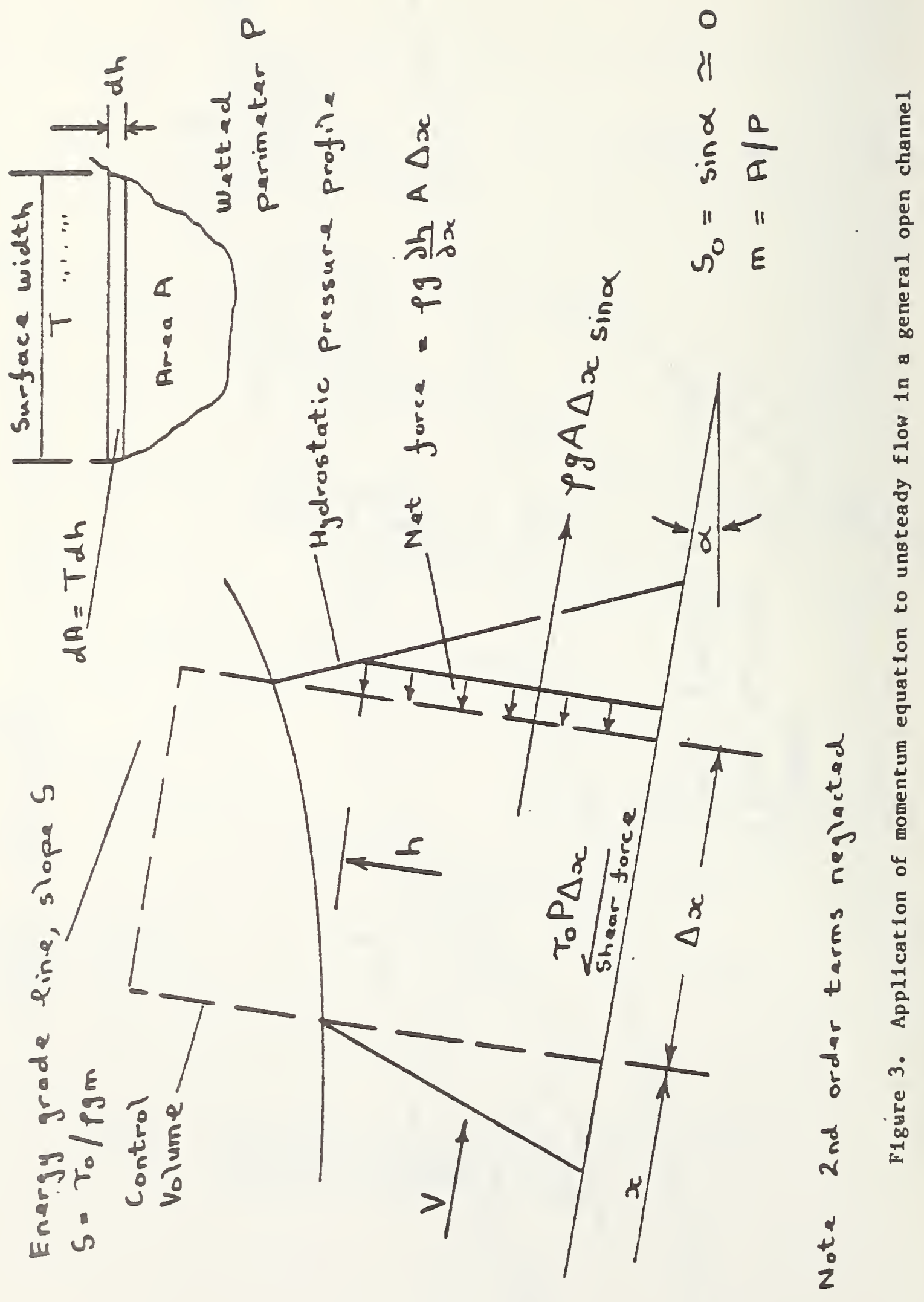




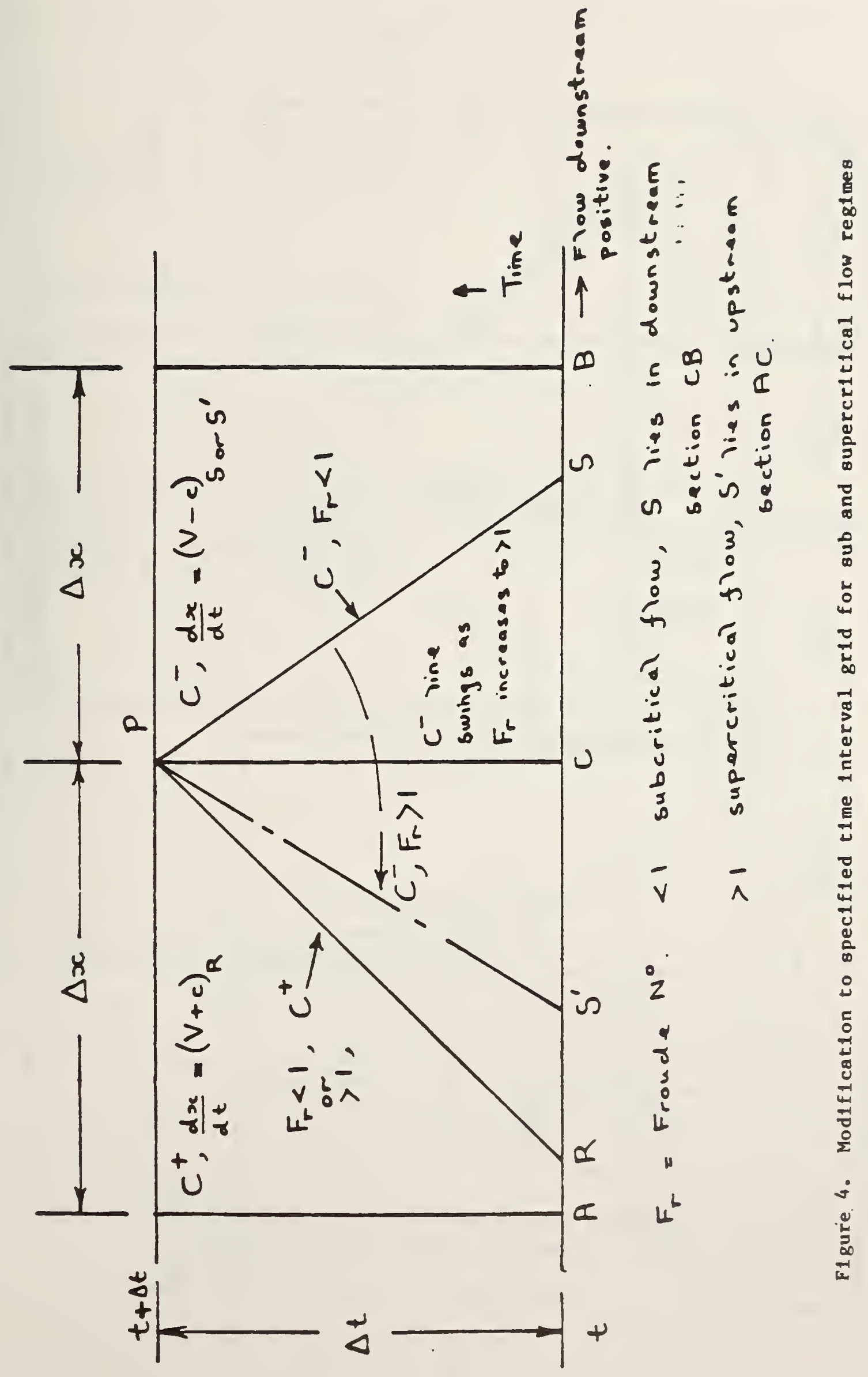




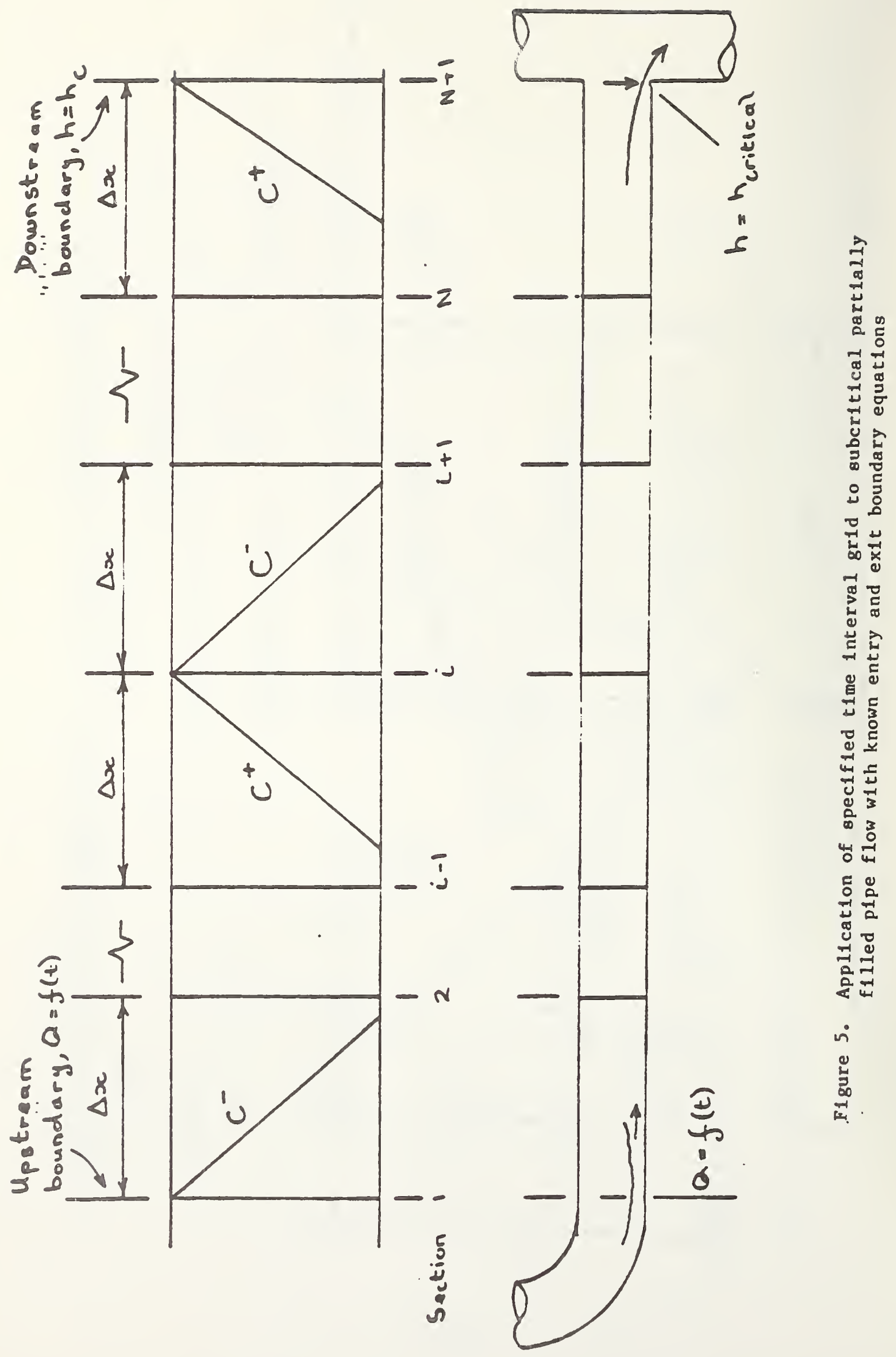



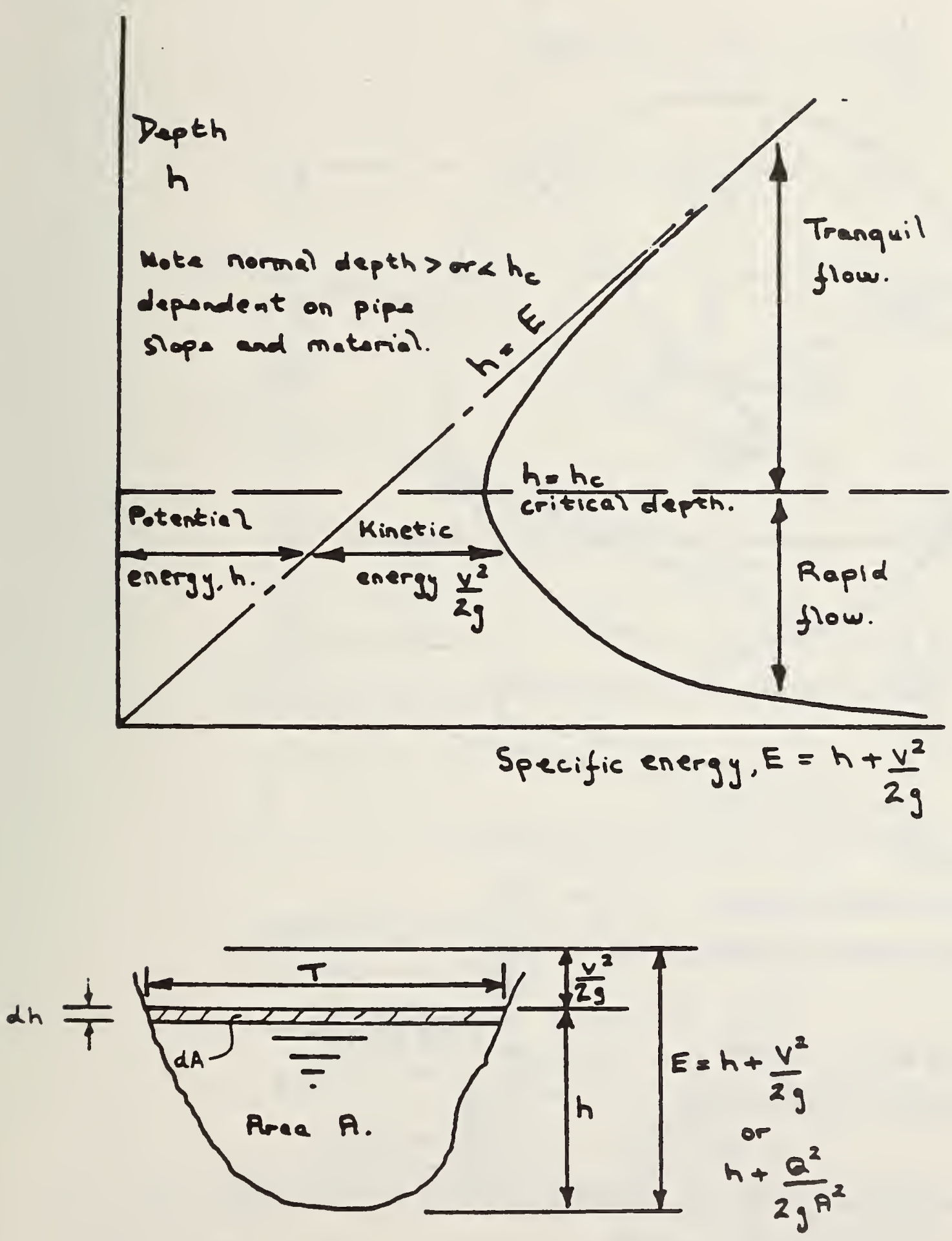

F1gure 6. Relationship between flow specific energy and flow depth, lllustrating the boundary between sub and supercritical flow regimes 


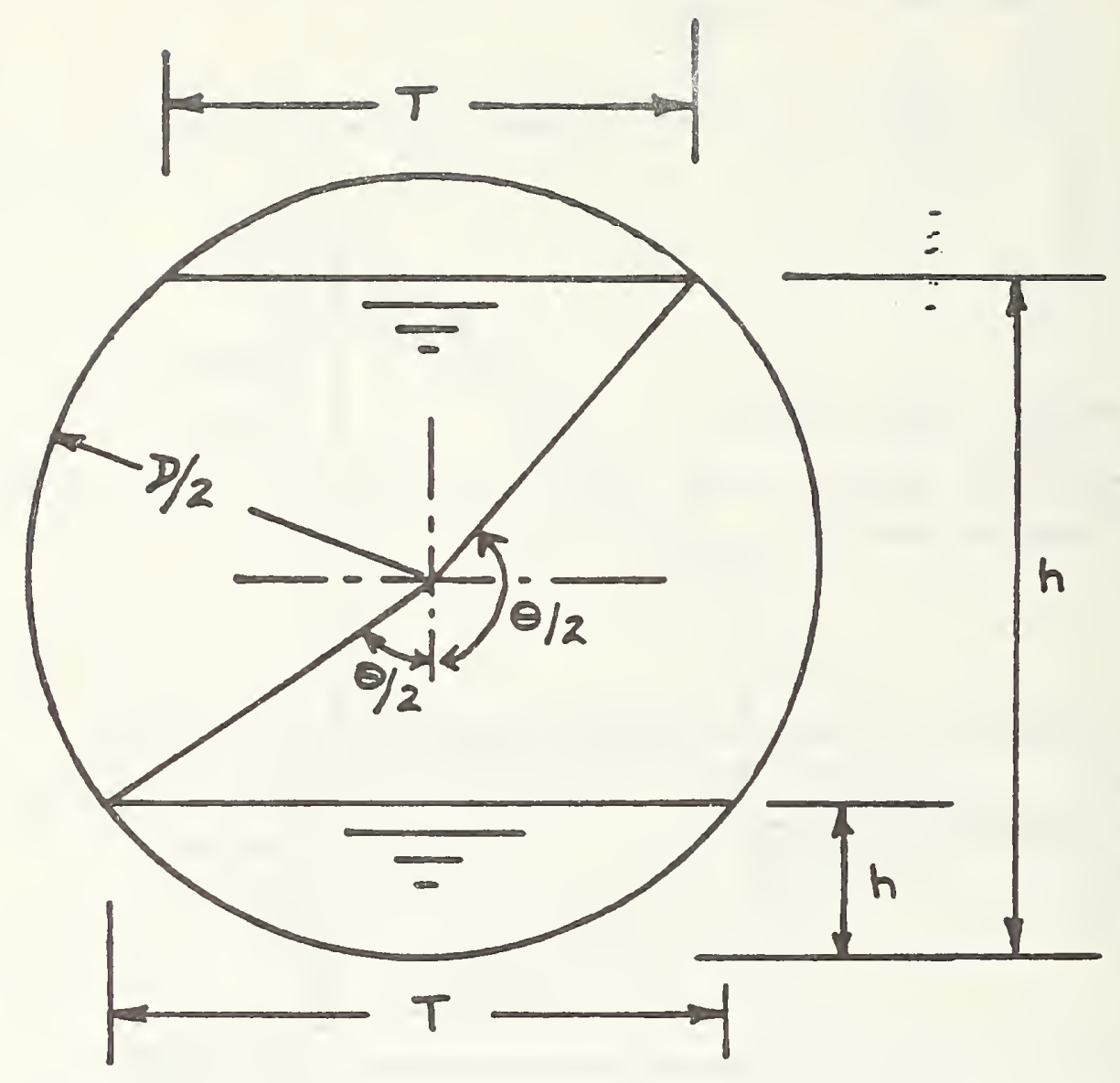

Depth

suptended angle

Flow cross section area $=\frac{D^{2}}{8}(\theta-\sin \theta)$

Surface width $\quad=2 \sqrt{h(D-h)}$

whetted perimeter $=\nabla \frac{\theta}{2}$

$$
\begin{aligned}
& h<D / 2, \theta=2 \tan ^{-1}(\sqrt{h(D-h)} /(D / 2-h)) \\
& h=7 / 2, \quad \theta=\pi \\
& \left.h>D / 2, \quad \theta=\pi+2 \tan ^{-1}(h-8 / 2) / \sqrt{(h(D-h))}\right)
\end{aligned}
$$

Figure 7. Summary of pipe cross section and depth dependent parameters calculations

34 


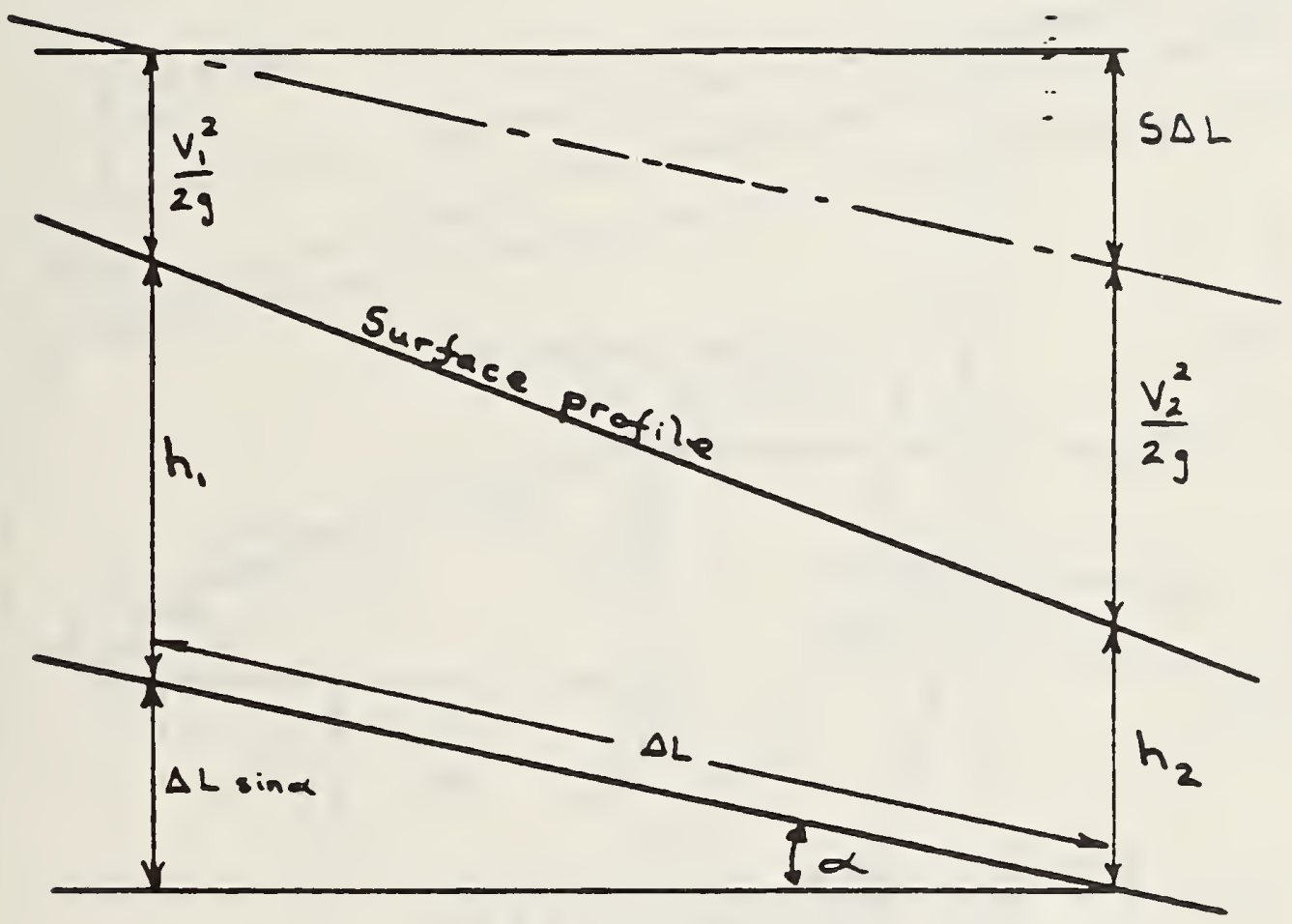

Gradually varied flow, analysis based on heed loss at any section being equal to manning loss prediction, where

$$
S=-\frac{\Delta E}{\Delta L}=\left(\frac{n Q}{A n^{2 / 3}}\right)^{2}
$$

F1gure 8. Basis of gradually varied flow depth prediction 


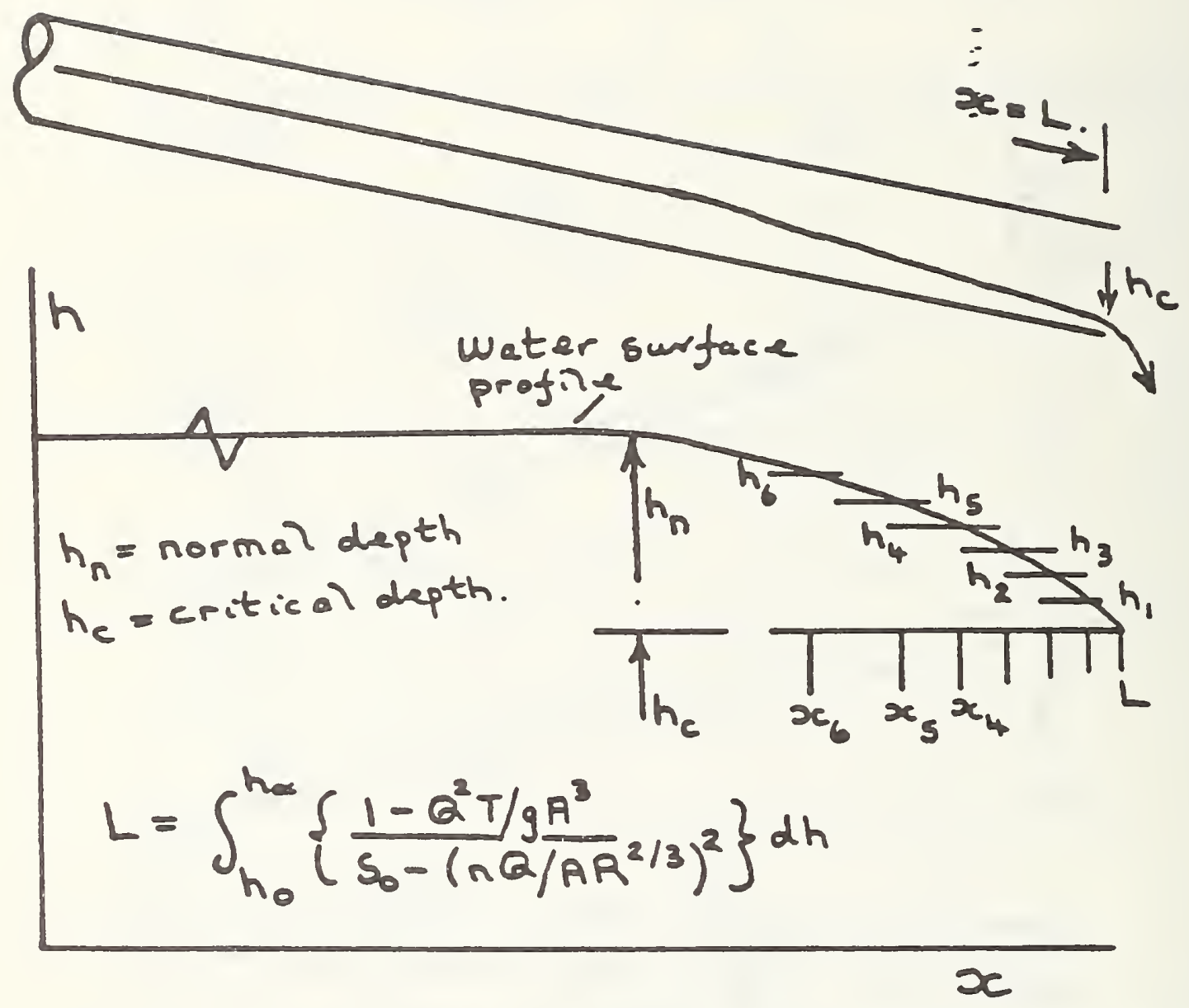

Note, $\Delta x$ increases as calculation proceeds. ii Calculation proceeds upstream from exit, $h=h_{c}$ initial condition. iii $\Delta h=\left(h_{n}-h_{c}\right) / n, n$ in range $10-30$.

Figure 9. Schematic representation of numerical integration to determine water surface profile

36 


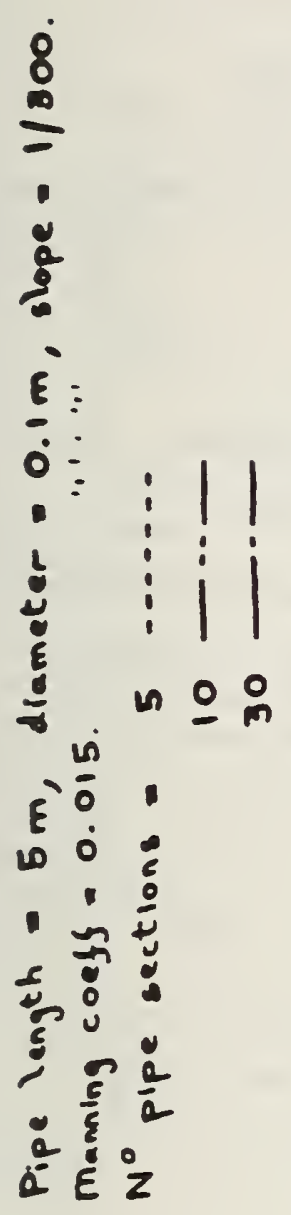




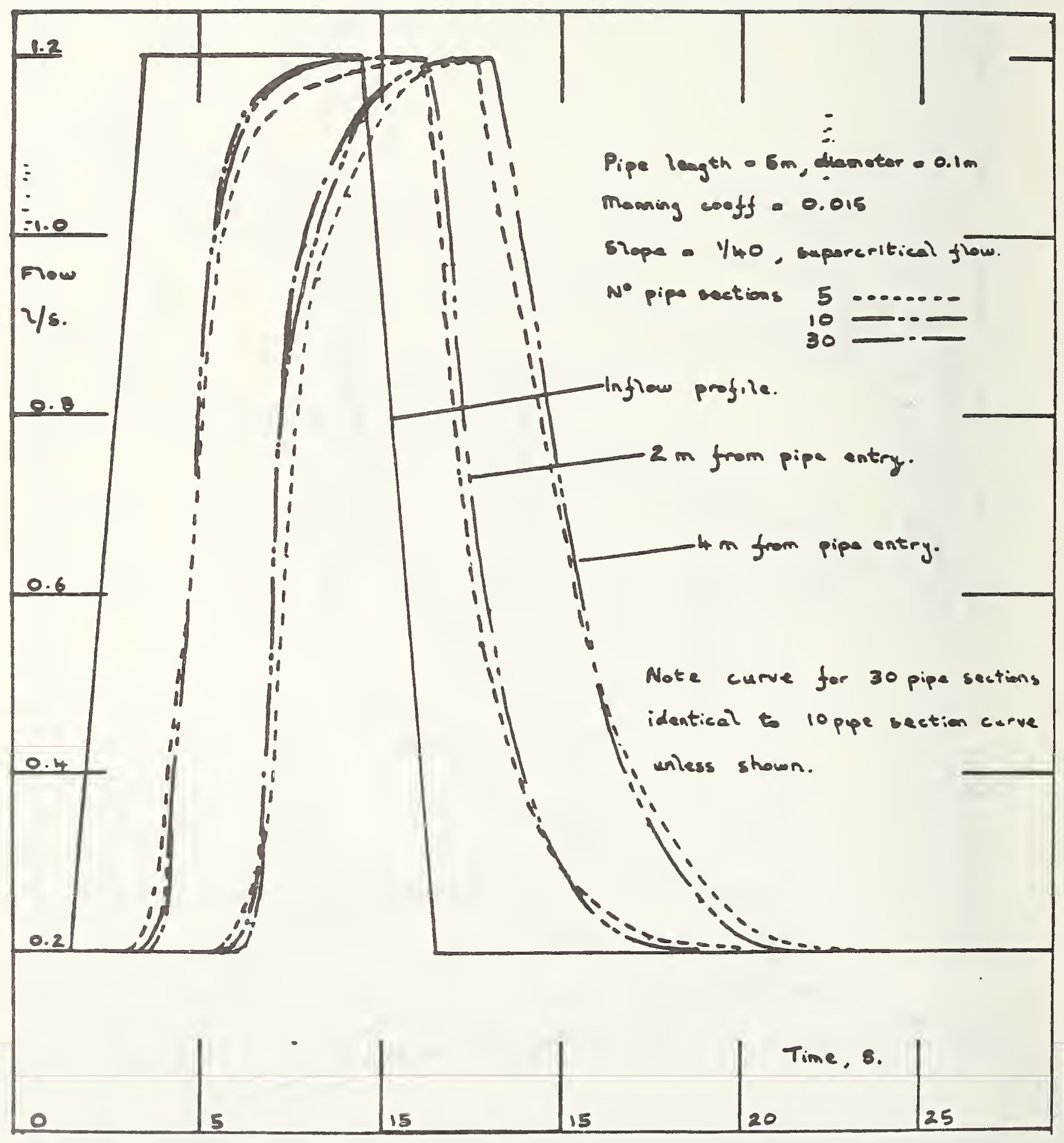

Flgure 11. Influeace of the cholce of pipe section length on supercritical flow parameter predictions 


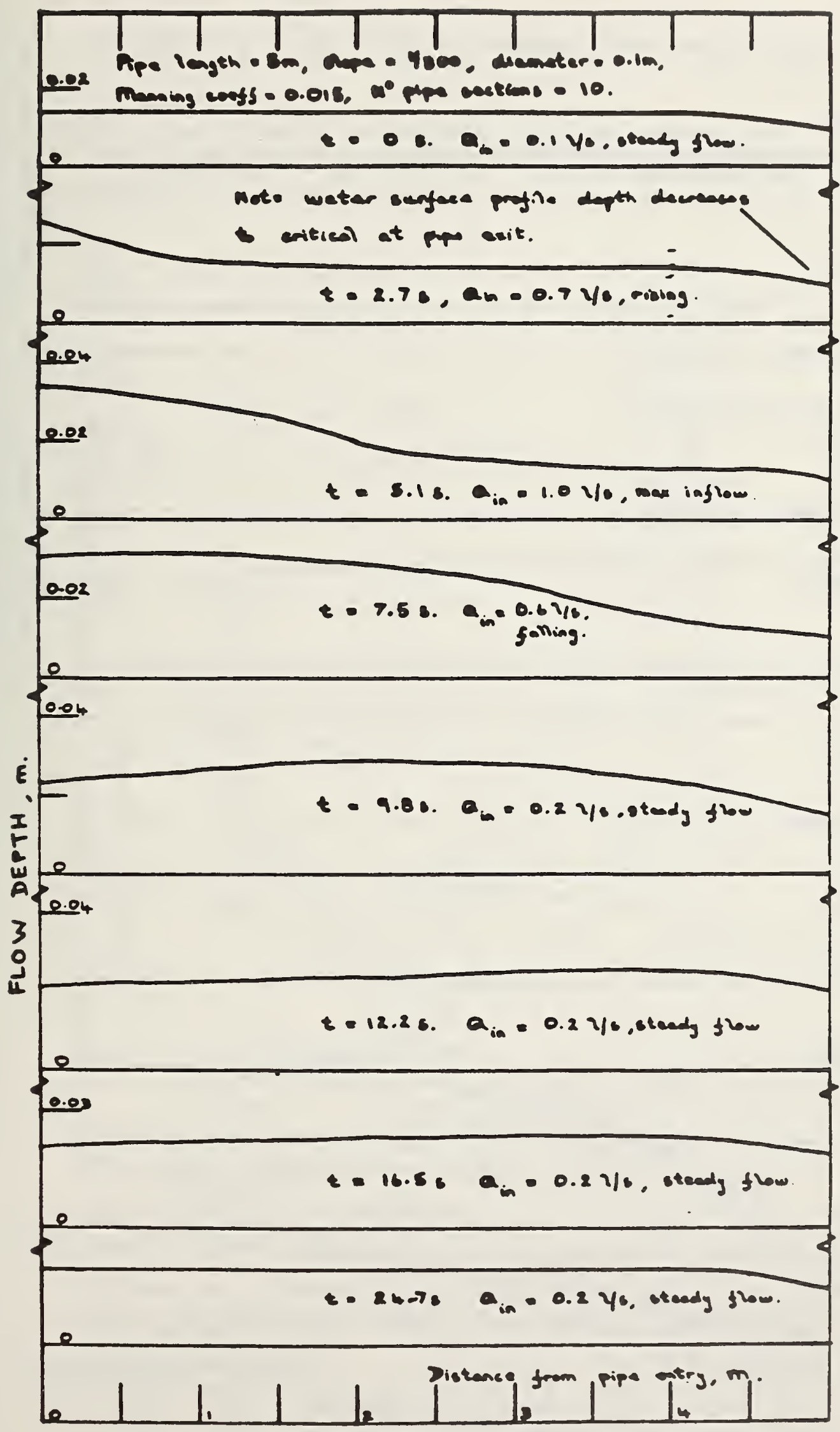

F1gure 12. Depth of flow predictlons for a surge Introduced into suberitical flow 


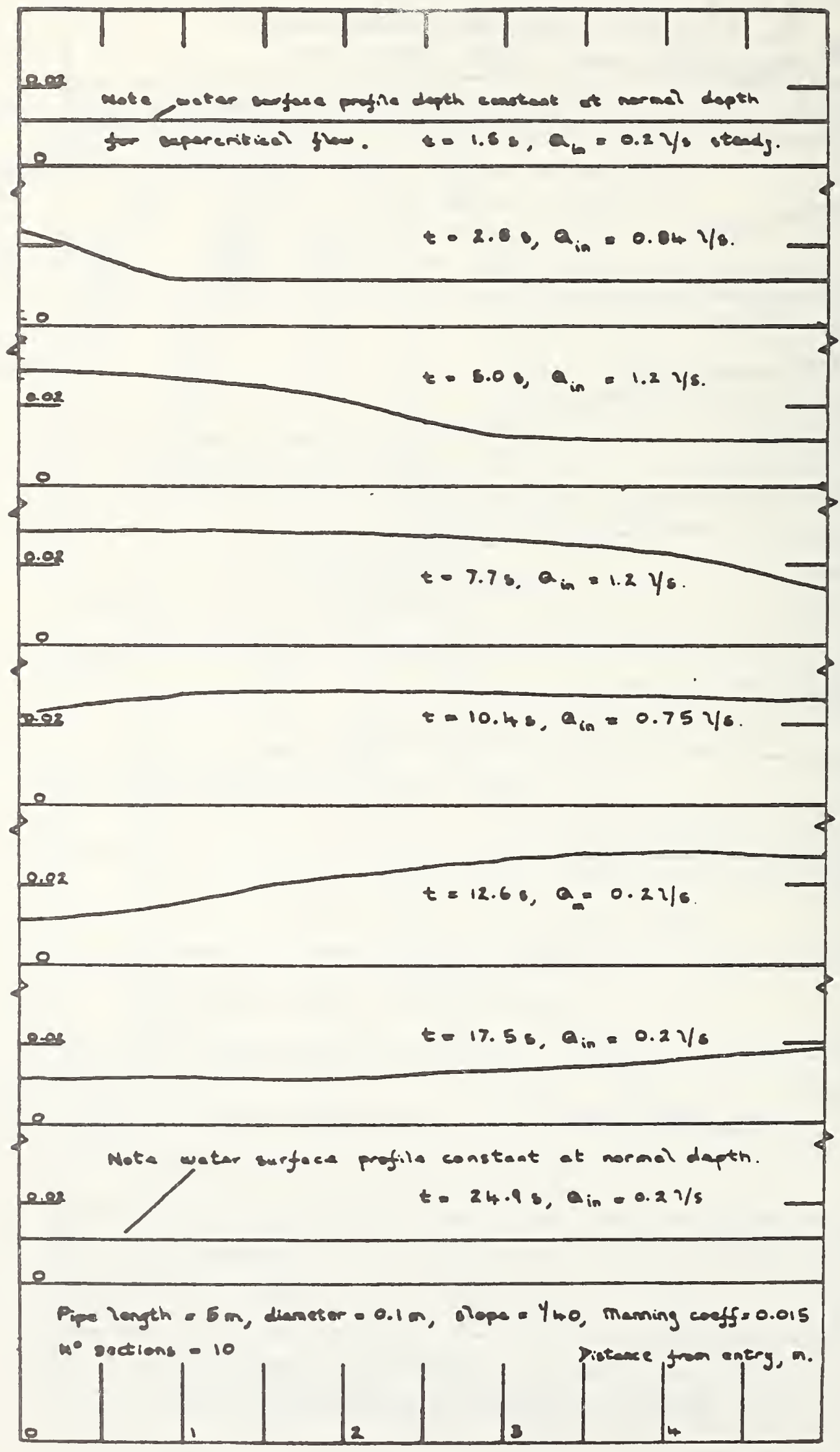

F1gure 13. Depth of flow prediction for a eurge Introduced lato oupercilical flow 


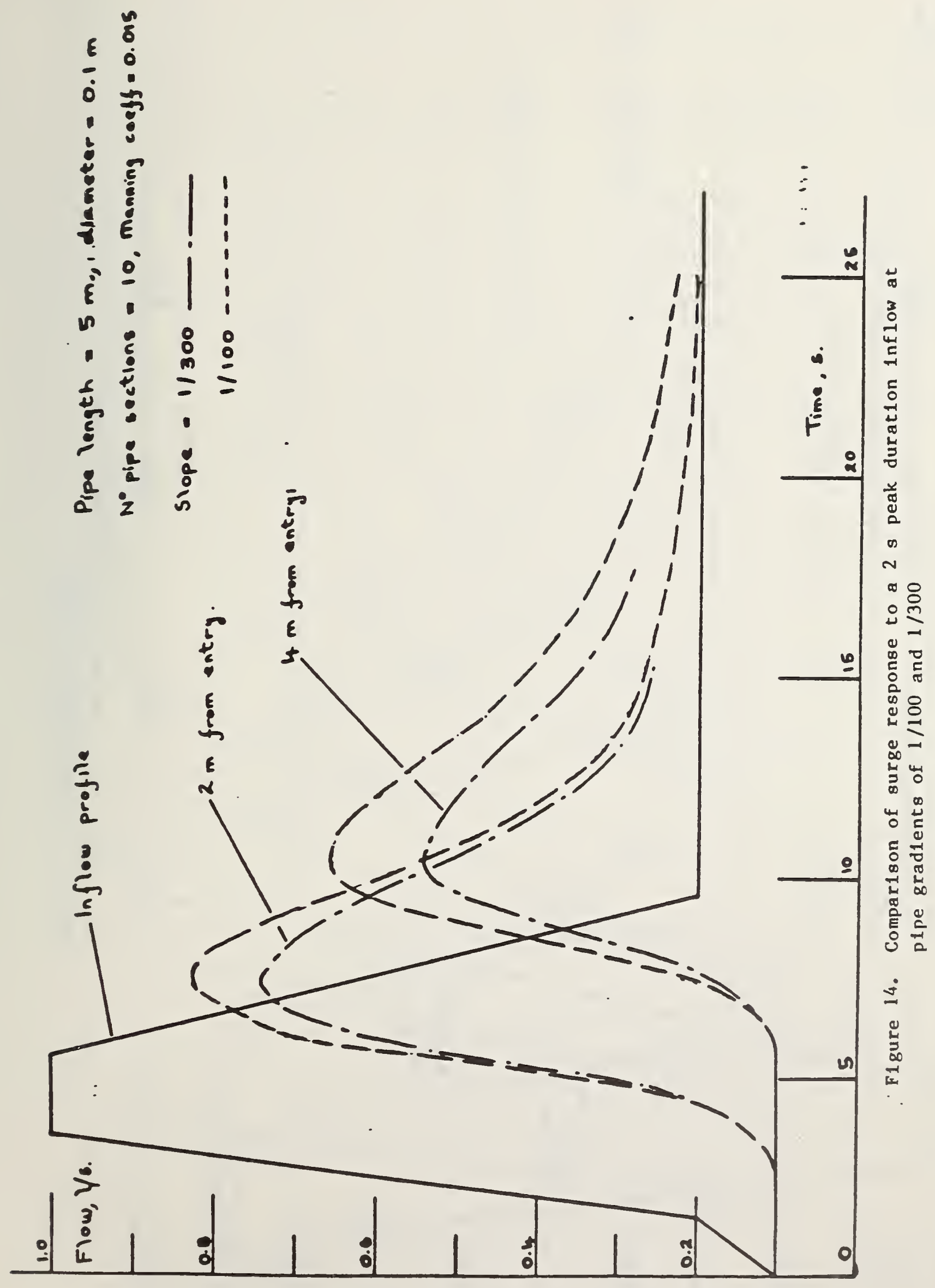


$\frac{8}{n} \frac{8}{\frac{0}{2}}$

$\frac{5}{0}$

है:

$=$

ह่

\&

ते है

i $\frac{a}{2}$ ह

$\frac{0}{2}$
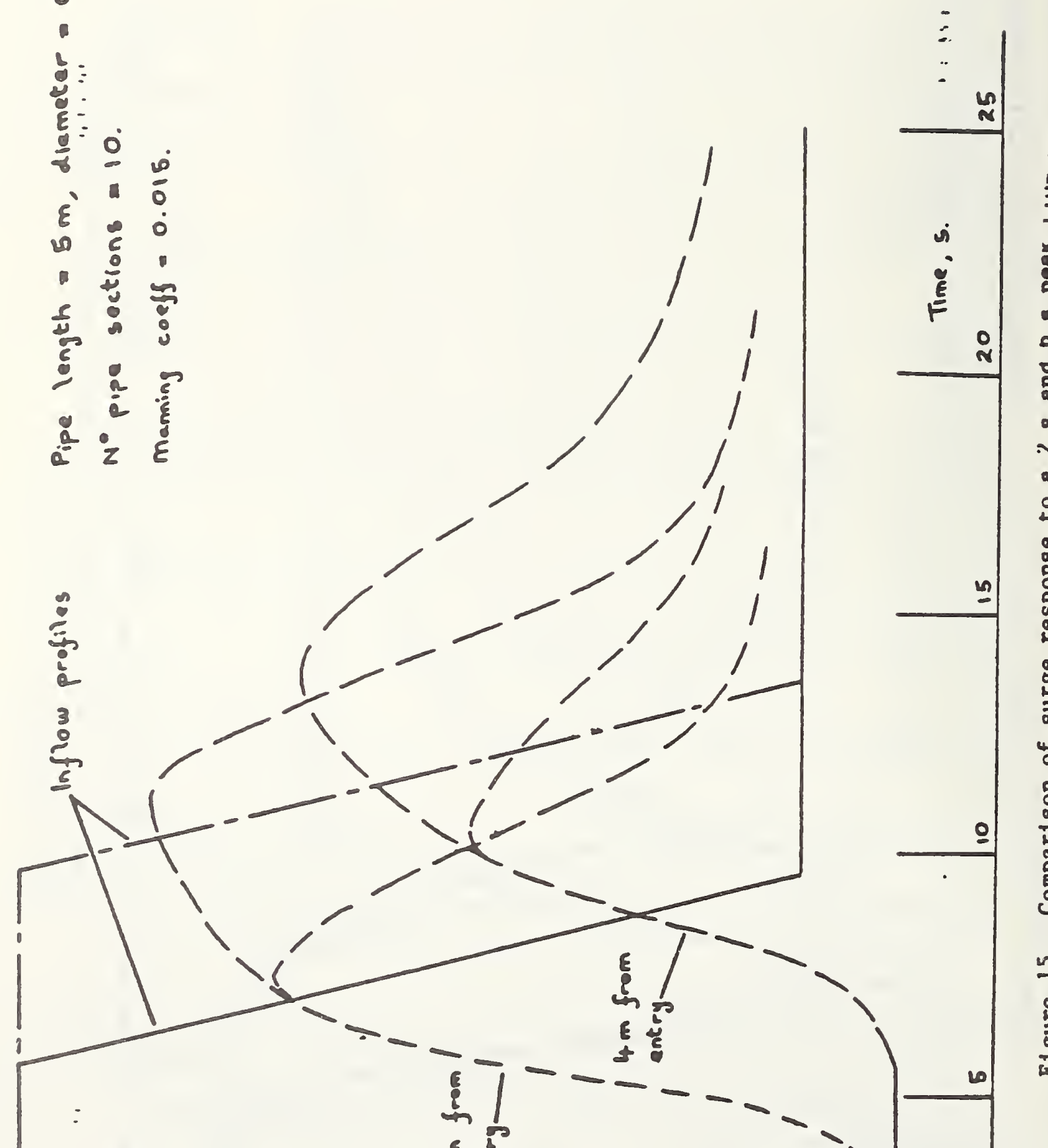


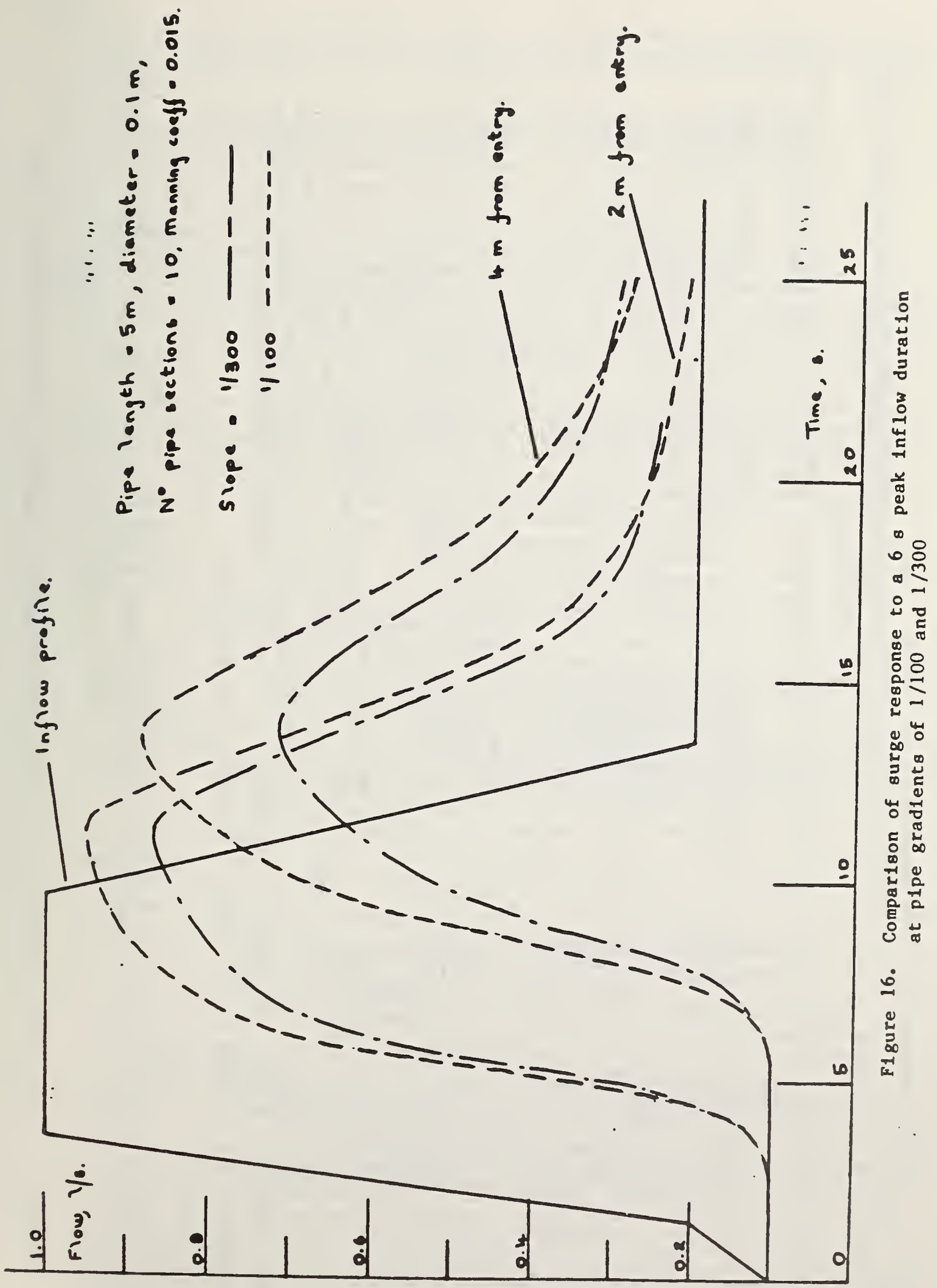




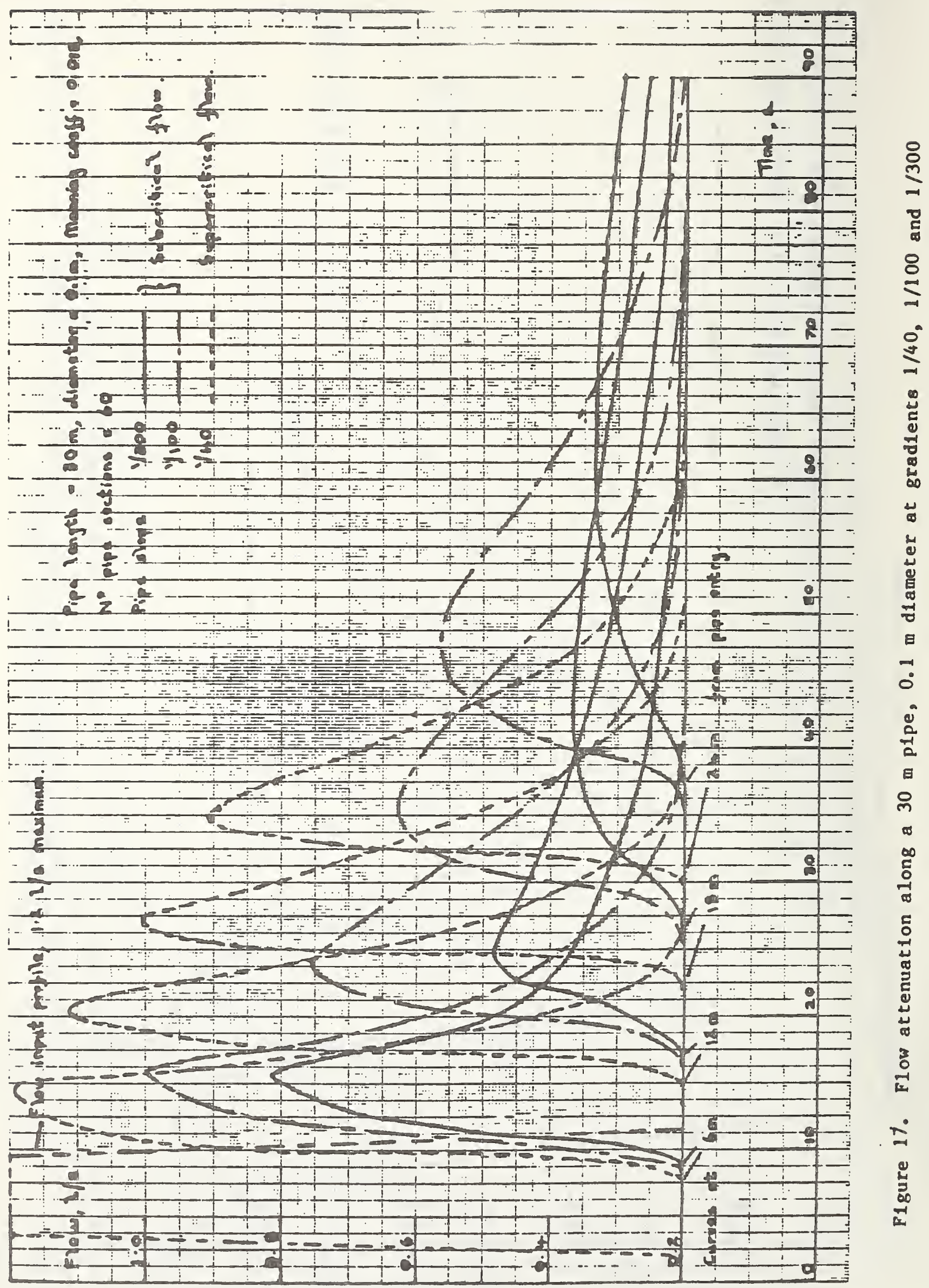




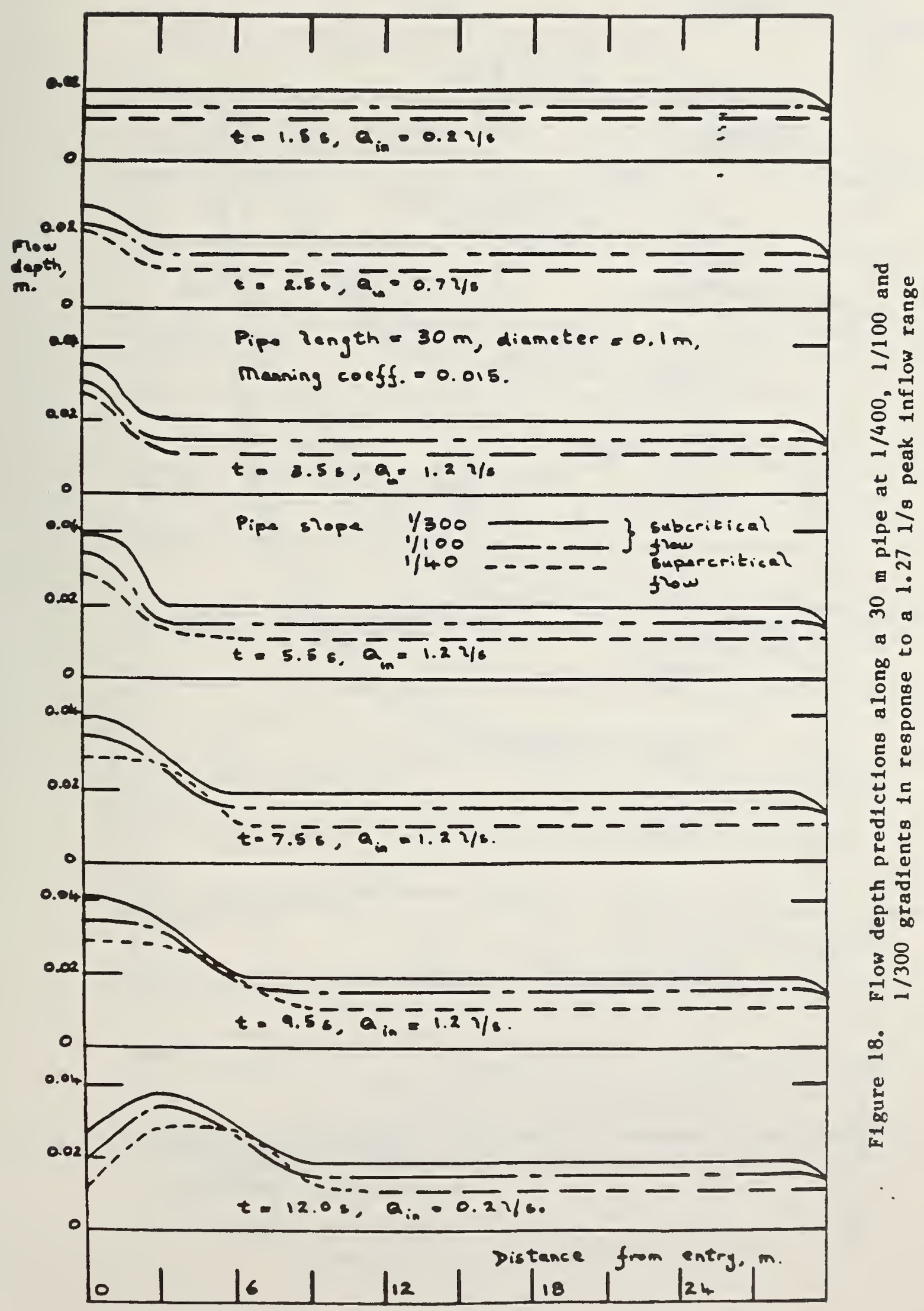




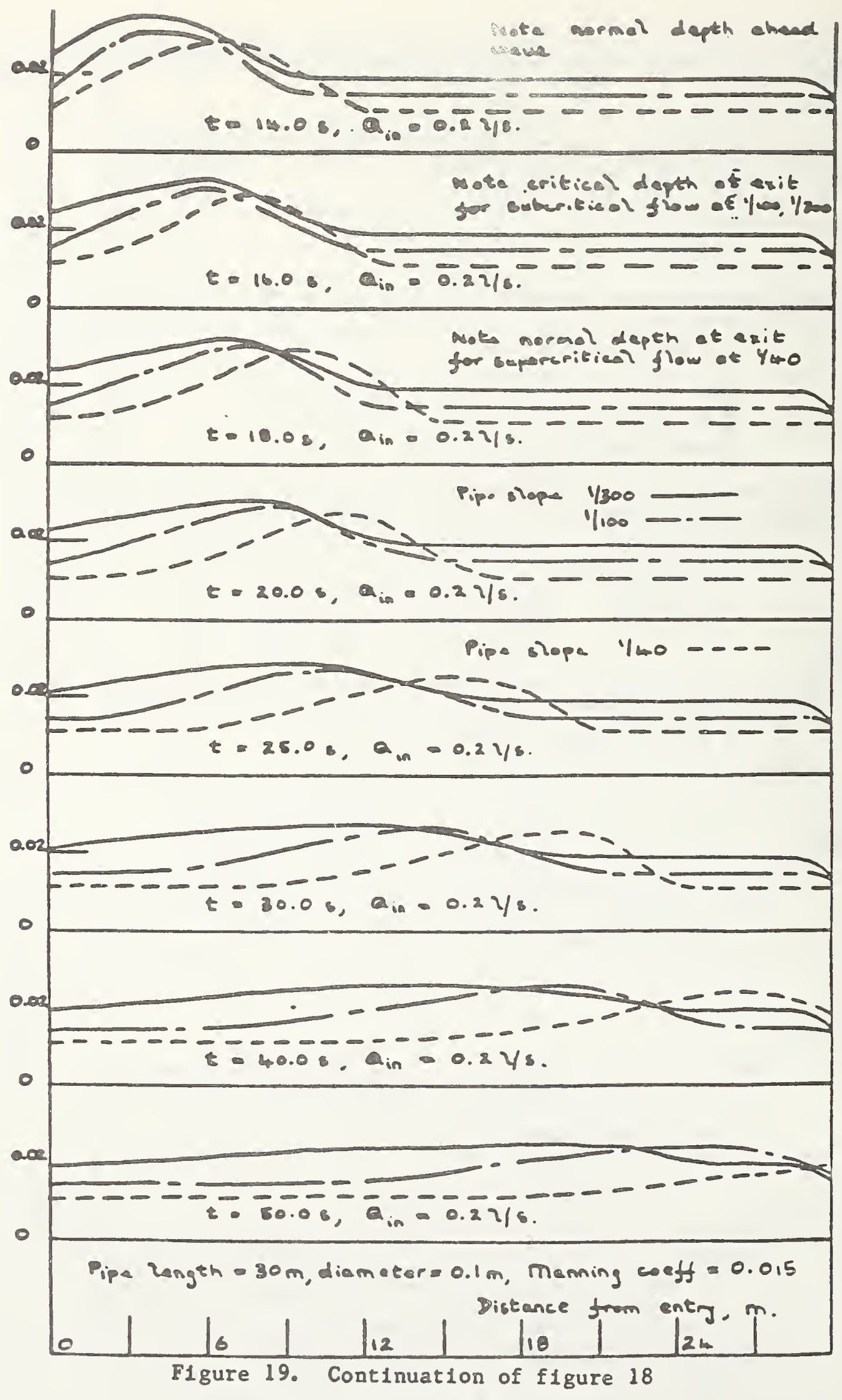




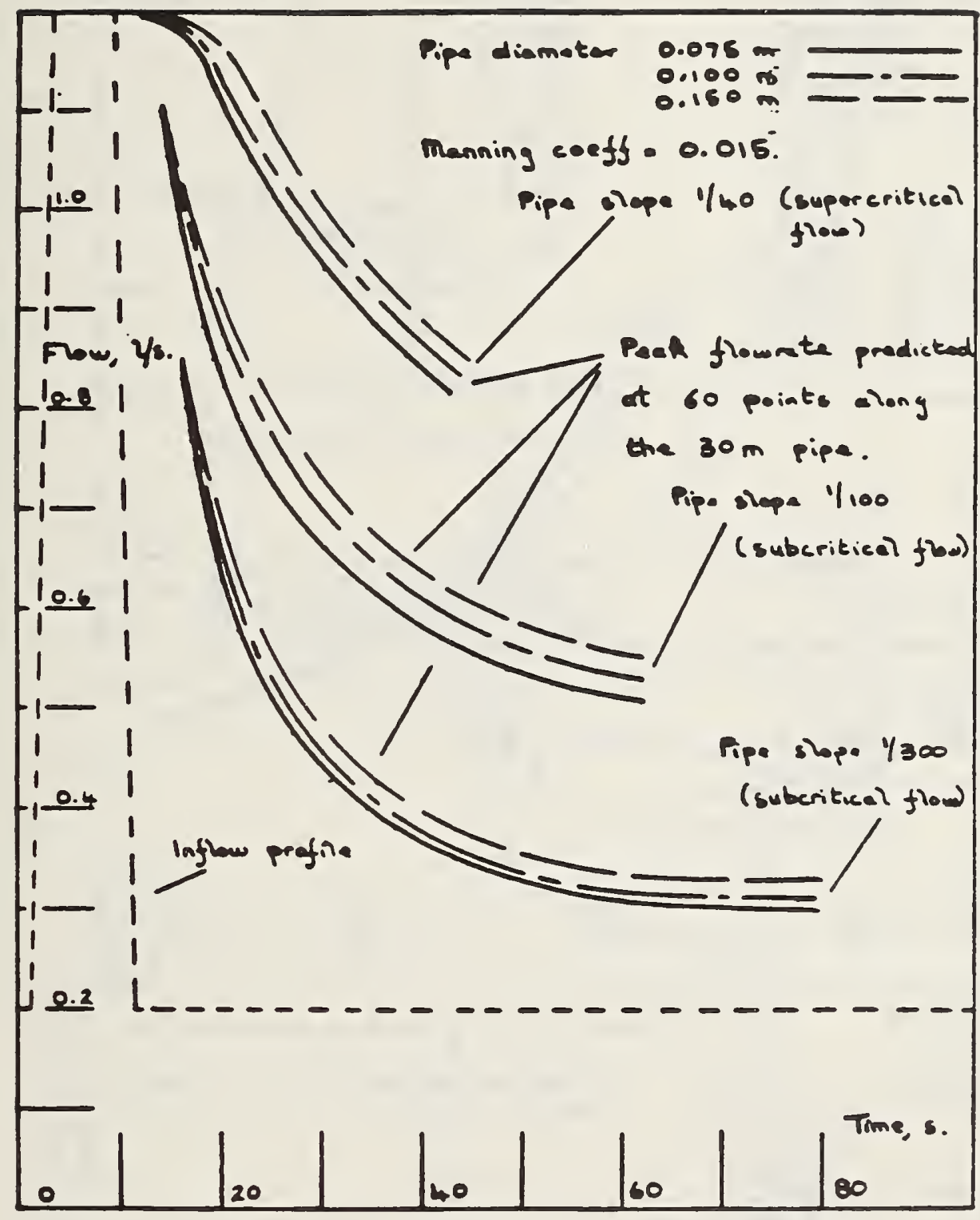

F1gure 20. Peak flow rate predicted along a 30 m plpe for plpe gradients $1 / 400,1 / 100,1 / 300$ and pipe diameters of $0.15,0.1$, and $0.075 \mathrm{~m}$ 


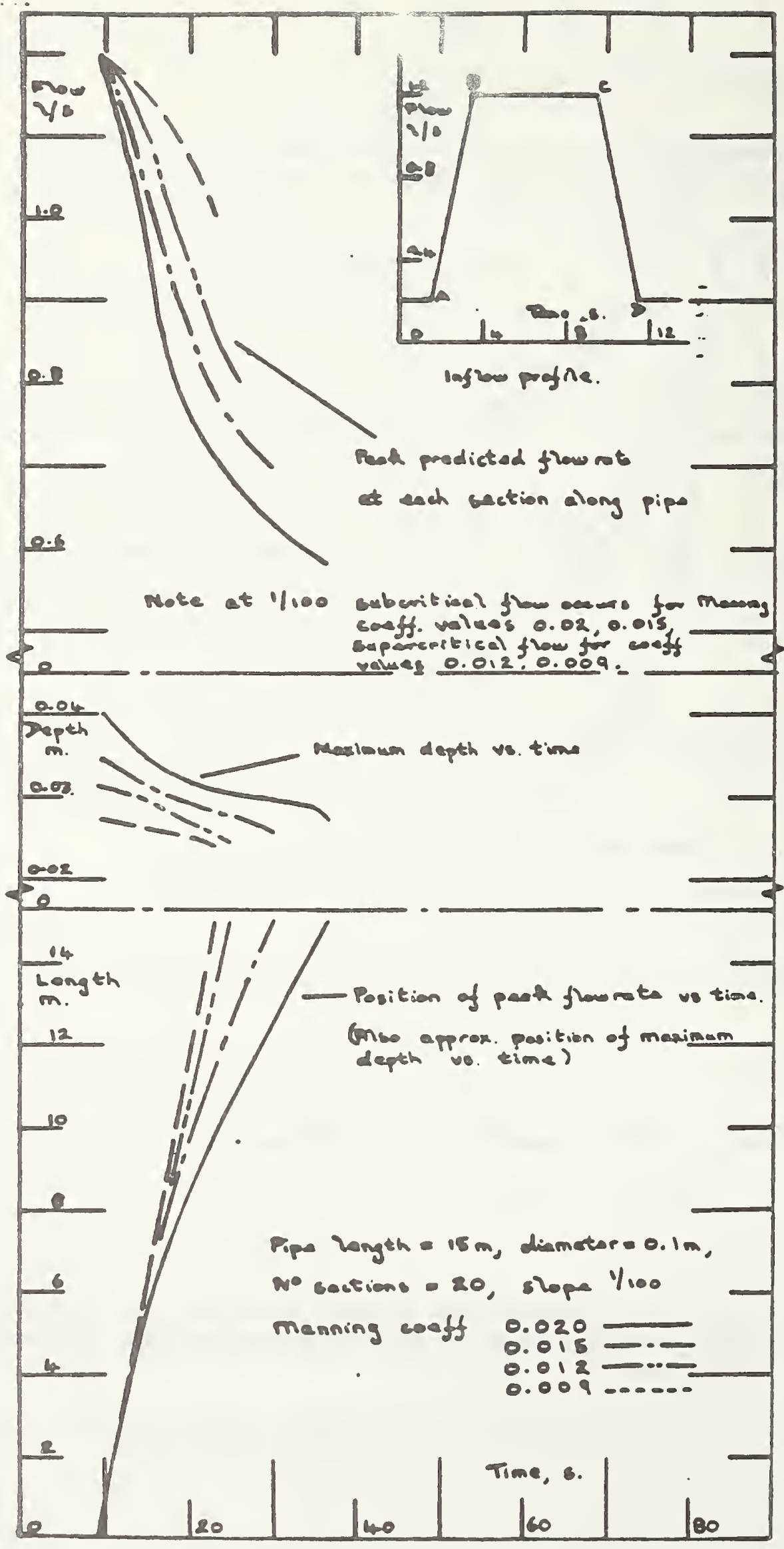

F1gure 21. Peak flow rate and depth predictions along a 15 a plpe, dlaveter 0.1 11luetrating the dependence on roughness coefflclent 


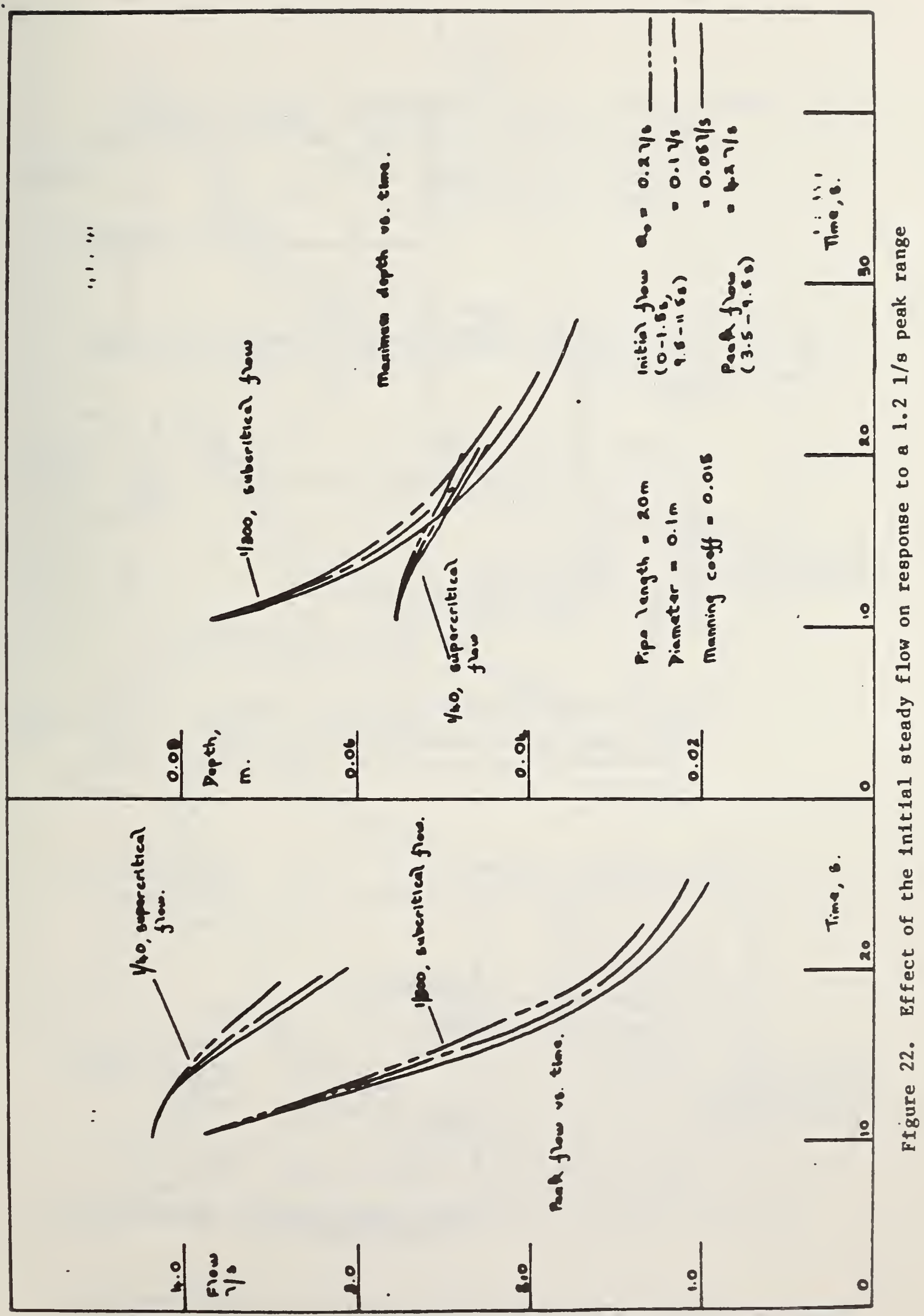




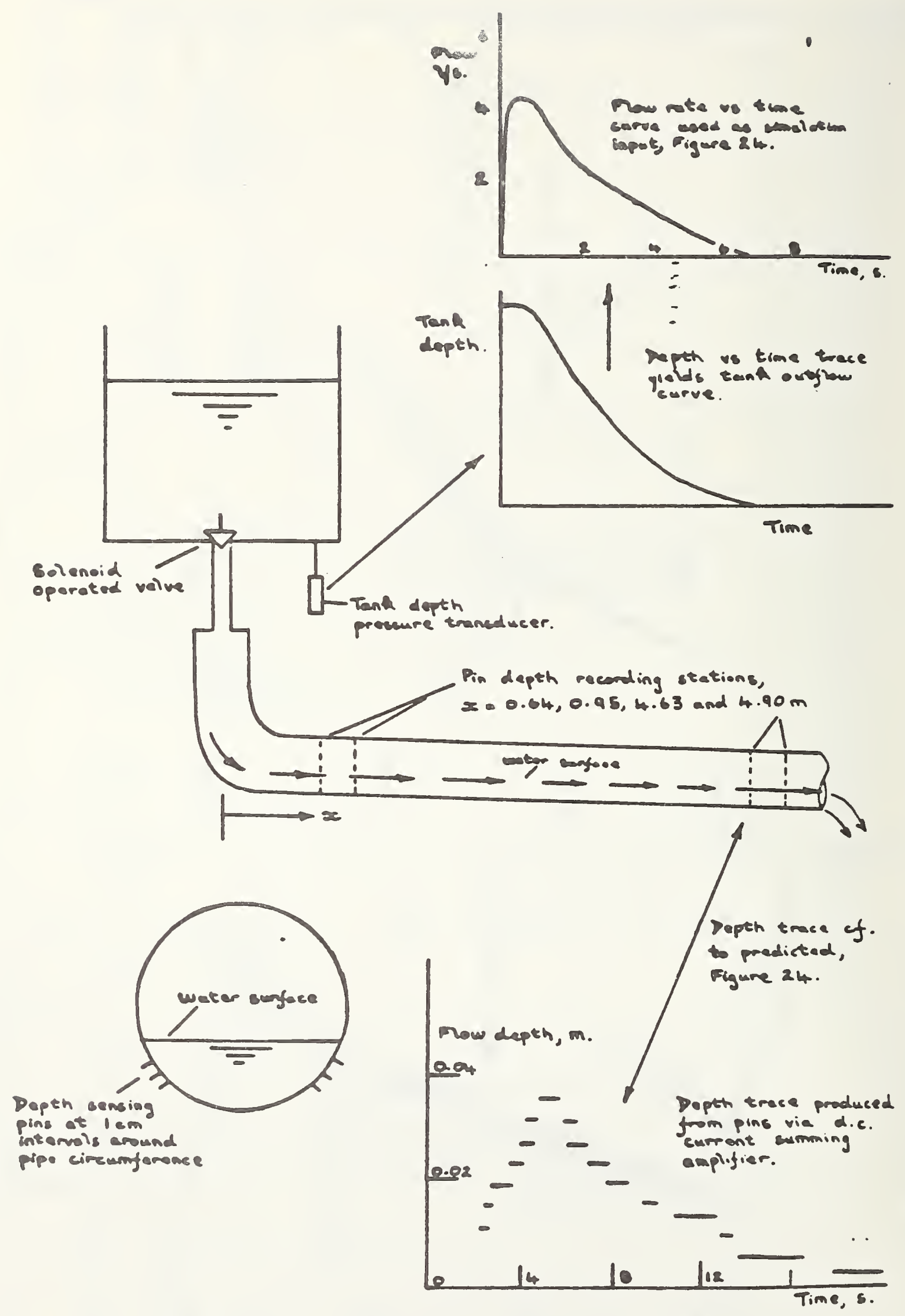

P1gure 23. Sunmary of experimental test $\mathrm{I}_{\mathrm{g}}$ and assoclated inflow and depth recording 1netrumentation 


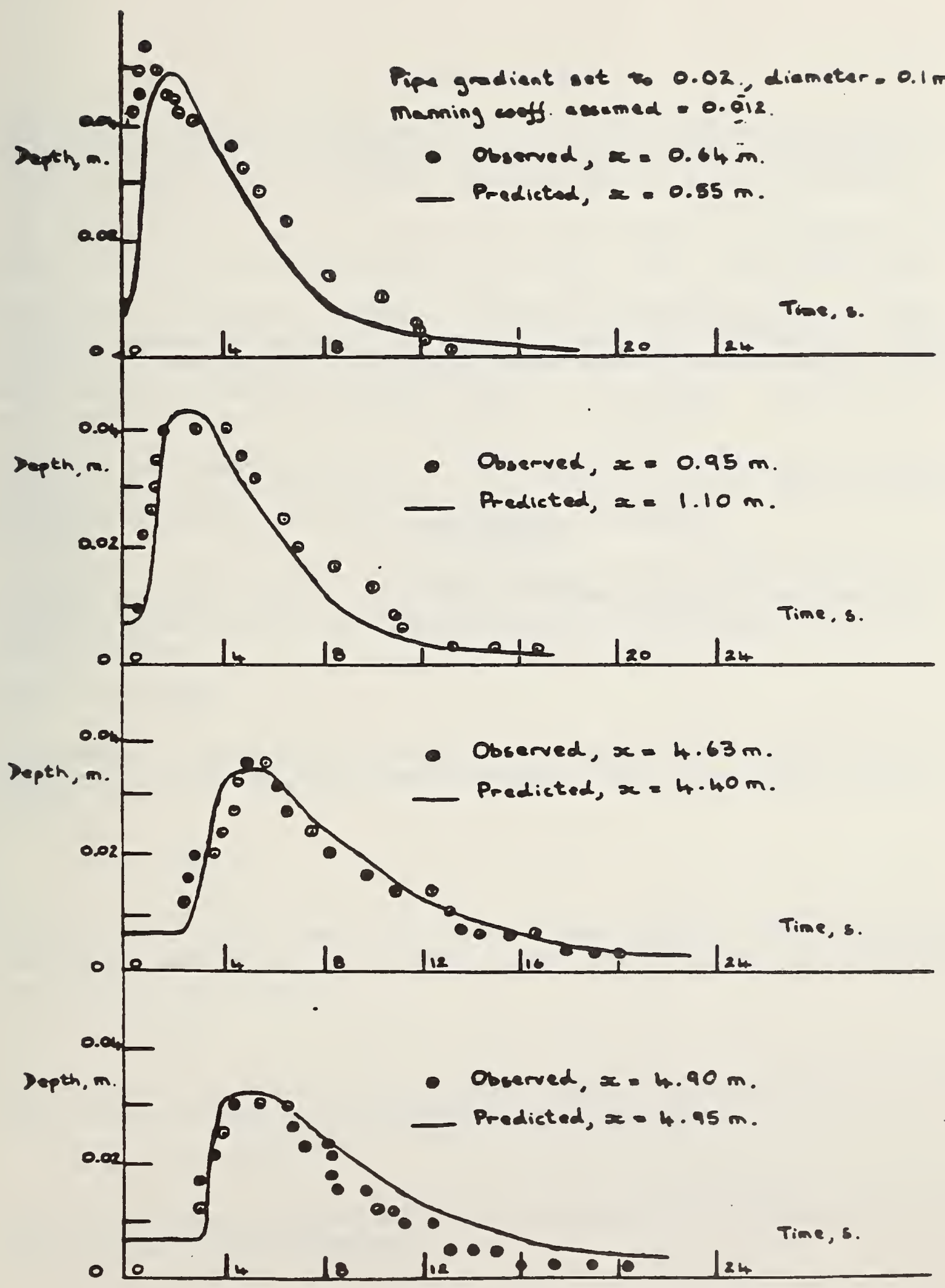

F1gure 24. Comparison of observed and predicted water depth VB. t1me profiles 
APPENDIX I

Program TRANSCC 


\section{Program TRANSCC}

Th1s appendix presents a complete print out of this program, written in Fortran, together with a flow chart and sample input data. The program was run on the NBS Center for Building Technology Perkin Elmer 732 computer.

The program accepts data in SI units with the exception of the inflow profile, this is read in as 11 tres/second and corrected to $\mathrm{m}^{3} / \mathrm{s}$ within the program.

The program is written in terms of a series of subroutines that deal with specific aspects of the numerical solution presented in the report. In order to aid the understanding of the program each subroutine is discussed individually, with the calculation methods outlined in each case. The titles used refer to the program print out included in this appendix.

Note that the notation employed in this appendix in describing the various subroutines is compatible with that used in the main report and not the program notation, although in most cases the variation is small.

The program as written applies only to simple straight pipes with choice of constant gradient, diameter and roughness, however these subroutines can obviously be utilized in the modelling of more complex pipe networks in

future programs.

Subroutine TIMINC

This subroutine determines the maximum values of wave speed and velocity at any section along the pipe at each time step. This ensures that the next time increment

$$
\Delta t=\frac{\Delta x}{(v+c)}
$$

is always sufficiently small to ensure a stable solution. This effectively removes the need for a time step factor, but this is retained in the program and normally set to unity.

Subroutine LOSS

This subroutine calculates the equivalent steady flow friction loss over each pipe section by means of the Manning equation, defined as

$$
s=v|v| n^{2} / m^{4 / 3}
$$

Note the use of $\mathrm{V}$ * absolute value of $\mathrm{V}$ to ensure that frictional forces always oppose the local flow direction. 


\section{Subroutine DEPTH}

This subroutine is only called at the initial time zero to calculate the normal and critical depths based on the initial assumed flow. The values of $h_{c}$ and $h_{n}$ are then used to guide the solution whenever a subcritical or supercritical flow calculation cholce arises.

\section{Subroutine INFLOW}

This subroutine calculates the inflow to the pipe at any time during the simulation, based on Iinear interpolation between successive pairs of $Q, T$ coordinates.

\section{Subroutine SHAPE}

This subroutine calculates flow surface width, T, area A and wetted perimeter depth.

It is also used, at the initial time zero to calculate the terms necessary to provide the subcritical water surface profile.

It should be noted that this subroutine could be rewritten for any other pipe cross sectional shape and that the program in general is not restricted to circular cross section pipes. SHAPE is called from many of the other subroutines.

Subroutine WAVSPD

This subroutine namely simply local wavespeed based on

$$
c=\sqrt{\frac{B A}{T}}
$$

and utilizes SHAPE

Subroutine PROFIL

This subroutine is only fully employed if the initial flow is shown to be subcritical as a result of the normal and critical depths calculated via DEPTH.

The water surface profile is calculated from an assumed critical depth at pipe exit by means of the techniques described in the report. The calculation ut1lizes SHAPE. If the flow is supercritical then PROFIL sets all depths equal to the normal flow depth. 


\section{Subroutine INTER}

This subroutine carries out the necessary interpolations to fix conditions at points $R$ and $S$ in subcritical flow, and $R$ and $S^{\prime}$ in supercitical flow, figure 4 main text refers.

\section{Subroutine ENTRY}

This subroutine deals with the flow depth, velocity and wave speed at the upstream boundary. The inflow at any time is calculated from INFLOW and this flow rate is then employed, in the subcritical case, in conjunction with the appropriate $C^{-}$characteristic to yield the required parameter values, figure 5 and the section 3.3 .4 of the main text.

In the supercrititcal flow case, identified in terms of the initial flow normal to critical flow depth comparison, the inflow curve is solved in conjunction with the normal depth relationship as the downstream conditions, represented by the $\mathrm{C}^{-}$characteristic previously employed, can no longer effect conditions at pipe entry.

Subroutine NODAL

This subroutine solves the $\mathrm{C}^{+}$and $\mathrm{C}^{-}$characteristics at all internal pipe sections between $x=\Delta x$ and $x=L-\Delta x$, figure 4 main text refers, for both sub and supercritical flow.

In addition for supercritical flow it also calculates the flow exit condition as these are based solely on upstream conditions.

Subroutine EXIT

This subroutine is only utilized for the subcritical flow case. The exit boundary conditions are determined by solution of the appropriate $\mathrm{C}^{+}$ characteristic, figure 4 main text, with the critical depth expression

$$
\frac{Q^{2} T}{g A^{3}}-1=0
$$

and $Q=V A=A(X 2-X 1 h)$

As this is effectively a loss coefficient concentrated at pipe exit the boundary equation must be solved in the form

$$
\frac{Q|Q| T}{8 A^{3}}-1=0
$$

or

$$
(x 2-x 1 h)|(x 2-x 1 h)| \frac{T}{g A}=1
$$


where | Indicate the absolute value of the term enclosed.

Solution is performed by means of the bisection technique described in the main text.

\section{Subroutine ASSIGN}

This subroutine reassigns the values calculated at the end of a time step, points $P$ in figure 4 main text, to allow the calculation procedures to move on one time increment. This is necessary to avold program storage space problems.

FLOW CHART PROGRAM TRANSCC

Set up inftial conditions.

Time $=0.0$

Read plpe data, diameter D, Manning coeff RM, slope S $\emptyset$, length PL.

Read calculation data, $\mathrm{N}-\mathrm{N}^{\circ}$ plpe sections, TMAX - calculation duration

TFAC - time step factor

Read inflow profile, NPTS - $N^{\circ}$ of coordinate palrs Flow - QIN, time TIN.

Adjust flow units from $i / s$ to $\mathrm{m}^{3} / \mathrm{s}$.

Calculation of initial steady conditions at time zero.

CALL DEPTH - calculation of normal and critical depths at inftial flow.

$h_{c}<h_{n}$

Subcritical flow

CALL PROFIL - calculate water

surface profile by gradually

varied flow analysis. Interpolate

to yield depth at $\mathrm{N}$ sections.

CALL ASSIGN - set up base arrays H, V, C

CALL TMINC - identify maximum $V, C$

Calculate time and pipe length increments,

$\Delta \mathrm{x}=\mathrm{PL} / \mathrm{N}$

$\Delta t=\Delta x /\left(\right.$ TFAC $\left.\times(V+C)_{\text {MAX }}\right)$

Output - Initial conditions and pipe description

- Table headings $\mathrm{h}_{\mathrm{n}}<\mathrm{h}_{\mathrm{c}}$

Supercritical flow

CALL PROFIL - set all pipe flow

depths equal to normal value. 
- Depth, Velocity, Flow, Wavespeed at each $\Delta x$ increment if $\mathrm{N} \leq 10$, at $1 / 10$ pipe length points length points if $\mathrm{N}>10$ and a multiple of 10 .

A - Update time and commence unsteady flow simulation

CALL TIMIC - identify maximum V, C. Calculate next time increment $\Delta t$.

Time $=\operatorname{Time}+\Delta t$

Check Time vs TMAX

$$
\begin{array}{ll}
\text { Time }<\text { TMAX } & \text { Time } \geq \text { TMAX } \\
\text { Go to B } & \text { Go to E }
\end{array}
$$

B - unsteady flow calculations.

CALL INFLOW - calculate pipe inflow value

CALL INTER - interpolate to obtain base conditions HR, HS etc. Contains choice based on flow regime.

CALL LOSS - calculation of equivalent steady loss terms SR, SS.

CALL ENTRY - solves upstream boundary dependant on flow regime

CALL NODAL - solves $\mathrm{C}^{+}, \mathrm{C}^{-}$, characteristics based on output of INTER and LOSS. For supercritical flow also calculates exist boundary conditions.

Supercritical flow, Go to C

Subcritical flow, CALL EXIT - solves exit boundary equation with $C^{+}$ characteristic

C - CALL ASSIGN - set up base arrays H, V, C.

Output - H, V, Q, C at appropriate points.

Go to A

$E-E N D$ 
SAMPLE INPUT DATA, PROGRAM TRANSCC

Line 1.

Plpe diameter, Manning coeff., slope, length

Format 4F10.4

$\nabla \nabla \nabla \nabla \quad 0.1000 \quad \nabla \nabla \nabla \nabla 0.0150 \quad \nabla \nabla \nabla \nabla \quad 0.0100 \quad \nabla \nabla \nabla \nabla \quad 5.000$

Line 2.

$\mathrm{N}^{\circ}$ calculation sections, Run time, Time step factor (Note: $\mathrm{N}^{\circ}$ calculation sections either < 10 or multiple of 10 to match output format, time step factor normally set $=1$. )

Format I3, $2 \mathrm{~F} 10.4$

$\nabla 10 \nabla \nabla 200.0000 \nabla \nabla \nabla \nabla 1.0000$

Line 3.

$\mathrm{N}^{\circ}$ pairs of coordinates on inflow-time curve.

Format I3

$\nabla \nabla 5$

Line 4 to 8 .

Inflow QIN at time TIN

Format $2 \mathrm{~F} 10.4$

$\nabla \nabla \nabla \nabla 0.0500 \quad \nabla \nabla \nabla \nabla 0.0000$

$\nabla \nabla \nabla \nabla 2.5000 \quad \nabla \nabla \nabla \nabla 1.0000$

$\nabla \nabla \nabla \nabla 2.5000 \quad \nabla \nabla \nabla 10.0000$

$\nabla \nabla \nabla \nabla 0.0100 \quad \nabla \nabla \nabla \quad 12.5000$

$\nabla \nabla \nabla \nabla \quad 0.0100 \quad \nabla \nabla 200.0000$

Units - SI units used in data fields except for inflow QIN in $\mathrm{l} / \mathrm{s}$, converted to $\mathrm{m}^{3} / \mathrm{s}$ in program output in SI, except flow rate in $\mathrm{l} / \mathrm{s}$. 

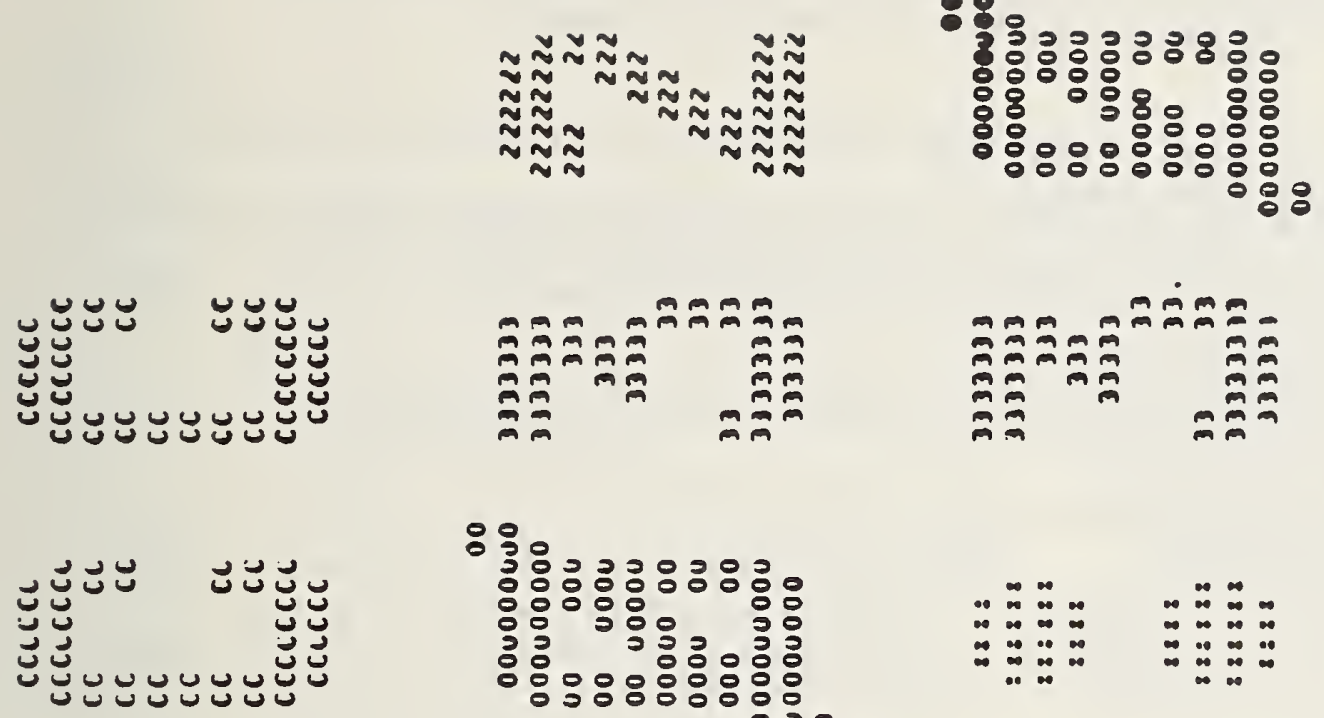

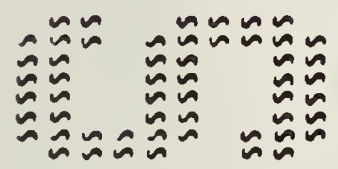

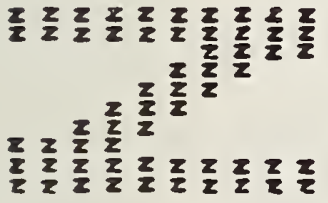
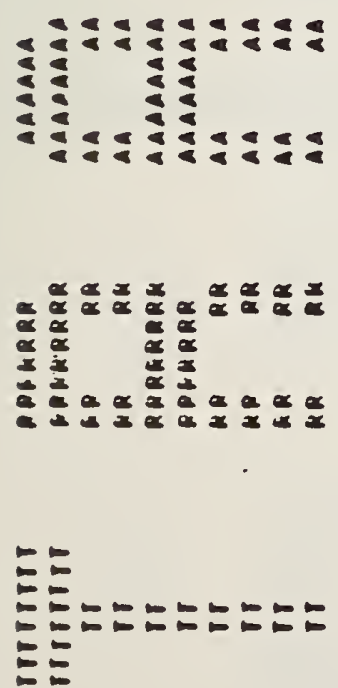

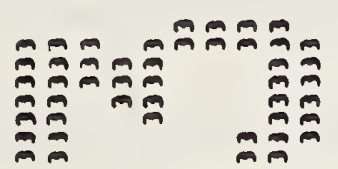

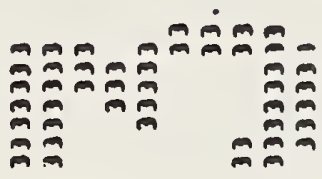
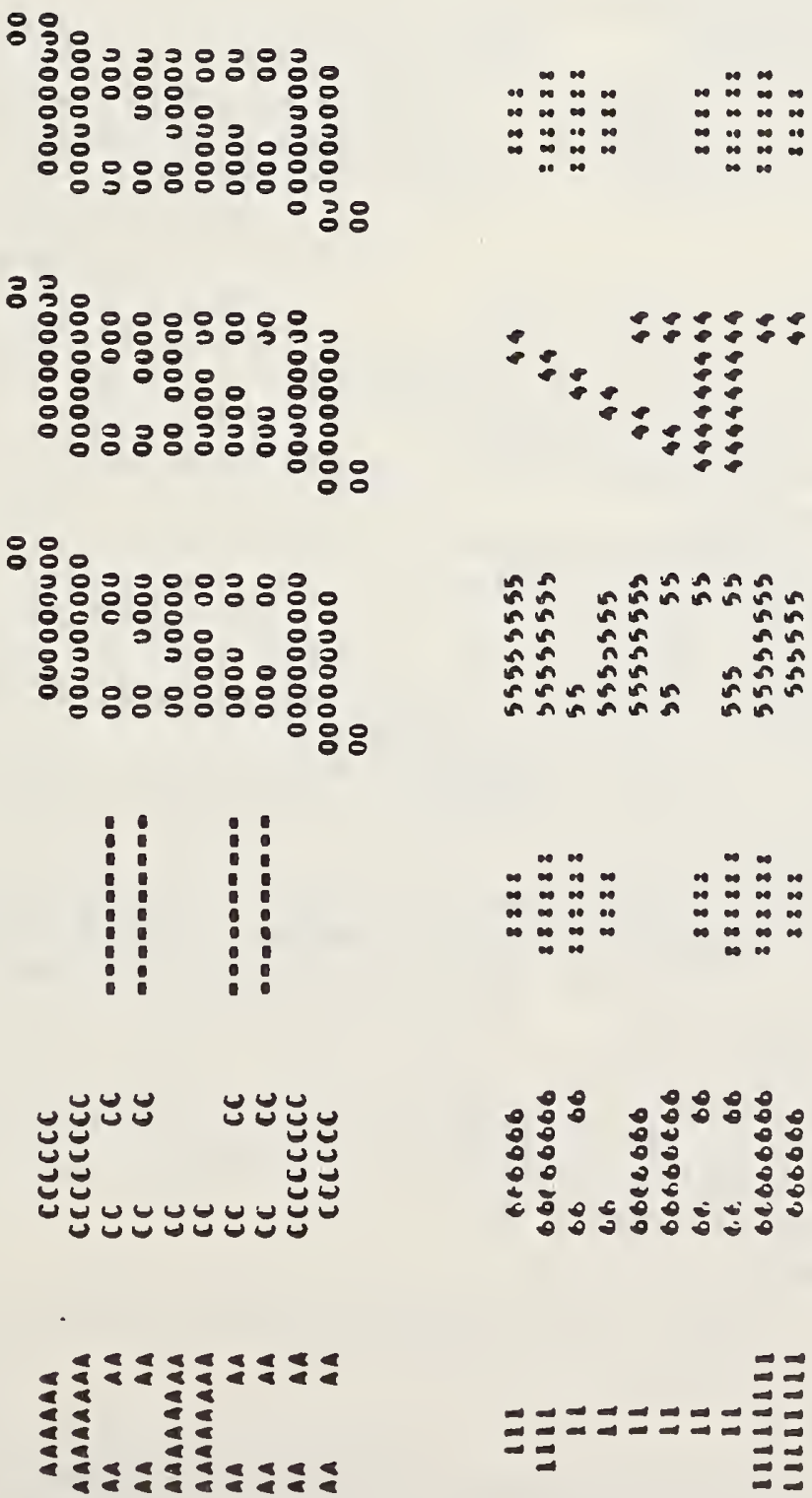
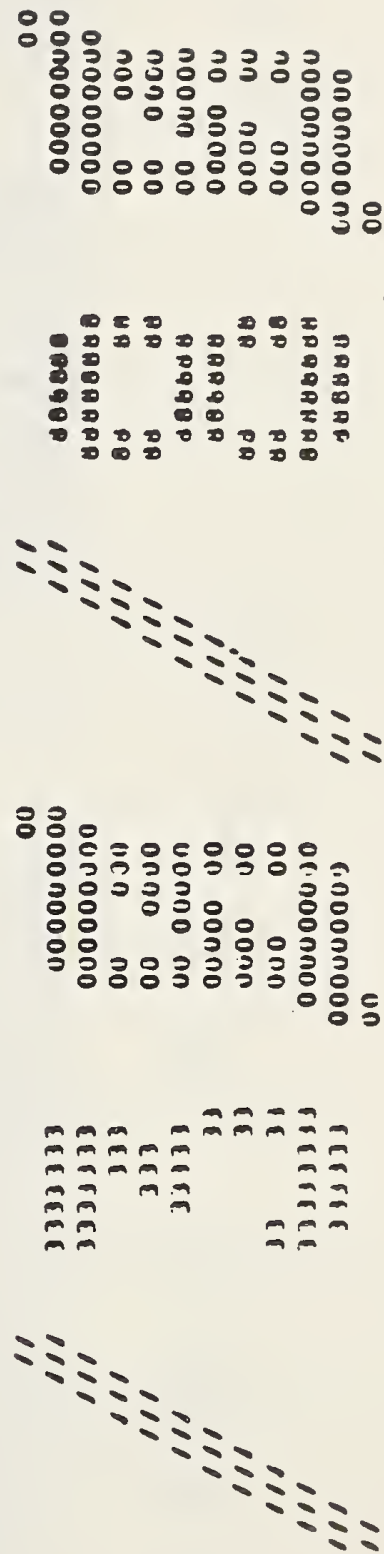

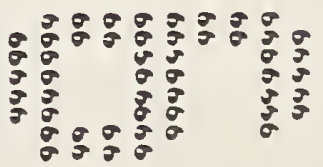

용용

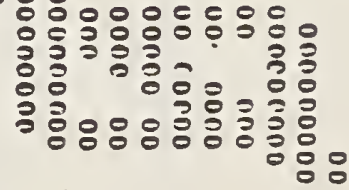




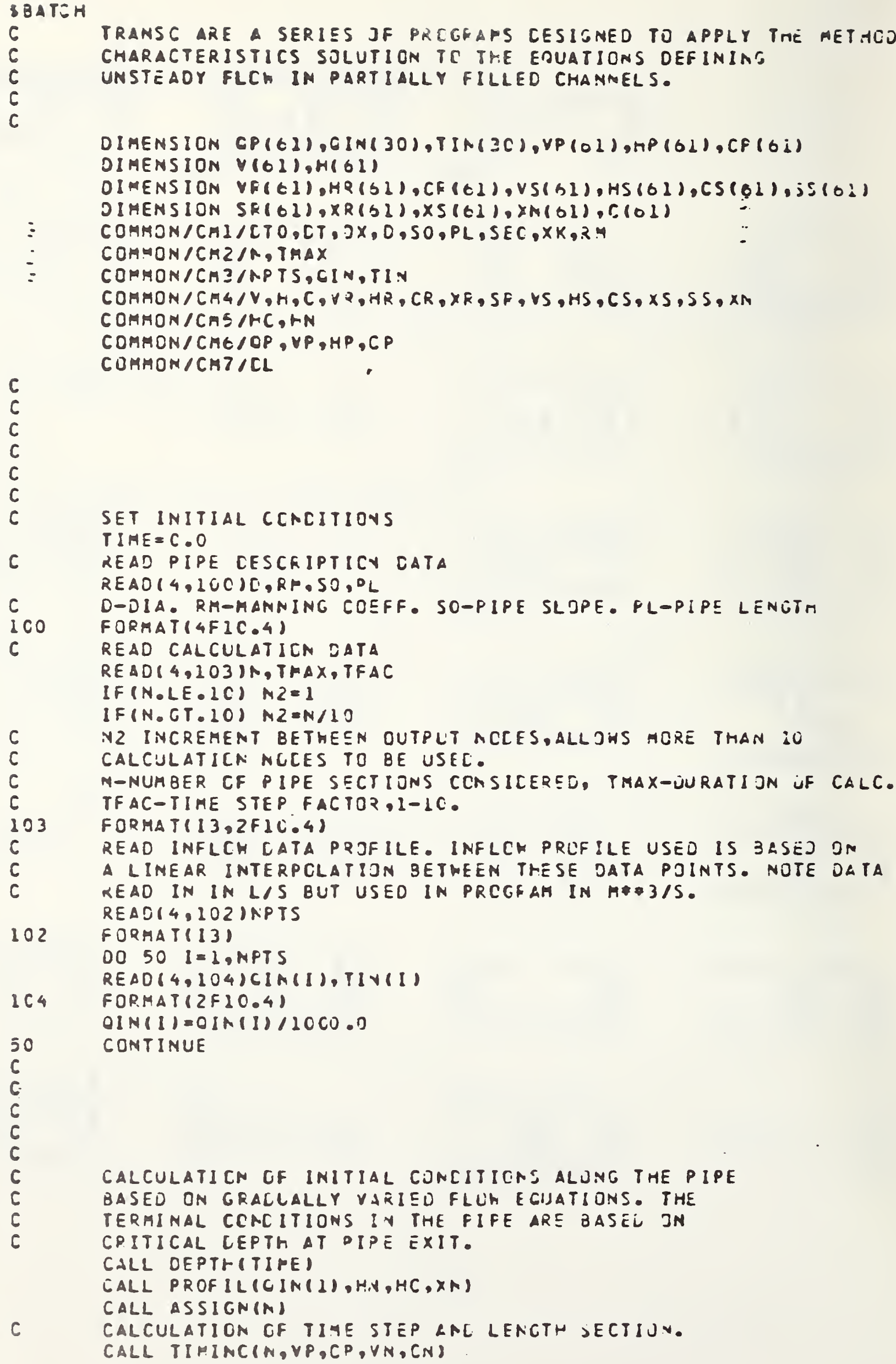

C

c

C

C

C

C

c

(4, IUC) [I,RP.SO,DL

C D-DIA. RM-MANNING CDEFF. SO-PIPE SLDPE. FL-PIPE LENETM

ICO FORMATI $4 F I C .4)$

C READ CALCULATICN SATA

READ $(4,103)$, TFAX, TFAC

IF $(N \cdot L E \cdot L C) M Z=1$

IF (N.CT.10) MZ $=N / 10$

6 N2 INCREMENT BETHEEN OUTPLT NCEES.ALLJHS ACRE TMAN IO

C CALCULATICN NGCES TO BE USEL.

C M-NUMBER CF PIPE SECTIONS CCNSICERED, TMAX-UUURTIJN UF CALC.

C TFAC-TIME STEP FACTOP,I-1C.

103 FORMAT(13,2F1C:.4)

$c$

C

READ INFLCH CATA PRJFILE. INFLCM PRLFILE USED IS $345 E J$ IN A LINEAR INTERPCLATIJN SETMEEN THESE DATA PJINTS. NOTE DATA KEAD IN IN L/S BUT USED IN PRCGFAK IN H* 3/S. REAS(4,102) NPTS

102 FORAAT(13)

DO $50 \quad 1=1$, NPTS

READ (4, 104)CIN(I), TIVII)

$1 C 4$ FORMAT(2F10.4)

$0 I N(1)=0 I N(1) / 10 \mathrm{CO} .0$

5O CONTINUE

$c$
$c$
$c$
$c$
$c$
$c$
$c$
$c$

CALCULATICN OF INITIAL CUNCITICNS ALJNG THE PIPE BASED ON GRACLALLY VARIED FLUH ECIJATIONS. THE TERMINAL CCACITIONS IV THE FIFE ARE BASEL JN CPITICAL CEPTH AT DIPE EXIT.

CALL DEPTHITIPE)

LALL PROFILICIN(1),HA, HC,XN)

CALL ASSIGN(N)

C CALCULATION GF TIAE STEP LAE LENCTH SECTIJN.

CALL TIHINCIN, YP,CP, VN,CN) 
JX PL / FLOATIN)

$D T=D X /(T F A C *(C N+V N))$

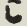
DTO-DT

DUTPUT TEST DESCRIPTICN PLUS INITIAL CONOITIUNS. HRITE(3,202IC,RM,SJ,PL

202 FORMATIIAL, I ICX, TEST PIPE CLNFIGURATION:-

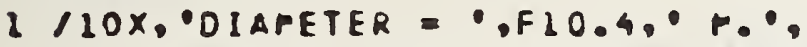

1 LOX, MANNING CGEFFICIENT:- , FIC.4,

$1 / 10 \times, \circ P I P E$ SLCPE $=$ ๑F 10.4, " PIPE LENUTH $=$,

$1 F$ IO.4, $M \cdot 0 / / 1$

IF (HC.GT.HN) MRITE $3,200 I$ IH,HC

IF (HC.LE .HN) HRITE (3,201IHN,HC

200

FORMATI1OX, OFLCW SUPERCRITICAL, " "NURMAL JEPTH = "F10.4,

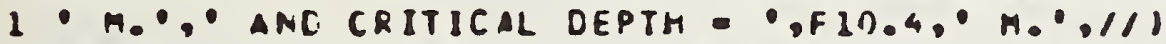

2CI FORMATILOX, $F L C H$ SUBCRITICAL, " "NORAAL CEPTH = "

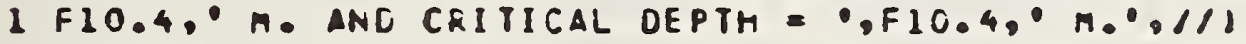

QINII) $=0 I N(2) * 1000 . C$

ARITE $(3,2 C 3) 0 I M(1), H N, C N$

QIN(1) =OIN(I)/ICCO.C

203

FURMATIIOX, 'INITIAL FLOH FLTE = "FIO.4." L/S.".

1 - INITIAL DEPTH $=\circ$, F $10.4,0^{\circ} \mathrm{M}, \circ$

2 - InItIAl have SPEED $=0,810.4,0^{\circ}$ M $/ 50^{\circ}, 11$

$M I=N+1$

HRITE $(3,204) C T, C X, N 1, T F A C$

204

FORMATIIOX, 'CALCULATIJM TIFE STEP = "FIO.4." $50^{\circ}$,

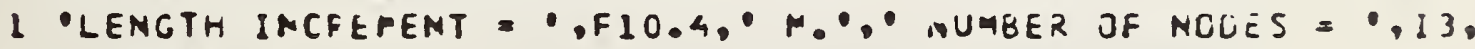

2 - TFAC $=\bullet, F E .2,11$

ARITE $(3,7) H P(N+1), V P(N+1), O P(N+1), C P(N+1)$

7

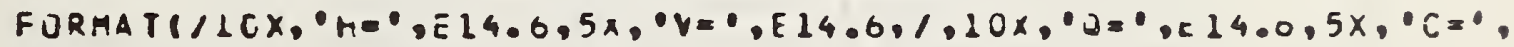

$1 \equiv 14.6,1 / 1$

C DUTPUT TEST SIPULATIJN RESLLTS.

ARITE $(3,2(5)(X M(1), I=1, N I, N E)$

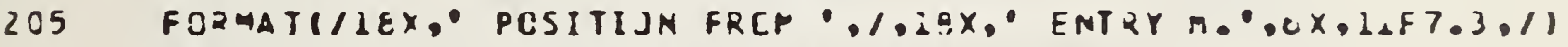
HRITE $(3,2 C O) T I H E,(H P(I), I=1, N I, N Z)$

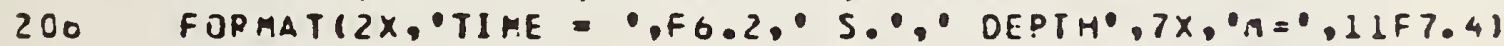

NRITE $(3,2 C 7)(V P(1), I=1, N 1, M C)$

WRITE $(3,3 C 7)(C P(I), I=1, N 1, N E)$

$3<7$

FIPRATIIdX," FLOW RATE L/S $=0,11 F 7.41$

HRITE $(3,2 C E)(C P(I), I=1, N 1, N 2)$

$2 C 7$ FORMATII3), VELCCITY M/S $=0.11 \mathrm{~F} 7.41$

2C3 FORMATILOX, MAVE SPJ. M/S $0^{\circ}, 11 F 7.4, / 1$

C

c

C

c.

uPOATE TIRE ANC CHECS CALCULATICN LENSTH.

CONTINUE

COMTINUE

CALL IIMINC(M,YP, $\left.C^{\circ}, Y N, C N\right)$

$D T=D X /(T F A C *(C N+V Y))$

DTO 0 OT

$T I M E=T I M E+C T$

IF (TIME.CT.TMAX) GJTJ 500 
DTRATEDT/CTC

IFIOTRAT.LT.O.CG) SOT!

CALL INFLOHITIFE,OI

$J I=I$

CALL INTER(N)

$J I=2$

CALL LOSS (VR, USOTR,HS,N,SE,SS,RF)

$d \perp=3$

CALL ENTRY (TIME)

$d 1=4$

CALL NCOAL (M)

$\triangle 2=5$

IF (HN,GT,HC)C ALL EXIT (TIAE)

IFIOT.LT.CTC) GCTO 600

$D T=D T O$

$J 1=6$

CALL ASSIGN (N)

$12=7$

WRITE $(3,2 C E) T I F E,(H P(I), I=1, N I, N Z)$

HRITE $(3,207)$ (VP(I), I= $1, N \perp, N 2)$

ARITE $(3,307)(O P(1), I=1, N 1, N 2)$

HRITE $(3,208)(C P(1), I=1, N 1, M 2)$

GOTO 501

SCO CONTINUE

END

$c$

SURROUTINE TIAINC(N,VP,CP, VN,CNI

C

THIS SUERCUTINE IOENTIFIES THE FIGHEST HAVE SPEEU

AND THE HIGLEST AVERAGE FLCF VELCCITY IN

THE SIMULATEL FLCH IN ORDER TL EASURE THAT THE TI AE STEP

CHOOSEN IS THE SMALLEST, MENCE ENSURING STABILITY.

JIMENSION VP(O1), CP(OI)

$C N=0 . C$

DO $1 \quad I=1, N+1$

IF (CP II $, C E, C N) \quad C N=C P(I)$

1

CONTINUE

$\checkmark N=0.0$

$002 I=1, N+1$

2 CONTINUE

$I F(V P(I), G E \cap V N) \quad V N=Y P(I)$

RETURN

END

c

C

$c$

c:

C

C

C

SUBROUTINE LUSS(VR, VS,HR,HS,N,SF,SS,R A)

DIMENSICN VR(EI), VS(O) D OHE (OL), TS $(61), S R(01), S S(t)$

COAMON/CMS/HC ORN

C THIS SUSRCUTIME CALCJLATES THE ECUIVALENT STEACY STATE

C LOSS QASEC CN THE MAYNING CCEFFIC:ENT.

SO $2 \&=2, n+1$

CALL SHAPE (TIME,MRII),AOT,PEK) 


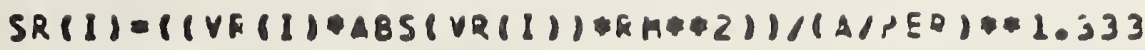

CONTINUE

$N Z=N$

NY $=1$

IF (HN.LE,MC) $N Y=2$

IF (HN.LE,$F C) \quad N Z=M+2$

DO 2 IONY,NI

CALL SHAPE (TIME,HSII),A,T,PEK)

2

$S S(I)=(1 Y S(I) * A E S(Y S(I)) * P P * 2) / /(A / P E R) * 1.333$

CONTINUE

RE TURN

END

SUBROUTINE DEPTHITIMEI

THIS SUBRCUTINE USES A SECTILN CF ENTRY TO CALCULATE NORAAL AND CRITICAL FLOM CEPTHS.

OIMENSION CIN(30), TIN $(30)$

COMMON/CMIINFTS, CIN,TIN

COMMON/CME/FC, MN

CALL ENTRY (TIFE)

RETURN

END

SUEROUT INE INFLOM(TIAE, GAY)

THIS SUERCUTINE CALCULATES INFLCH RATES AT PIPE ENTAY BASEO UN THE ENTKY FLOH PRJFILE CATA. NDTE THAT THE C CALEJLATEJ

IS AN $\triangle$ VEPACE VALUE FGR THIS TIFE STEP.

DIMENSION CISC),T $(30), E X(3 C)$

COMMON/CMLICTC,OT, DX, C, SO, PL, SEC,XK,RA

COMMON/CA $3 / A F T S, C, T$

$T I=T I M E$

TO $=$ TIME-NT

$j=1$

$T X=T 2$

DO $31=1$, NPTS -1

IF (TX.GE.T(I).ANE.TX.LT.TII+1)I GOTO 4

3 CONTINUE

$a x(j)=E(1)+(C(I+1)-\partial(I))(T X-T(1)) /(T(I+1)-T(1))$

$Q A V=Q \times(1)$

RETURN

ENO

$c$
$c$
$c$
$c$
$c$
$c$
$c$

SUBROUTINE SMAPE (TIME,H,A,T,PEF)

OIMENSICN CIN(ZC),TI.N(30)

CJMMON/CMLICTC,DT,EX,C, SO,PL, SEC,XK, X A

COMMON/CMZ/APTS, CIN,TIN

COMMUN/CMT/LLL 
THIS SUGRLUTINE CALCJLAT'S FLLH AREA, SURF ACE WIDTH AND HETTEC PEPIPETER BISEL OIA ILIH CEPTH

THIS SLBROLTINE ALST EALCULATES MATER SURFACE PROF ILE ANU SETS UP CASE CINDITIONS ALUNC THE PIPE AT TIME ZERC. $R=0 / 2.0$

$P I=3.142$

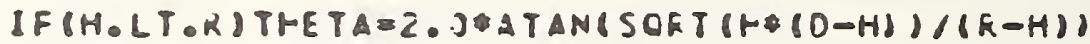

IFIH.EC.R)THE TA $=P$ I

IF (H. GT.R)THETA $=P I+2 . C * A T A M((H-R) /(S D R T(H *(D-H))))$

$A=(1 D+2) / 8, C) *(T H E T A-S I N(T M E T A))$

$P E R=D$ THETA/Z̈,C

$T=2.0 *(1, *(C-H))+0.5)$

IF (TIME.GT.C.O) CJTS I

$\theta=0$ IN (1)

$G=9.81$

CON=RH $2 / S C$

HCRIT $=1.0-(C * 2) * T /(S * A * 3)$

HNORM $=1.0-(C * 2) * C[N /((A * 3.333) /(P E X * 1.333))$

$D L=H C Q I T /(H N L R F+S D)$

CONTINUE

RE TURA

C

ENC

\section{SURRCLTINE HAVSPC $(4,6)$}

C

THIS SUERCUTINE CALCULATES haVE SPEED BASEO JN GEPTH AND GROSS

SECTICN SHAPE.

CALL SHAPE (TIME,H, AREA,T,PER)

$C=S Q R T(9.8 I \$ A K E A / T)$

RETURN

END

ᄃ

\section{SURRDUTINE FFCFIL $(6,4 N, H C, X N)$}

c

THIS SUBRCUTINE CALCULATES THE INITIAL HATER SURFACE

PROFILE BASEC CN CRITICAL DEPTH AT PIPE EXIT.

DI AENSIJM HP(OI), VP $(61), O P(61), C P(61)$

DIMENSION $X(30)$, CEP(3J), XN(tI)

OIMENSIGN $\times 2(30)$, DEDI 130$)$

COMMON/CMI/CTO,DT,JX,O,SO, PL, SEC,XK,R.

COMMON/CMZIN, TPAX

COMMON/CME/CP, $Y P, H P, C P$

COMAON/CF $7 / C L$

IF (HN.LE.HC) GOTC $3 D J$

$D H=(H M-H C) / 30.0$

IS $=1$

$H I=H C$

CALL SHAPE TIIPE, H, I, A, T,PEF)

$X(2)=P L$

DEP $(2)=H C$

$S L=0.0$

C HATER SURFLCE PROFILE CALCULATICNS.

DO $80 \quad I=1,2 \mathrm{CO}, 2$

$15=15+1$

$M 2=H C+D K F L C A T(I+2)$

$H 3=H C \otimes C H \approx F$ LCAT (I) 
CALL SHAPE (TIME,HI,A,T DPEF)

$O L \&=D L$

CALL SHAPE (TIME,HZ,A,T,PER)

$O L 2=O L$

CALL SHAPE (TIME,H3,A,T DPEF)

$D L 3=D L$

$D X P=O H+C D L 1+C L 2+4, C * D L 3) / 3,0$

$S L=S L-D \times P$

$H I=H Z$

IF (SL.GE.PL) CCTC 81

$X(I S)=P L-S L$

IF (HI.CE . FN ) GOTC 93

OEP (IS) $=H$ I

80 CONTINUE

(2) $\quad x(I S)=0.0$

NIS $=I S$

IF $(H I \cdot C E \circ H)$ CCT: 93

$D E P(I S)=M I$

$83 \quad D E P(15)=M N$

GOTO 84

COTO 84

Q4 IF $(X(15) .6 T .0 .0)$ G JTJ 85

GOT? 86

3 5. $\quad x(15+1)=0.0$

DEP $(1 S+1)=F-A$

NIS $=1 S+1$

86 CONTINUE

c

C

C INTERPOLATICN REOUIRED TU CETEFPINE UEPTH AT EACH NÜUE.

SCC CONTINUE

$D X=P L / F L O L T(A)$

$X N(1)=0.0$

JO $87 \quad I=2, N+1$

3)

$X N(I)=X N(I-1)+[X$

CENTINUE

IF(HN.LE.HC) CCTC 901

$V Z=N I S+1$

DO $94 \mathrm{~J}=1$, NIS

$N 2=N 2-1$

$\times 1(J)=X(N 2)$

DEDI $(J)=0 E F(N 2)$

HRITE $(3,53) \times I(J), D S P 1(J)$

8? FORMATIIOX,2FIC.5)

S4 CONTINUE

ग0 $95 \quad s=1, N$ IS

$x(J)=X 1(J)$

$J E P(J)=D E P(2(\lambda)$

จE CONTIMUE

$H P(1)=C E P(2)$

$H P(N+1)=H C$

D) $88 \quad I=2, N$

ग0 $87 K=1, M I S-1$

IF $(X N(I), C T \cdot X(K), A N D, X N(I), L E \bullet X(K+1))$ CDTJ $9 \bar{U}$

19 CONTINUE

70

$H P(I)=D E P(K)+(C E P(K+i)-C E F(K)) *(x \vee(I)-x(k)) /(x(K+1)-x(k))$

CONTI NUE

$3 \mathrm{e}$

SET UP SASE CCNCITIJNS AT TIPE ZEFJ.

SCl

CONTINUE

DO $91 \quad I=1, M+1$

IF (HN.LE OTC) MPII) =HN

CALL SHAPE (TIFE,HP(I),A, T,PEF)

$\checkmark P(I)=0 / A$ 
$O P(I)=0 * 10 C C_{0} C$

SUBROUTINE IATER(N)

DIMENSION V(OL),H(B), C(OL), VR(CL), HK (SI), CR(OL), VS(OI)

DIMENSION HS $(01), C S(S 1), S R(01), 5 S(61), X N(61)$

OIMENSION XS(E), 1 , $2(31)$

COFMON/CAL/CTO,CT, JX, D, SO,PL, SEC,XK,RA

COMMON/CMA/V,H,C,VR, TR,CR,XR, SF, YS, HS, CS, XS, SS, XN

COAHON/CAS/HC, HN

c

THIS SUBRCUTINE SETS UP, EY INTERPOLATICM, THE BASE CONDITIJNS F.JR THE NEXT TIME STEP.

THE TA $=C T / C X$

$N \perp=N+1$

DO $1 \quad I=2, N I$

$V R(I)=(V(I)+T R E T A+(C I I)+V(I-I)-V(I) \neq C(I-I))$

$1 /(1.0+T H E T A+(V(I)-V(I-2)+C(I)-C(I-1))$

$C R(I)=(C(I) \neq(1 . C-V P(I) * T M E T A)+C(i-1) * V R(I) * T H E T A)$

$1 /(1.0+C(1) * T H E T A-C(I-1) * T+E T A)$

$H R(I)=H(I)-(H(I)-H(I-1))=T H E T E \&(V R(I)+C K(I))$

$X R(I)=X N(I)-(V \&(I)+C R(I)) \neq C\}$

CONTINUE

IF (HN.LE॰HC) GOTC 4

JO $2 I=1, \mathrm{~N}$

VS $(I)=(V I I)-T H E T A *(\forall(I) \neq C(I+1)-C(I) \neq V(I+1))$

$1 /(1.0-T H E T A *(V(I)-V(I+I)-C(I)+C(I+I))$

$C S(I)=(C(I)+V S(I) * T H E T A *(C(I)-C(1+1))$

$1 /(1.0+T H E T A \&(C(1)-C(1+1))$

MS $(1)=H(1)+T H E T A *(Y S(I)-C S(1)) *(H,(I)-H(I+1))$

$X S(I)=X N(I)+($ VS $(1)-C D(I)) \neq C T$

CONTINUE

COTO 3

DO $5 \quad 1=2, N+1$

$V S(T)=(V(1) \neq(1.0+T H E T A \neq C(I-1)) V(I-1) \neq T H E T A \neq C(1))$

1 (1. $0+$ THETA $(V(1)-V(1-1)+C(1-1)-(1))$

$C S(I)=(C(I)+V S(I)=(C(I)-C(I-1))) /(2.0+T M E T A+(C(I-1)-C(I))$

HS II) $=H(I)-(H(I)-H(I-1))=T H E T A \#(Y S(I)-C S(I))$

RETURN

END

SURRJUTINE ENTRYITIAEI

THIS SURKCUTINE CALCULATES THE LFSTREAM GOUNIARY CIJNJITILNS AT EACH TIFE STEP IASEC ON A KNCHN INFLIII PQUFILL.

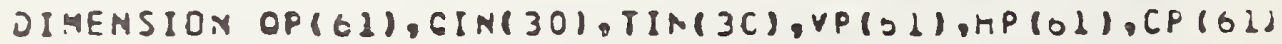


DIMENSICN V(O2),HISII

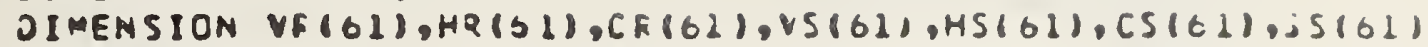

DIMENSIDN SF(61),XQ161),XS(01),XN(6), C(O1)

COMMON/CMI/CTO,DT, JX, C, SO,PL,SFO,XK,K 7

COMMON/CHZ/N,TRAX

COMHON/CA3/NPTS,OSH, IIN

COM $O N / C M 4 / V, T, C, V P, H R, C R, X R, S F$, YS,HS, CS, XS, SS, XN

COMMON/CME/TC,HN

C

COMMON/CMG/CP, YP,MP, CP

$G=9.81$

$C O N=R M+215 C$

IF (TIME.CT.C.OICALL INFLOW (TIRE,C)

IF(TIME.GT.0.O) COTO SOC

IFITI Y.E.E C.C.OSIO=CIN(I)

C

CALCULATION CF CRITICAL DEPTH.

$U P=D$

$\partial N=0.0$

$H C=(U P \vdash O N) / 2.0$

7

CONTINUE

CALL SHAPE (TIME,HC, AREA,T,PEE)

MCRIT $=1.0-(C * 2) * T /(G * A R E A * 3)$

IF (HCR IT I 3,4,5

3

$O N=H C$

SDTO 6

$U P=H C$

5

$H C Y=(U P+D N) / Z, C$

IF (ABS ( $(H C N-H C) / H C), L E, C . C O 1)$ GCT]

$H C=H C N$

GOTO 7

8

$H C=H C N$

CONTINUE

CALCULATICN CF NORPAL DEPTH.

$U P=D$

$J N=0.0$

$M N=(U P+C N) / \bar{Z} \cdot C$

$\rightarrow$

CONTINUE

CALL SHAPE (TIME,HN.AREA,T, PEK)

HNORM $=1.0-(C * 2) * C J N /($ IAREA* $* 3.333) /(P E K * 1.333))$

IF (HNCRM) 10.11 .12

$1 C \quad O N=H N$

GOTO 13

$12 \quad J 8=H M$

13 $\quad H N N=(U P+D A) / 2.0$

IF ( $\triangle B S$ S (HAN-HM)/HN).LE.O.CO1) CCTO 14

HN $=$ HNN

GOTO $Q$

$14 \quad H N=H N N$

11 CONTINUE

IFITIME.EC.C.OI COTC 500

6

c

c

C

eco

CALCULATICN CF BOUNCAPY DEPTI.. CONTINUE

IF(HN.LE.FC) CCTE ICJ

$U P=0$

$O M=0.0$

$A B=(U P+D N) / 2 \cdot C$

15 CONTINUE

CALL SHAPE (TIME,HB,AREA,T,PEF)

$\times 3=C / C S(i)$

$x_{4}=V S(1)-C *(5 S(1)-50) * D T-x .3 * r .5(1)$ 
$H F L O W=0-(x 4+x 3 * H B)+92 \subseteq A$

16

IF (HFLOW) I6,17,18

l6 $\quad U P=H B$

GOTO 19

$18 \quad \mathrm{ON}=\mathrm{HB}$

15 $H B E=(U P+O N) / 2 \cdot C$

IF (ABS ( (HBE-MB)/HB) .LE.0.OCI) CCTO 20

$H B=H B B$

GOTO 15

$20 \quad H B=H B B$

17 CONTINUE

$\because \quad H P(1)=H B$

- $\quad V P(1)=X 4+\times 3 \neq M P(1)$

- CALL SHAPE (TIFE,HG,AREA,T,PEK)

$O P(1)=A R E A \& P(1) 1000.0$

CP $(1)=S Q R T$ (C AREA/T)

500 CONTINUE

GOTO BOO

7 CO CONTINUE

C CALCULATION GF NORMAL DEPTH.

$U P=D$

$O N=0.0$

$H B=(U P+D N) / 2 \cdot C$

79 CONTINUE

CALL SHAPE(TIFE,HE,AREA,T,PEK)

HMORA $=1.0-(C * 2) * C O N /((A R E A * 3.333) /(P E R * 1.333))$

IF(HNORA)

उC $\quad \mathrm{DN}=\mathrm{HB}$

GOTO 83

$82 \quad U P=H B$

$33 \quad H B B=(U P+C N) / 2.0$

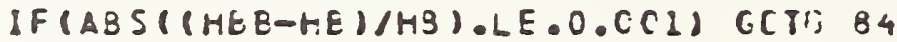

$H B=H B B$

GJTC 79

$34 \quad \mathrm{HB}=\mathrm{HBE}$

91 CONTINUE

$H P(1)=H E$

CALL SHAPE (TIIE, HB, AREA,T,PEK)

VP $(1)=0 / A R E A$

$O P(1)=C \$ I C C C . O$

$C P(1)=S O R T(G \backsim A R E A / T)$

ZOO CONTINUE

RETURN

END

C

C

C

C

C

SUBROUTINE NCLAL (N)

DIMENSION OP(EI),OIN(3O),TIN(3C), VP(O1), HP $(62), C P(61)$

OIHENSION VICI), H(SI)

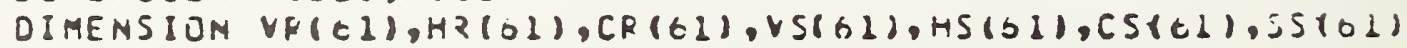

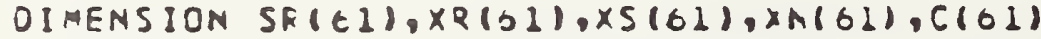

CכMMOK/CAI/CTC,DT, CX, O,SO,PL,SEC,XK,

COAMON/CAB/APTS, CIN, TIN

COMHON/CMA/V,H,C, VQ, AR, CR, XF, SE, YS, MS, CS, XS, SS, XN

COMMCN/CAS/RC, RN

COMMON/CAE/CP, VP, HO, LP

THIS SUBRCUTINE CALCULATES THE FLDH VELOCITY aNO DEPTH ANO HAVE SPEEC AT EACH OF THE NCLES BETHEEN THE LPSTREAM AND OOWNSTFEAM BOUNCARIES EY SCLUTIJ. CF THE THO WAVE 
IF (HN.LE•HC) NZ=N+I

$001 I=2, A Z$

$x I=6 / C R(I)$

$x 3=6 / C S(I)$

$\times 2=x 1 * M R(I)+V R(I)-5 *(S R(I)-S C)+[T$

$X_{4}=V S(I)-X 3 * M S(I)-? *(5 S(I)-50) * C T$

$M P(1)=(\times 2-x 4) /(\times 1+\times 3)$

$\checkmark P(I)=x 4+x 3 * 4 P(I)$

CALL MAVSPOIHP(I),CP(I))

CALL SHAPE(TIHE,HP(I), $\times 1, \times 3, \times 4)$

$O P(I)=X I * V P(1)=1000.0$

1 CONTINUE

RETURN

END

$c$
$c$
$c$
$c$
$c$
$c$

SUBRCUTI.VE EXITITIHE)

OIMENSION CF(t), VO(bI), HP (EI),CP(B)

DIMENSION $V(E I), M(S I)$

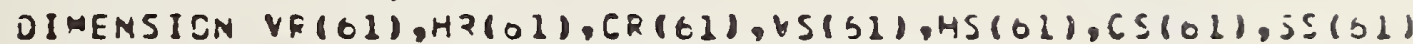

JIMENSION SF (El), Xर(01), XS(01),XN(61),C(5I)

COMMON/CMI/CTC,OT, OX, O,SO,PL, SEC,XK,RY

COMMON/CMZIM, TMAX

COMMUN/CMS/HC, HN

COAMOM/CA4/V,H,C,VZ, IR, CR, XF, SF, VS, HS, CS, XS, S S, XM

COMHON/CME /OP, YP,HD, $\triangle P$

$c$
$c$
$c$
$c$
$c$
$c$

THIS SUBROLTINE CALCULATES THE FLCH DEPTH AT PIPE OISCMARG 3ASED CN THE ASSUMPTIJN OF CFITICAL DEPTH AT SUCH A DUUNJAKY.

$C=9.81$

$X I=C / C R(N+1)$

$X 2=X 1 * H R(N+1)+V R(V+1)-C *(S F(N+1)-S O) * 0 T$

UP $=0$

$J N=0.0$

$H B=(U P \vdash O M) / 2.0$

CALL SHAPE (TIME,HB,A,T,PER)

HEXIT $=1.0-(\angle E S(X 2-\times I * H 9) *(\times 2-\times 1 * K B)) * T /(U \neq A)$

IF (HEXIT) $1 \cdot 2,3$

$D N=H 3$

GOTD 4

3: UP $=$ :HS

COTO 4

$4 \quad H S B=(L P+D N) / Z . O$

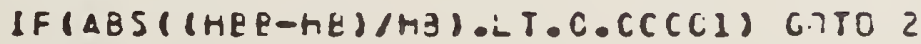

$H E=H B \equiv$

GeTO 5

2

EGNTINUE

$\forall P(N+2)=x 2-x I+E$

HP $(N+1)=H E$

CALL SHAPE (TIME,HB,A,T,PEK)

CALL HAVSFC $(1-B, C P(Y+1))$

$J P(N+1)=2 C C C, O * A * V P(V+1)$

MRITE $(3,7)$ HF $(N+1), V D(N+1), C P(N+1), C P(V+1)$ 


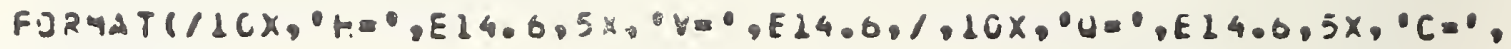

I E14.6.1/1)

RETURN

END

$c$
$c$
$c$
$c$
$c$

SUARJUTINE ASSIGN(N)

C: THIS SUGRCUTINE SETS UP THE NEH EASE CONOITIONS -ALONG THE

C. PIPE IN PIEFARATION FOR THE NFXT TIME STEP.

$=\quad$ DIMENSION CP(EI), BIN(30),TIN(30),VP(O) , HP(61),CP(B!)

DIAENSICN V(OI),H(BI)

JIMENSION VF(EI),HP(SI), CE (61), VS(E)

DIHENSION SF(01),XR(S1), XS(6) , XN(61), C(61)

COAMON/CMB/APTS,OIN,TIN

COMAON/CA4/V,H,C,VR,TR,CR,XR, SF, VS, HS, CS, XS, S S, XM

COMESN/CAE/CF, VP, $4 P, C P$

OD $1 \quad I=1, n+1$

$V(I)=V P(I)$

$H(I)=H P(I)$

$C(I)=C P(I)$

1 CONTLNUE

RETUR̂N

END

SBENU 
APPENDIX II

Typical Output Program TRANSCC 


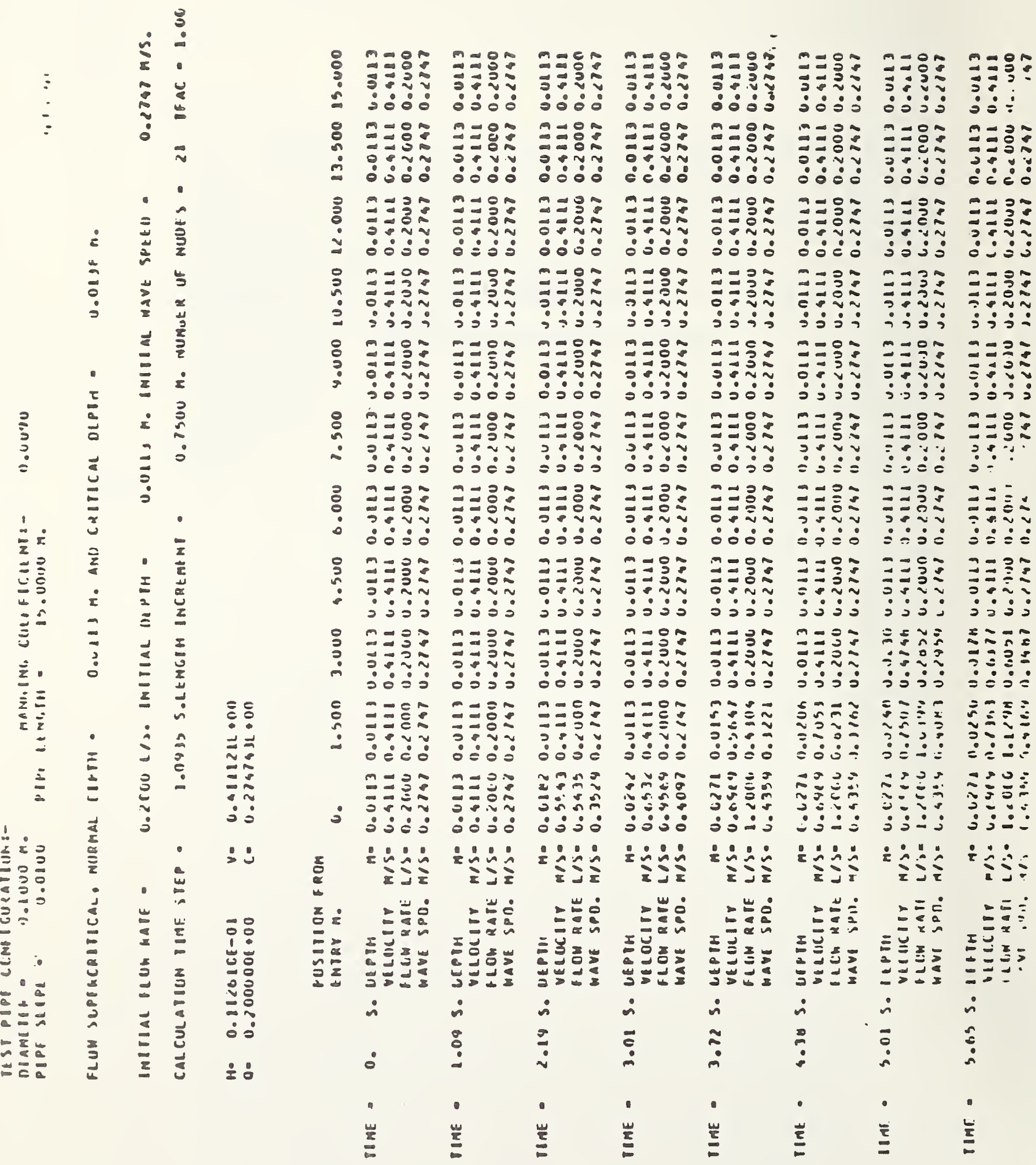




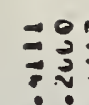
○。 $=3$

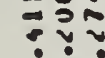

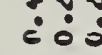

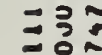

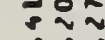
ऽ

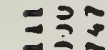

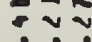
; 政

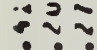

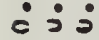
三是 (a) $3=$

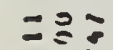
人) $\therefore \therefore$ 彭王 年

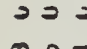
(1) 0
0 $\therefore ;$

วิ亡

0
3

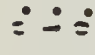

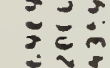

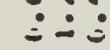

政

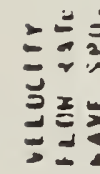

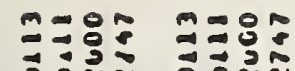
ว.ㄱำ : 프율 $3: \div$ ¿ะ்

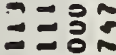
วาㅇำ $\dot{0} \dot{0} \dot{0}$

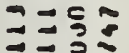
궁 $\dot{j} \dot{j}$ =을 $\vec{z}=2 \pi$ jํㅣ こํำ $3: \div y$ jo $=0$ = $=3:$

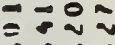
$\dot{0}=\dot{90}$ $\because=5=$ ำ

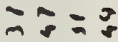
$\therefore$ 군? ji:

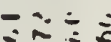

正高

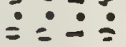

$\bar{\Sigma}=\geq$

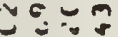

- $\dot{0}$

$\because \because \because \frac{1}{x}$

$-\div \dot{\square}$

工芦落

王

$= \pm$

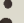

$\approx$

:

$\stackrel{1}{\Xi}$

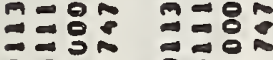

ว:บะ ำ.

oció ó:ó

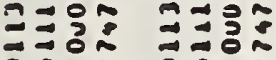

$0+\pi$ o.

ój: 0ं0.

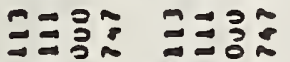

อีำ รีF유

$\dot{5} \dot{9} \div$

=

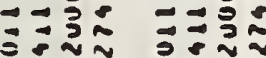

jزj

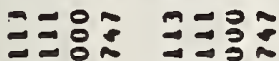

$3 \div 2 \frac{1}{2}$ $\therefore \therefore \therefore:$

르응

วีของ

jᄋ:

2ํㅗㄹ

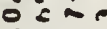

Dว:

คำก

วัะ $\because \dot{9} \dot{0}$

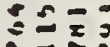

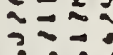

: $\div:=$

550. 5050

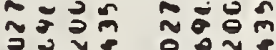

$0: \dot{0}$

เ

$\geq \ddot{\circ}$

$=x^{2}$

- $5 \pm \pm=$

$\dot{n}$

$\dot{n}$

$\because$

$\dot{n}$
$\vdots$
$\dot{0}$

$\stackrel{\square}{\Sigma}$
로ㅇㅝㅗ
$\underline{\underline{E}}$

เะ்

눙영

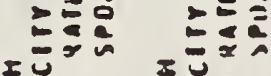

폴동

崩范

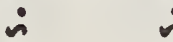

:

:

¿

$\dot{n}$ ma:

구 ำ

(1)

프융

อนทr

$\therefore \dot{0} \dot{0}$

포?

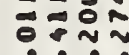

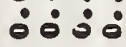

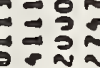

कें

$=3$

อีรูป

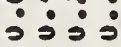

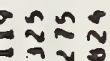

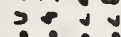

¿0:-

오을용

रुखा

ó:

บะ๊

ชำร

j:영

오요요

ํํำ

$\therefore \therefore-\dot{0}$

은요도

ปรำ?

$\therefore \therefore:$

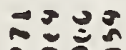

ํํํํำ

¿\$:

เำำ

충

픙

넌원

플
ดீ: :

2ㅍㅇㅇ

ํㅏㅇ

0005

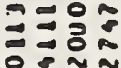

jंj:

등유

อีㅊำ

jंj:

으릉ㅇ

$3 \rightarrow ?$ ?

วับำ

มิกับะ

ํำㄴำ

$\therefore \therefore \dot{0}$

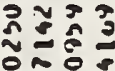

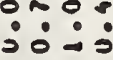

คำ

ธุะะ ○ं

ㄱํำ

3.?.

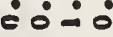

กีะกี้

ำ

ऽ $\dot{0}:$

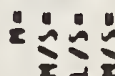

눙

동

롤

현돈

n

$\because$

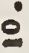

:

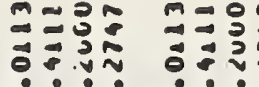
- jo: $0 \dot{0}$

$= \pm=ㅇ ㅠ$

구 $=0$

¿ㅇ:

a융

ำㄴำ

ดें:

릉ำ

อีด

i்

คิ⺈

วีะ

jं

곡ำ

3039

0j0

윽

ว융유:

¿०:-

กำ

ดี

i: :

คํํ을

유:=

$\dot{0}: \dot{0}$

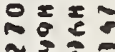

ว

$\therefore: \div$

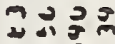

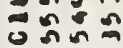

ن영

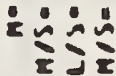

눙

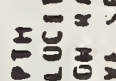

녕롱

$\dot{0}$

:

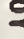

:

$\underline{\underline{\underline{z}}}$

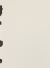

늘

$\underline{=}$

ก 0

ํํㅇำ

0 $\dot{0}$

ㄷำ

ว. =

$0 \dot{0}=0$

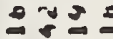

$\overrightarrow{0} \approx$

ocis

ํํำ

二岸宫

둥

로로요

눙종

i

$:$

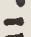

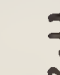

2

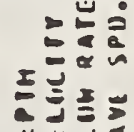

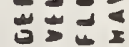

$\therefore$

:

崩

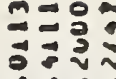
$\therefore 0: 0$

$2 \approx 2=$

ำำ - $\dot{0} \dot{0}$

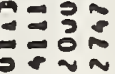




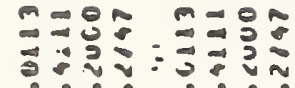
00: $0: 050$

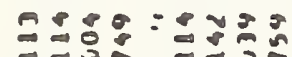

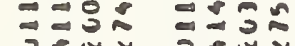
ग0: 2000 0000

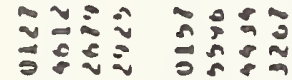
$\dot{0} \dot{j} \dot{j} \dot{0} \dot{j}$

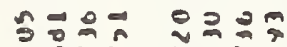

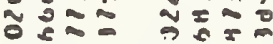
jjij jijs

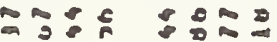

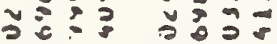
jذjز joj

ำ

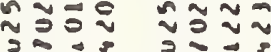
ப்: $\dot{0} \dot{0} \dot{0}$ $3: 53$ วิธ⿻一𠃋工 $\circ \dot{\circ}=$

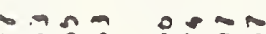
จำำ $\dot{j} \dot{2}$ च ज०० =

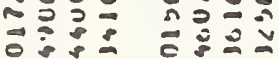
j:5 䓂自:

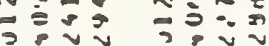
ட்: च一五

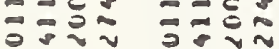

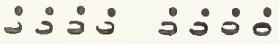

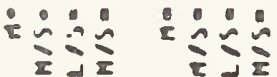

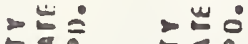
乙岕这

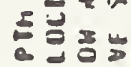

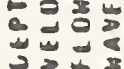
거용 $\because$ $\therefore$

른 हีที丶

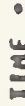

프룽 $\therefore \therefore \dot{0}$

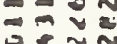
$\therefore \therefore \therefore$ ํำ: $0 \%$ $\therefore \dot{0} 0$

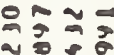
0 jis

ำ早是

궁ำ íं

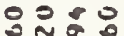
งรำ $\dot{5}: \dot{0}$ ละว ำ ำ $\therefore \therefore \therefore$ 권ㄱำ joj ำ는

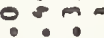
ஸ்0

चิำ

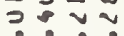
ऽㅇ: $a=3 *$ 可式 வீं ํํำ ح 든 도ㅇㅝㅛ $\dot{n} \quad$ - $0 n \approx$

$m N \leftarrow N$ วีอ $\therefore 000$ 드능ㅇㅇ 곤응 วัน m வீं

구요

गुำ o:j:

요요

ลว?

$\dot{j} \dot{j} \dot{s}$

동ํํㄹ

$0 \div ?$ ஸ் $\dot{0}$

ำล ข. $0: 0$

$\therefore \div$

ป

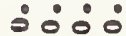

กิะน

$\frac{20.0}{2}$

ว5:

응유

ธีด จำ

ज沽

×도

곤ำ óㅇํ

그르로

필ㄷ

ذं०

ํํำ

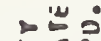

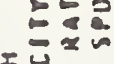

듬등중

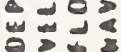
$\dot{n}$

$\div$

$\therefore$

를
용유 $0=\pi$ $\therefore \circ \dot{0}$ รํํำ $\therefore: 00$

$\approx \simeq$ กำ

ํํำ

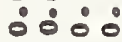

กระ กิระ $\dot{5} \dot{0}$

ลิธีริ

ำำ $\dot{j} \dot{j} \dot{0}$

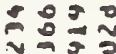
$30:=$ $\therefore: \dot{0}$

를ำ วิํํㅇํㅇ 0ं் $0 \Rightarrow$ 들

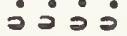

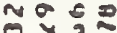
ธี้นี่ डंड:

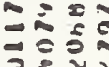
$\therefore: 0$ กี $=$ N 금요 कं० है仓

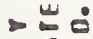

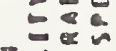
를 엉

¿

บิธอำำำ

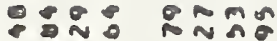
อีะ กิ $\therefore \dot{0} \dot{0}$ 요유: $\rightarrow+2$ :0:0

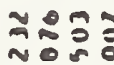

ำ: O: 0

공ํㅇ

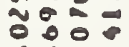
$\dot{9} \dot{j} \dot{0}$

ㄷำ ००0 தं்

ำํำ 잉 :0:0

ํำ:

$\overrightarrow{5} x$ v ว

तีำ

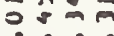
गें

ปิวกี้

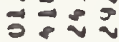
วं0:

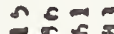
उ० ¿ீं

maja maz

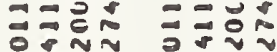

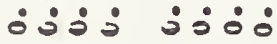

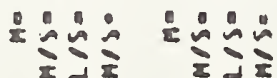
इ

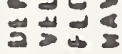
$\dot{n}$

:

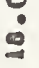

岁 눙

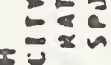

2 工 를를 동 $\dot{n}$

$\vdots$

崖
岂
อีอำ: ¿: : : 숭요유 \% 0:

$\because=0$ 工 ก::유: क: $: 0$

우ㅇㅛㅛ กิดร iे: 눈돈 ○ं j:

눙요요

7 ฟ ○்:

อำร

롱ำ ऽंड் 푤 ०ै: ذं 菓云 อี่ปล o: 0 :

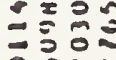
$3 \frac{1}{3}$ iv - ¿

교응 ว-กำ ذ50: ع 岕

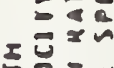
등리롱 명농 $\dot{\circ}$

:

풀

두유

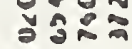
๑ : 0 수음 몽 ๑०: กีกํำ วั0. i०: ㄴำ: ปี่ jรjs 도 วิํㅠㄹㅛ josj กีีะ์ ี่ปี ¿ச் 두으 =

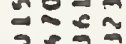
ós ปี $0: ?$ ว 50 월요 ํำำ ojo 드원용 
풍 รี: o: 50

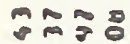
$\because \div=0$ $\therefore: \div 0$ 물 듀: $\dot{0}=0$ ํㅡㄹㅡ ช้อะ $\dot{3} \dot{3}$ ㄷำ $\overrightarrow{0} \overrightarrow{5} \cdot \stackrel{0}{0}$ 5j

ำำ $\approx \frac{3}{3}=$ j: an วีำำ $\dot{0} \dot{0} \dot{0}$

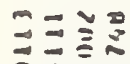
จำ m=욜

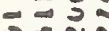
$\dot{0} \div 00$ 플 三 क⿺⿻一𠃋

m = o उ플 $\dot{j} \dot{j}$

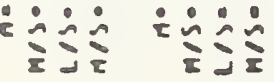

$\approx \dot{a}$ 를 5 i : 。

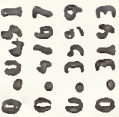
풍요 궁요 ¿๐०。 จำำ วีะ์ $\therefore \dot{0} 0$ ㅇำ:

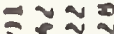

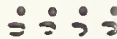
¿ 돌 ?ำ วง

로ำ $2 \%$ oj : :

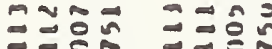
วदू 영

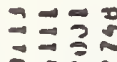
: $\because=3 \pm$ $\vec{B}=2 \approx$ $\dot{\check{0}} \dot{0}$ ここ三ま $\because \dot{=}=$ 可早 3.20
0.52 ن $=0 \dot{0}=0$

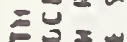
可石 $\pm \doteq$ : n:

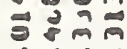
o: $\dot{0}$ ㄱ: ๑๐ $: e^{\circ}$ บิํํำ อี $\dot{0 \dot{0}}$ 웅교 อี 풍ำ sं $\dot{9}$ $\because A R 2$ ㄱำ 过

aอ 0 ニㅡำ ว.: : : 0050 ㅁำ $\therefore \therefore \dot{0}$

$\cong \Xi \overrightarrow{3}$

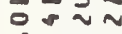
ปj $\Xi \Xi 0^{\circ}$ ำㄹำ $\dot{0} \dot{0}=$

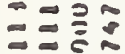
วั: : 든 르용 ○ं $\dot{0}$ $\dot{\Sigma} \tilde{\Sigma} \tilde{\Sigma}$ $\geq \div 0$

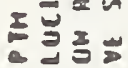

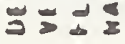
$\dot{\sim}$ : $\dot{m}$

: คำㅇํㅇ
요요

-

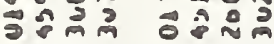
வீத: $0 \dot{0} 0$ 용ㅇㅇㅇ $-2,0$ 0.0:

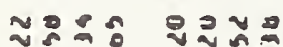
ב $\mathcal{E}$ ก O5j: $0 \dot{0}$ ํํำำ ำรั

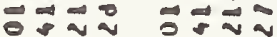
i்j íj ¿ อำ ojs 5:58 $=0 \frac{2}{2}$ $\therefore: 0$

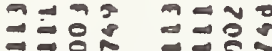

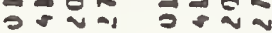
ப்ㅇ வ0் 可焉 물 วं

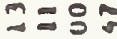
aำ $\therefore \dot{0}$ 高是 $2: \frac{1}{0}$ $\therefore \dot{0} 0$ m-Ja m 플ㄷำ ๑ீத் தீீத

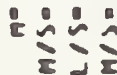

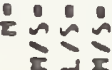
는

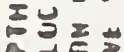
$\geq$ $=\sum a$ 들를

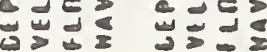

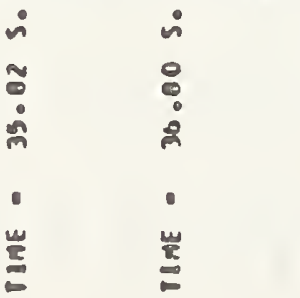

กำ उี:-4 ப்த: $\dot{0} \dot{0}$

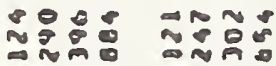

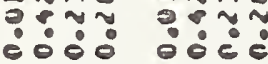

굴용 ํำ ขี รீㅇํㅇ ㄷำ은 루워 j于:

드ำ

플 ว jo:

ต 90

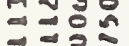
$3: 4$ osos 픙 ว. ป⿻ $\therefore \therefore 0$

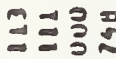
อำ ว 政强 ืำ文

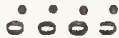
$\Rightarrow=0=$ 3 coss

플 궁주 ๑5:

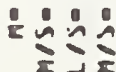
=을 플 풀 :

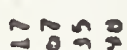

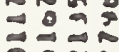
$30 \%$ 도요 궁으 isj

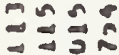
วดะก jos 릉ํㅇ ㄷ:웅 $\vec{z}=\overrightarrow{0}:$ วद् วย் 필ํㄹ ำำ ìj $m=8$ ำㅊ $\therefore \dot{0} 0$ ว:

플 궁주 ن

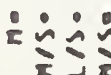
2 흘 可 $\therefore$ : :

를 픟ํำ
$\stackrel{5}{\Sigma}$ ○ं อㅇ 프요 จำ อㅇํㅇ 옹요 그은 ¿ㅇํㅇ

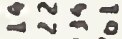
플ำ oj $\dot{j}$ $-25 \%$ 군 ○०० 三ี ํㅇㅇ 3.82 00: 그을 o $\therefore \therefore: 0$ ปำ c. j j5 m=35 อี ว่อ: Е是: ○ं०: 프웡 00:

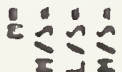
¿ 들일

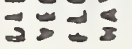
ڤே

$\approx \approx=$ ธีะบ ojo: ำㅇํㅇ อ.ศ 


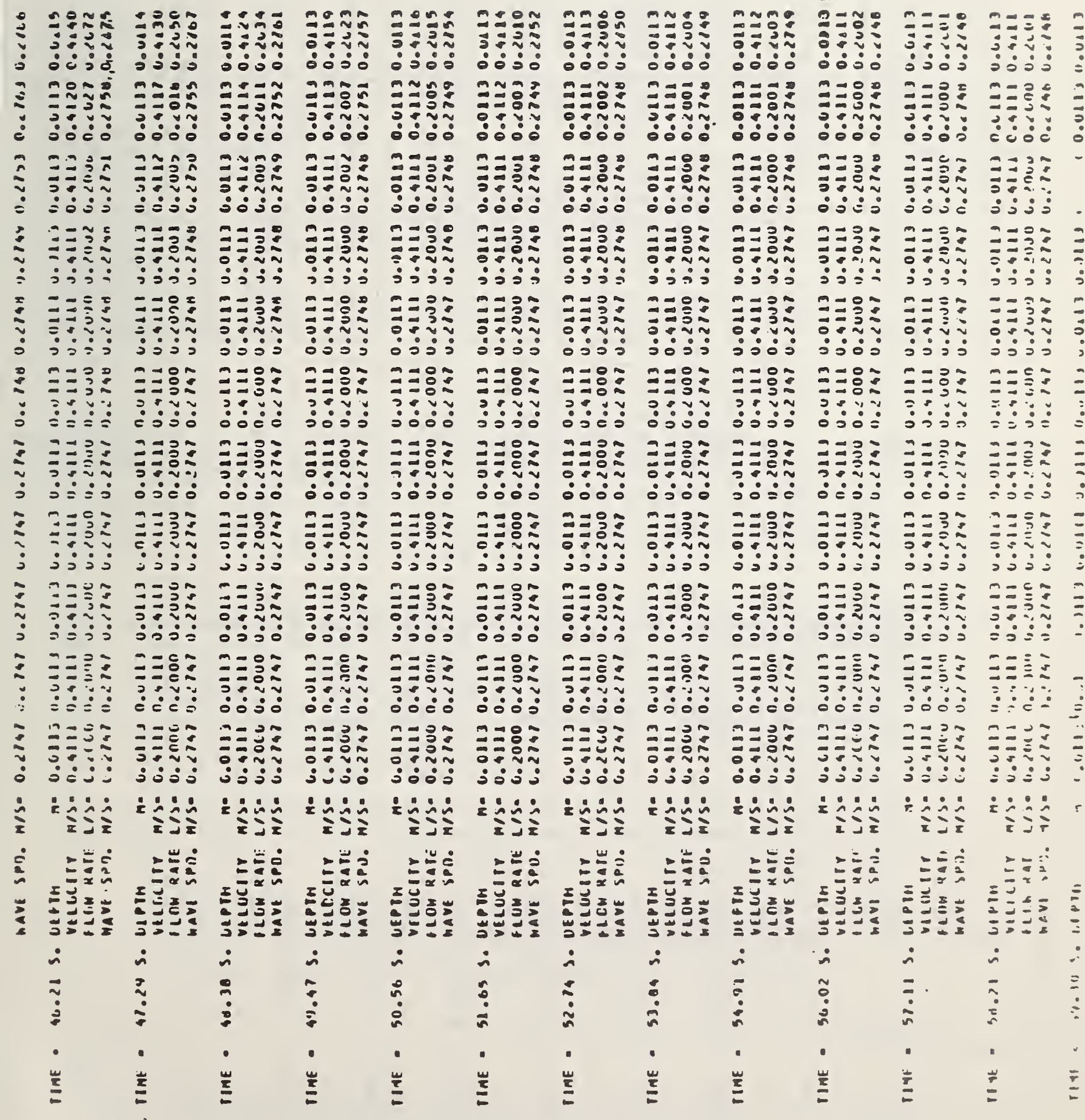




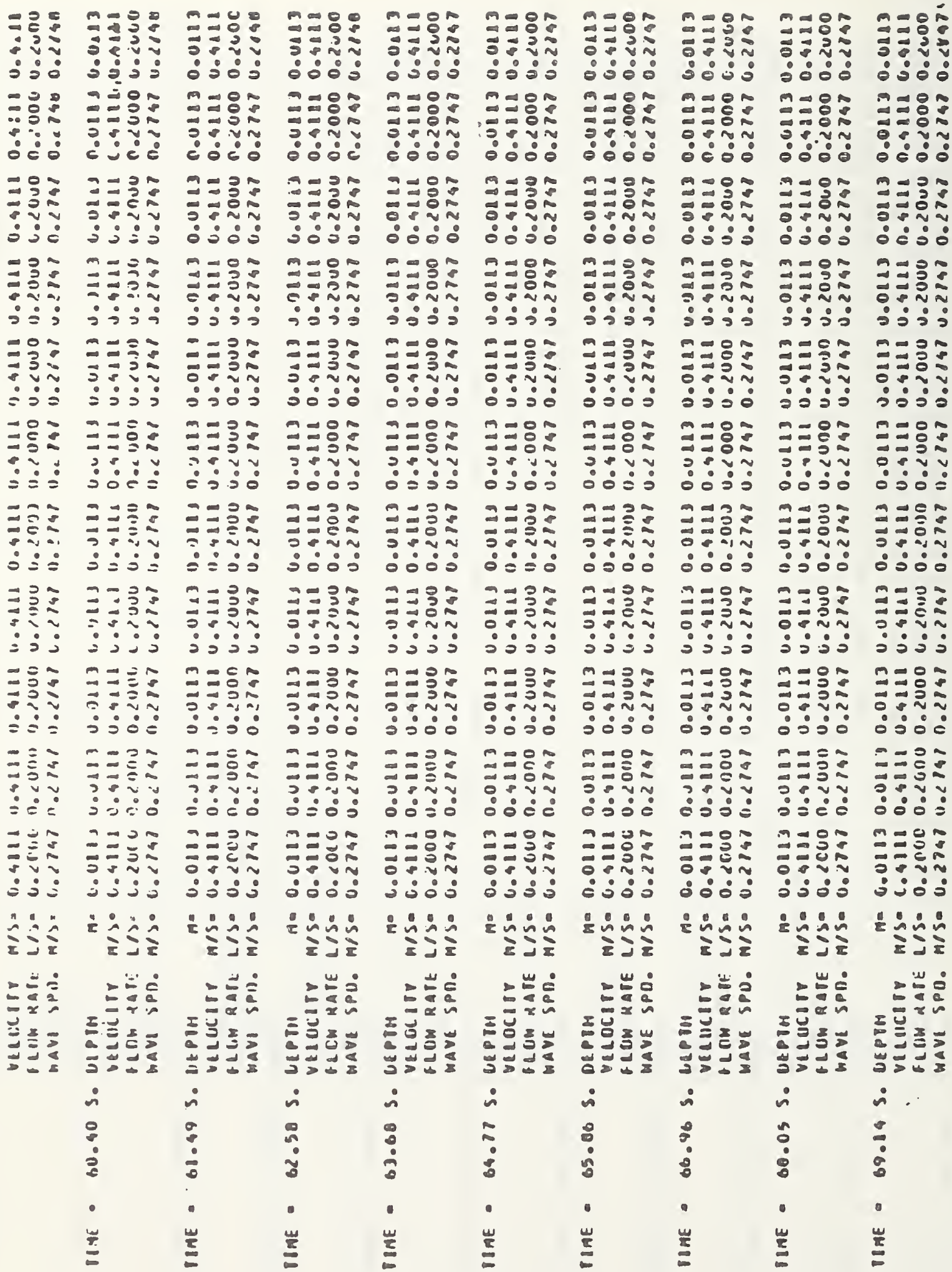


BIBLIOGRAPHIC DATA

SHEET (See instructions)

\section{PUBLICATION OR REPORT NO. \\ NBSIR 82-2478}

2. Performing Organ. Report No.

3. Publication Date

March 1982

4. TITLE AND SUBTITLE

Application of the Method of Characteristics to Predict Attenuation in

Unsteady Partially-Filled Plpe Flow

\section{5. $A U T H O R(S)$}

John Swaffield

6. PERFORMING ORGANIZATION (If joint or other than NBS. see instructions)

MATIONAL BUREAU OF STANDARDS

DEPARTMENT OF COMMERCE

WASHINGTON, D.C. 20234

\section{SPCNSORING ORGANHZATHON NAWE ANO COMPLETE ADORESS (STEG, CHY, SLOL, ZIF)}

7. ContracuGrant No. $\mathrm{H}-48-78$

8. Type of Report \& Period Covered

Department of Housing and Urban Development

4517 th Street, SW

Washington, DC 20410

10. SUPPLEMENTARY NOTES

Document describes a computer program; SF-185, FIPS Software Summary, is attached.

11. ABSTRACT (A 200-word or less foctual summory of most significont informotion. If document includes a significant bibliogrophy or literoture survey. mention it here)

The mechanism of flow attenuation in partially filled unsteady pipe flow is presented and shown to have relevance to the design of gravity drainage systems.

The equations defining unsteady flow in partially filled pipe are derived and shown to be capable of solution by means of the method of characteristics. This technique as a method of predicting flow depth, velocity and wave speed along a long drainage pipe at a range of pipe gradients, diameters, and roughness coefficients was tested by means of numerical examples for a series of simulations run on a digital computer. Additionally, limited experimental verification of the analysis technique is presented for the supercritical flow response to a short duration inflow surge.

Generally, the technique developed was found to be applicable to the design of drainage systems and further work is proposed to both extend the experimental verification and for the greater complexity of the multi-branched pipe system.

12. KEY WORDS (Six to iwelve entries; alphabetical order: copitalize only proper nomes; ond separate key words by semicolons) building drainage; computer model; surge attenuation; unsteady flow.

\section{AVAILABILITY}

Q] Unlimited

For Official Distribution. Do Not Release to NTIS

Grder From Superirtendent of Documents, U.S. Government Printing Office, Washington, D.C. 20402.

[X] Order From National Technical Information Service (NTIS), Springfield, VA. 2216I
14. NO. OF

PRINTED PAGES

88

15. Price 


